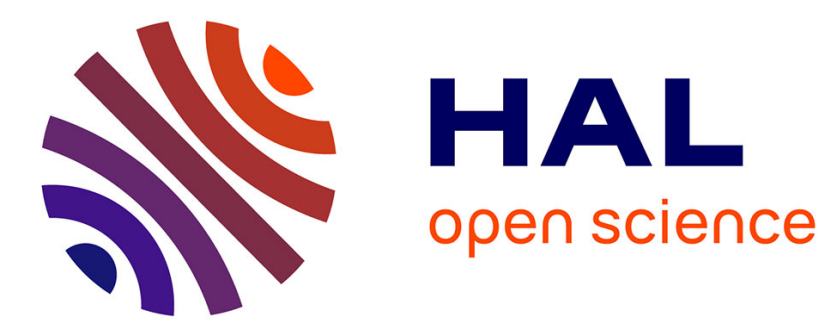

\title{
L'entrée uox du Liber glossarum. Les sources et leur mise en oeuvre
}

\author{
Anne Grondeux
}

\section{To cite this version:}

Anne Grondeux. L'entrée uox du Liber glossarum. Les sources et leur mise en oeuvre. A. Zucker. Encyclopédire: Formes de l'ambition encyclopédique dans l'Antiquité et au Moyen Âge, 14, Brepols, pp.259-275, 2013, Collection d'études médiévales de Nice, 978-2-503-55148-7. hal-01379427

\section{HAL Id: hal-01379427 \\ https://hal.science/hal-01379427}

Submitted on 10 Nov 2016

HAL is a multi-disciplinary open access archive for the deposit and dissemination of scientific research documents, whether they are published or not. The documents may come from teaching and research institutions in France or abroad, or from public or private research centers.
L'archive ouverte pluridisciplinaire HAL, est destinée au dépôt et à la diffusion de documents scientifiques de niveau recherche, publiés ou non, émanant des établissements d'enseignement et de recherche français ou étrangers, des laboratoires publics ou privés. 




\section{ENCYCLOPÉDIRE}

FORMES DE L'AMBITION ENCYCLOPÉDIQUE

DANS L'ANTIQUiTÉ ET AU Moyen ÂGE 


\title{
COLLECTION D’ÉTUDES MÉDIÉVALES DE NICE
}

Collection fondée par Rosa Maria DESSÌ, Michel LAUWERS et Monique ZERNER

\author{
Direction \\ Michel LAUWERS \\ Comité éditorial \\ Germain ButAud, Cécile CABY, Yann Codou, \\ Rosa Maria DESsì, Stéphanie LE BRIZ-OrGEUR
}

Comité scientifique

Enrico ARTIFONI (Università di Torino), Jean-Pierre DEVROEY (Université Libre de Bruxelles), Patrick J.GEARY (Institute for Advanced Study, Princeton), Dominique IoGNA-PRAT (EHESS, Paris),

Florian MAZEL (Université de Rennes 2), Didier MÉHU (Université Laval, Québec),

Jean-Claude SCHMITT (EHESS, Paris), Élisabeth ZADORA-RIO (CNRS, Tours)

Cultures et Environnements. Préhistoire, Antiquité, Moyen Âge

UMR 7264, Université Nice Sophia Antipolis - CNRS

Pôle Universitaire Saint-Jean-d'Angély

SJA3

24, avenue des Diables-Bleus

F-06357 Nice Cedex 4

Maquette

Antoine PASQUALINI

Illustration de couverture

Montage A. Pasqualini sur une lithographie de M. C. Escher

(Main tenant un miroir sphérique, 1935) \& un manuscrit de Bède (Hexaéméron)

M. C. Escher, Main tenant un miroir sphérique (1935), lithographie sur papier vélin avec couche argentée,

31,8 × 21,4 cm. MBAC. Don de George Escher, Mahone Bay (Nouvelle-Écosse), 1989.

(C) 2013 The M.C. Escher Company, Pays-Bas. Tous droits réservés. www.mcescher.com.

St. Gallen Stiftsbibliothek Cod. Sang. 255 (IX siècle). Bède le Vénérable, Hexaemeron.

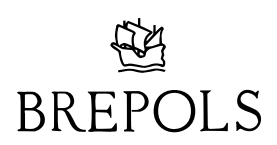




\section{CENTRE NATIONAL DE LA RECHERCHE SCIENTIFIQUE}

Cultures et Environnements. Préhistoire, Antiquité, Moyen Âge

COLleCtion D’études MÉdiévales DE NiCE

\section{ENCYCLOPÉDIRE}

FORMES DE L'AMBITION ENCYCLOPÉDIQUE

DANS L’ANTIQUITÉ ET AU MOYEN ÂGE

ÉTUDES RÉUNIES PAR

ARNAUD ZUCKER

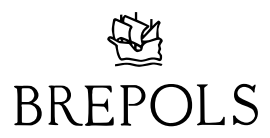


(C) 2013 BREPOLS PUBLISHERS, Turnhout, Belgium. All rights reserved. No part of this book may be reproduced, stored in a retrieval system, or transmitted, in any form or by any means, electronic, mechanical, photocopying, recording or otherwise, without the prior permission of the publisher.

$\mathrm{D} / 2013 / 0095 / 231$

ISBN 978-2-503-55148-7

Printed in the E.U. on acid-free paper 


\title{
L'ENTRÉE UOX DU LIBER GLOSSARUM. LES SOURCES ET LEUR MISE EN EEUVRE
}

\author{
AnNe Grondeux \\ Laboratoire d'histoire des théories linguistiques, Université Paris VII Diderot - CNRS
}

es rapports entre le genre encyclopédique et celui des lexiques sont com-
plexes à analyser, dans la mesure où il n'est pas toujours aisé de déterminer précisément face à quel type d'instrument l'on se trouve. La question se pose tout particulièrement à l'époque carolingienne, dans un monde où le latin devient, sous l'impulsion des réformes alcuiniennes ${ }^{1}$, une langue seconde, apprise de façon scolaire. On peut ainsi se demander ce que l'on recherche alors, en ouvrant un répertoire tel le Liber Glossarum: veut-on en effet avoir accès à des mots ou à des choses, à des définitions brutes ou à l'avis éclairé de savants, au vocabulaire ou aux réalités mêmes dont il parle? C'est dans ce contexte alcuinien de la fin du VIII siècle que s'élabore cet instrument de travail colossal qu'est le Liber Glossarum, que nous présenterons brièvement ici avant de nous concentrer sur l'entrée uox de ce glossaire.

On sait encore peu de chose sur le Liber Glossarum, dont on s'accorde généralement à placer la naissance à Corbie, sous le grand abbatiat d'Adalhard, donc entre 780 et 814 (Bischoff, 1981). Plus récemment encore, on a supposé que les moines aient pu bénéficier d'un grand travail de dépouillement, réalisé par les moniales de Chelles ou de Soissons, qui leur ont fourni les quelque 65000 fiches nécessaires à la confection du grand œuvre 2 . Dans le $L G$, chacune des 27000 entrées latines donne des explications, soit brèves, soit parfois extrêmement longues, qui sont extraites de sources d'une grande variété. Les Étymologies ${ }^{3}$ d'Isidore de Séville ont été minutieusement exploitées, nous y reviendrons; mais le Liber connaît et utilise aussi son Liber de rerum natura, son Liber officiorum, ses Libri de ortu et obitu patrum, ses Differentiae. En parallèle, sont aussi invoqués quantité d'auteurs patristiques comme Augustin d'Hippone (principalement le De Ciuitate Dei), Ambroise de Milan (Hexameron), Jérôme (surtout les

1. Voir en particulier Law, 1982: 100 sq.; Holtz, 2000 ; Huglo, 2001.

2. Voir en particulier Bischoff, 1966; Huglo, 2001: 11. Pour la bibliographie sur le Liber Glossarum (désormais $L G$ ), voir GRondeux, 2009.

3. Pour les éditions des œuvres mentionnées dans cette contribution, nous renvoyons à la bibliographie finale. Ne figurent en note que des annotations spécifiques (projets d'édition en cours, levée d'ambiguïté lorsque plusieurs éditions sont disponibles, etc.) 
Quaestiones hebraicae in Genesin), Hilaire de Poitiers ${ }^{4}$, Eucher de Lyon, Fulgence de Ruspe, Grégoire le Grand (Dialogi et Moralia), mais aussi des auteurs profanes comme Orose et ses Histoires contre les païens, Eutrope et son Abrégé de l'Histoire romaine, des collections de Differentiae, les Synonyma Ciceronis anonymes, le Glossaire dit de Placide, des gloses sur Virgile, ainsi que des sources médicales et grammaticales (comme l'Ars grammatica de Donat ${ }^{5}$ et les Institutiones grammaticae de Priscien de Césarée, nous y reviendrons aussi plus longuement).

Ce qui fait la force du $L G$, comme l'a souligné M. Huglo (2001), est le fait qu'une bibliothèque qui se procure cette somme peut se dispenser de copier toutes sortes de traités, puisque le travail de dépouillement qui a été effectué permet de retrouver des données savantes, en connaissant en outre leur origine, celle-ci étant indiquée en marge de chaque citation. Ce système d'une grande commodité est censé garantir la fiabilité de l'information véhiculée par le $L G$; nous verrons cependant que quelques bémols doivent être apportés. Quoi qu'il en soit, le succès a été instantanément au rendez-vous, et le $L G$ a largement circulé pendant le Moyen Âge carolingien. Mais paradoxalement le caractère colossal du $L G$ est aussi ce qui fait sa faiblesse: sa copie nécessite des forces considérables, en particulier si l'on considère que les exemplaires complets pèsent entre onze et treize kilogrammes. Celui qui est conservé à la Bibliothèque Nationale de Paris ${ }^{6}$ se compose ainsi de deux grands volumes (respectivement 115 et 246 feuillets), chaque page comportant 3 colonnes. Le Liber a donc donné lieu à des versions abrégées, comme le Glossarium Salomonis ${ }^{7}$ ( ca 900); le Summarium Heinrici ${ }^{8}$, vers 1010; et surtout le Vocabularium ou Elementarium de Papias ${ }^{9}$ ( ca 1050), dont la diffusion a mis un point final à la circulation de sa source principale (et muette), le $L G$. Aujourd'hui encore, la taille du $L G$ continue de le desservir, en sorte que l'on manque toujours d'une édition intégrale, les deux éditions de W. M. LinDSAY (1926-1931) et G. GoETZ (1894) étant partielles. À cause de l'ampleur du $L G$, W. M. Lindsay a ainsi pris le parti de se contenter d'un système de renvois drastiques, pour chaque lemme du $L G$, aux sources repérées, ce qui masque la méthode rédactionnelle qui nous occupera ici.

Le résultat de cette façon de procéder est que le $L G$ est presque totalement ignoré des chercheurs aujourd'hui. Autant l'on se réfère volontiers à Papias ou à Jean de Gênes, parce que l'Elementarium de l'un et le Catholicon de l'autre

4. Les œuvres complètes d'Hilaire de Poitiers sont en cours de publication dans la collection CCSL depuis 1997. Pour une première approche de cet auteur, on consultera JouRJon, 1992 et surtout HenNE, 2006.

5. Sur le rôle de Donat dans la tradition grammaticale, on consultera Holtz, 1981.

6. Paris, BnF lat. 11529 et 11530, sigles P1 et P2; cf. Huglo, 2001 : 18-19. Nous fondons notre analyse sur des relevés effectués dans ces deux manuscrits, ainsi que dans le manuscrit Vatican, Pal. lat. 1773.

7. Saint-Gall, Stiftsbibliothek, 905 ; sur le Glossarium Salomonis, ses relations avec le Liber glossarum ou encore sa conservation dans un ms. de Saint Gall, voir McGeachy, 1938: 309-318; MeInEcKe, 1991 : 459-469; Schmuki, Ochsenbein, Dora, 1998: 100-101.

8. Sur le Summarium Heinrici et ses rapports avec le Liber glossarum, voir Hildebrandt, DE BidDER, 1974-1995 (3 vol.) et MeinecKe, 1994.

9. Une édition critique de Papias a été entreprise (DE Angelis, 1977). Trois volumes sont parus, couvrant partiellement les mots ayant pour initiale la lettre A. 
sont accessibles dans des reproductions anastatiques des éditions princeps, et même maintenant consultables en ligne dans ces mêmes éditions incunables, autant le $L G$ demeure profondément enfoui dans son oubli. On doit ici rendre justice à G. Goetz, qui a procuré, dans son volume d'introduction au Corpus Glossariorum Latinorum, paru après les autres en 1923, un plaidoyer en faveur du $L G$, critiquant, citations à l'appui, l'édition de Lindsay. Le fait que ce copieux volume d'introduction soit rédigé en latin n'a cependant pas contribué à faire mieux connaître le $L G$, comme le souligne C. DionisotTi (1996: 202-252). Des chercheurs se sont plus récemment attelés à démontrer l'intérêt majeur de cette source pour la connaissance de la pensée carolingienne ${ }^{10}$.

L'entrée uox a été choisie de façon à illustrer d'une part la richesse des sources du Liber Glossarum et d'autre part la complexité de leur traitement ${ }^{11}$. La uox est en effet à la croisée d'influences multiples, philosophiques, théologiques, grammaticales, et a été l'objet de débats antiques mentionnés dans les Nuits Attiques (5.15) d'Aulu-Gelle, au cœur desquels se trouve la question épineuse de la corporéité ou de l'incorporéité de la uox, du son vocal (BARATIN-DESBORDES, 1981 : 115-116). L'étude de son traitement dans le $L G$ permettra de se faire une idée plus précise de la manière dont un « recueil de gloses », intitulé sous lequel circule cette somme alphabétique des arts libéraux, véhicule en réalité des données de nature encyclopédique.

\section{LES SOURCES DE L'ENTRÉE UOX DANS LE LIBER GLOSSARUM}

Le tableau ci-dessous résume la structure de l'entrée uox, dont une analyse détaillée suivra:

\begin{tabular}{|l|l|}
\hline Augustin, De genesi ad litteram libri XII & uox materia uerborum est... \\
\hline Audax, Excerpta + Quod, grammaire anonyme ${ }^{12}$ & uox est aer ictus auditu sensibilis... \\
\hline Isidore, Étymologies & $\begin{array}{l}\text { uox est aer spiritu uerberatus... } \\
\text { uoces species multae... } \\
\text { suaues } \text { uoces sunt... }\end{array}$ \\
\hline Diomède, Ars & uox est spiritus tenuis auditu sensibilis... \\
\hline Suétone, Prata ou une source analogue & nam uocem tam mutorum animalium... \\
\hline
\end{tabular}

10. Sur le rôle culturel du Liber glossarum à Monza et Milan, voir FerRARI, 1972: 45-53; sur ce rôle à Auxerre, voir Ganz, 1991: 297-312; sur son rôle comme transmetteur de sources et notamment de Végèce, voir VON BürEn, 2002: 269-287 et vON BüREN, 2003: vol 5, 39-49; 1'édition critique du $L G$ est actuellement en cours, coordonnée par l'auteur de ces lignes, et soutenue par le Conseil Européen pour la Recherche (projet ERC StG 263577).

11. Sur ce passage, voir éd. GoEtz, 1893 : 265-266; BARBero, $1993: 268-269$.

12. Cette grammaire est contenue dans les feuillets 46r-60v du ms. d'Erfurt, Wissenschaftliche Bibliothek, Amplonianus 10, qui a par ailleurs tous les caractères d'un recueil scolaire. On se reportera pour une description complète du ms. à BARBERO, 1993: 253-255. Cette petite grammaire est en réalité une compilation thématique d'auteurs très variés, Donat, Priscien, Isidore, Audax, Sergius, Pompée... 


\begin{tabular}{|l|l|}
\hline Priscien, Institutiones grammaticae & uocis differentiae sunt quattuor... \\
\hline Gloses sur Virgile & uox dira... \\
\hline Gloses indéterminées & uox dicitur quidquid sonat \\
\hline
\end{tabular}

Nous sommes, si l'on admet la datation généralement proposée pour le $L G$, vers la fin du VIII ${ }^{e}$ siècle. S'il n'est guère étonnant de voir pris en compte des auteurs comme Augustin, voire Isidore, qui ne devait pourtant pas figurer dans toutes les bibliothèques carolingiennes, il est beaucoup plus surprenant de voir figurer en bonne place des sources comme les Excerpta d'Audax, la Grammaire anonyme connue sous le titre $Q u o d^{13}$, et surtout la Grammaire de Priscien de Césarée. Nous sommes en effet à une époque où cet auteur est encore pratiquement inconnu sur le continent. Ce n'est en fait qu'avec Alcuin, auteur d'Excerptiones super Priscianum maiorem, que la situation commence à changer, car son arrivée à la cour de Charlemagne marque le début de la diffusion de Priscien sur le continent, comme l'a montré L. HolTz (2000: 289-326). Ces Extraits réalisés par Alcuin sont en cohérence avec sa Grammaire $^{14}$, autre œuvre alcuinienne qui suit classiquement le plan de Donat, mais un Donat enrichi grâce à Priscien (HoLtz, 2004: 133-145). On ne peut donc éviter de poser la question du relais qui a mis à la disposition des compilateurs la multitude de sources utilisées dans le $L G$. G. BARBERO (1993: 142-145) a avancé le nom d'Alcuin, en présentant des arguments convaincants pour identifier ce dernier avec le personnage que le $L G$ appelle "Paul". Il semble que l'on doive la suivre sur ce terrain, tant les parallèles qu'elle propose sont frappants par leur exactitude.

\section{UN TRAVAIL DE DENTELLIÈRE}

\section{$\underline{\text { Augustin, De genesi Ad litteram libri XII }}$}

On trouvera dans le tableau ci-dessous la comparaison entre la première section de l'entrée uox du $L G$ et sa source, un passage du De Genesi ad litteram d'Augustin. Nous indiquons par les caractères gras les interventions du compilateur (colonne de gauche); on lira dans la colonne de droite la source, dont les coupes ont été matérialisées par des ratures. Les variantes textuelles des manuscrits ${ }^{15}$ sont renvoyées en note.

13. Sur la question des sources, voir BARBERO, 1990 : 151-174 et BARBERO, 1993 : 253-278.

14. Pour la confrontation des descriptions grammaticales avec des définitions philosophiques, celle du Boèce du Peri Hermeneias, ce qui est une autre innovation de la Grammaire d'Alcuin, voir SwIGgERs, 2004: 147-161.

15. Voir supra note 6 . 


\begin{tabular}{|c|c|}
\hline $\begin{array}{l}\text { Liber Glossarum } \\
\text { Codd. P 239uc-240rc, L 347uc-348rc }\end{array}$ & Source \\
\hline $\begin{array}{l}\text { Agustini } \\
\text { Uox materia ueruorum est, uerua uero } \\
\text { formatam uocem indicant. Non autem qui } \\
\text { loquitur prius emittit informem uocem } \\
\text { quam possit postea colligere adque in } \\
\text { uerbaformare. }\end{array}$ & 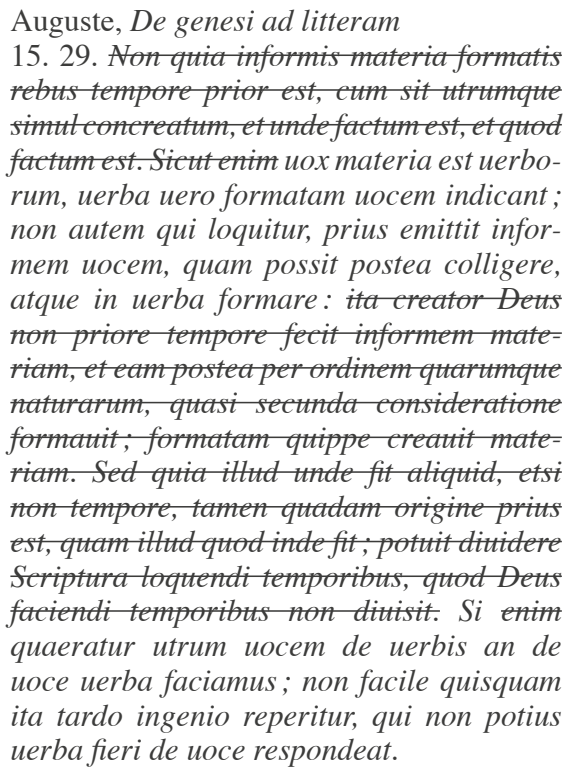 \\
\hline
\end{tabular}

Nous sommes ici dans un passage du De genesi ad litteram qui expose le mode de création de la matière, en réfutant l'idée que Dieu aurait d'abord créé une matière informe avant de l'informer. Pour ce faire, Augustin propose une comparaison avec la uox, le son vocal, qu'un locuteur ne laisse pas sortir informe de sa bouche pour le rattraper ensuite et lui donner la forme des mots. On notera l'habileté avec laquelle le Liber Glossarum récupère l'opinion d'Augustin sur la uox au détour d'un passage qui parle de tout autre chose, mais offre l'avantage d'être concis et de proposer une réflexion sur la uox dans sa matérialité phonique.

Après ces généralités sur le son vocal, nous entrons dans le domaine grammatical, dans une section très longue qui va cumuler plusieurs définitions de la uox. On y repère, dans l'ordre, celle d'Audax combinée avec celle de la Grammaire Quod; celle du livre III des Étymologies d'Isidore; celle de l'Ars de Diomède. C'est probablement cette section qui a donné le plus de fil à retordre aux compilateurs, confrontés à la difficulté de juxtaposer des sources qui s'inspiraient au préalable les unes des autres.

16. an de uoce uerba $\left.L^{\text {p.c.. }}\right]$ unde uerba $P$, unde uoce uerba $L^{\text {a.c. }}$

17. ita scripsi] in $P L$ 


\section{Anonyme, Quod + Audax, Excerpta de Scauro et Palladio}

\begin{tabular}{|c|c|}
\hline $\begin{array}{l}\text { Liber Glossarum } \\
\text { Codd. P 239uc-240rc, L 347uc-348rc }\end{array}$ & Sources \\
\hline $\begin{array}{l}\text { Uox est haer ictus }{ }^{18} \text { auditu sensibilis. } \\
\text { Vocis autem due sunt partes, articulata et } \\
\text { confusa. Articulata est hominum tantum, } \\
\text { que scribi potest, id est 'orator uenit et } \\
\text { docuit', et dicta articula quod articulo }{ }^{19} \\
\text { scribentis comprehendi possit. Confusa est } \\
\text { que scribi non potest, ut puta uelut ouium } \\
\text { balatus, equi innitus, mugitus bouis, latratus } \\
\text { canis et cetera. Sed articulata uox } x^{20} \text { quam- } \\
\text { quam sit prolixa, oratio soluitur et facit } \\
\text { sermonem. Iterum sermonem soluis et facis } \\
\text { sillabam. Si uero sillabam soluas remanet } \\
\text { littera et iam non procedit }{ }^{21} \text { ultra resolu- } \\
\text { tio. Sonos quoque omnes uoces dicimus, } \\
\text { ut 'fractasque a litore uoces'. Secundum } \\
\text { Stoicos }{ }^{22} \text { autem uox }{ }^{23} \text { corporalis est, qui eam } \\
\text { sic definiunt }{ }^{24}, \text { ut nos in principio respondi- } \\
\text { mus. Plato autem non esse uocem corpus } \\
\text { putat: 'non enim percussus, inquid, aer, sed } \\
\text { plaga ipsa adque percussio, id est uox'. Ex } \\
\text { indiuisis corporibus uocem constare dicunt, } \\
\text { corpus autem esse aut efficiens aut patiens. }\end{array}$ & $\begin{array}{l}\text { Les sources de ce passage se repèrent par les } \\
\text { codes suivants: } \\
\text { En caractères normaux: Audax } \\
\text { En soulignés: Quod } \\
\text { En gras: Sergius par l'intermédiaire } \\
\text { de Quod }\end{array}$ \\
\hline
\end{tabular}

On notera ici le travail spectaculaire de dentellière qui a été réalisé sur le premier extrait grammatical, la combinaison d'Audax et de la Grammaire Quod. G. Barbero a pu démontrer que plus d'une trentaine de passages du $L G$ ont pour source directe cette grammaire, parmi lesquels un extrait de l'entrée uox qu'elle a d'ailleurs édité et étudié dans son article ${ }^{25}$.

Dans ce passage, on voit se mêler, et de façon relativement harmonieuse, trois sources, Audax, Sergius et $Q u o d$, mais seulement en réalité deux textes, puisque Sergius est déjà fondu dans Quod. G. Barbero a attiré l'attention sur ce passage en soulignant le recours autonome à Audax, qui s'interpénètre de façon continue avec l'extrait de Quod.

\footnotetext{
18. ictus $P]$ h- $L$

19. articulo scripsi cum fonte] $-\mathrm{si} P L,-\mathrm{s}<\mathrm{i}>b$

20. uox $L]$ uo $P$

21. procedit $L]$ precedit $P$

22. stoicos scripsi cum fonte] sticor $P$, fisicos $L$

23. uox scripsi cum fonte] uxor $P L$

24. definiunt scripsi cum fonte] defiunt $P L$

25. Sigle $b$ dans mon édition, voir colonne de gauche supra)
} 


\section{Isidore, Étymologies III}

L'extrait d'Isidore qui fait immédiatement suite dans le $L G$ est emprunté au troisième livre des Étymologies. Il propose une nouvelle définition de la uox, ainsi que de longs développements sur les différentes qualités de sons. Nous notons là encore les interventions du rédacteur par les caractères gras. On voit ainsi qu'une longue section du livre III, qui était consacrée aux espèces de la voix et détaillait l'harmonie, la symphonie, etc., a été résumée à grands traits en une phrase, ce qui permet de préserver la structure du passage tout en restant concentré sur la voix humaine. L'extrait d'Isidore se conclut par une mention de la uox crocodilla, de provenance inconnue mais qui tendrait à se rattacher à la longue section qui traite plus bas des cris des animaux et de leurs dénominations latines.

\begin{tabular}{|c|c|}
\hline $\begin{array}{l}\text { Liber Glossarum } \\
\text { Codd. P 239uc-240rc, L 347uc-348rc }\end{array}$ & Source \\
\hline $\begin{array}{l}\text { Isidorus }{ }^{26} \\
\text { Uox est } t^{27} \text { aer spiritu uerberatus, unde et } \\
\text { uerba sunt nuncupata. Proprie autem uox } \\
\text { hominum seu inrationalium animantium, } \\
\text { nam in aliis abusiue non proprie sonitum } \\
\text { uocem uocari, ut 'uox tube infremuit' 'frac- } \\
\text { tusque ab litore uoces'. Nam proprium est ut } \\
\text { litorei sonant scopoli. Et, At }{ }^{28} \text { tuba terribi- } \\
\text { lem sonitum procul aere canoro. } \\
\text { Vocis species multae, armonia, simpho- } \\
\text { nia, euphonia, diastigmee, diesis, thonus, } \\
\text { cantus, arsis et thesis. Vocum autem appel- } \\
\text { latio multiplex est. } \\
\text { Suaues uoces sunt subtiles et spisse, clare } \\
\text { atque acute. Prespice uoces sunt que longius } \\
\text { protrahuntur, ita ut omnem impleant }{ }^{29} \text { conti- } \\
\text { nuum locum, sicut clangor tubarum. Subtiles } \\
\text { uoces sunt quibus non est spiritus, qualis } \\
\text { est infantium uel mulierum uel egrotantium, } \\
\text { sicut in neruis. Que enim subtilissime corde } \\
\text { sunt, subtiles [h]ac tenues sonus emittunt. }\end{array}$ & $\begin{array}{l}\text { Isidore, Etym. } 3.20 .2 \\
\text { Uox est aer spiritu uerberatus, unde et uerba } \\
\text { sunt nuncupata. Proprie autem uox hominum } \\
\text { est, seu inrationabilium animantium. Nam } \\
\text { in aliis abusiue non proprie sonitum uocem } \\
\text { uocari, ut: 'uox tubae infremuit', (Virg., } \\
\text { Aen. } 3.556) \text { : Fractasque ad litore uoces. } \\
\text { Nam proprium est ut litorei sonent scopuli, } \\
\text { et (Virg., Aen. } 9.503 \text { ): At tuba terribilem } \\
\text { sonitum procul aere canoro... }\end{array}$ \\
\hline
\end{tabular}

26. isidorus ] legitur in cod. $L$

27. uox est $P]$ om. $L$

28. at scripsi cum fonte] ad PL

29. impleant $L]$-at $P$ 


\begin{tabular}{|c|c|}
\hline $\begin{array}{l}\text { ber Glossarum } \\
\text { odd. P 239uc-240rc, L 347uc-348rc }\end{array}$ & Source \\
\hline $\begin{array}{l}\text { Pingues sunt uoces quando spiritus multus } \\
\text { simul egreditur, sicut uirorum. Acuta uox } \\
\text { est tenuis, alta, sicut in cordis uidemus. } \\
\text { Dura uox est que uiolenter emittit sonus }{ }^{30} \text { sicut } \\
\text { tonitruum, sicut [in] incudis sonus }{ }^{31} \text { quotiens } \\
\text { in durum malleus percutitur ferrum. Aspera } \\
\text { uox est rauca et que dispergitur per minutos } \\
\text { et indissimiles pulsus. Ceca uox est que mox } \\
\text { emissa fuerit conticescit }{ }^{32} \text { atque }{ }^{33} \text { suffucata } \\
\text { nequaquam longius }{ }^{34} \text { producitur, sicut in fic- } \\
\text { tilibus. Vinnola est uox mollis atque flexibilis, } \\
\text { et uinnola dicta a uinno hoc est cincinno mol- } \\
\text { liter flexo. Perfecta autem uox est alta, suauis } \\
\text { et clara, alta ut in sublime }{ }^{35} \text { sufficiat, clara ut } \\
\text { aures adimpleat }{ }^{36} \text {, suauis ut animos audien- } \\
\text { tium }{ }^{37} \text { blandiat. Si ex his aliquid defuerit }{ }^{38} \text { uox } \\
\text { perfecta non erit. } \\
\text { Crocodilla uox acuta. }\end{array}$ & $\begin{array}{l}\text { Pingues sunt uoces, quando spiritus multus } \\
\text { simul egreditur, sicut uirorum. Acuta } \\
\text { uox tenuis, alta, sicut in cordis uidemus. } \\
\text { Dura uox est, quae uiolenter emittit sonos, } \\
\text { sicut tonitruum, sicut incudis sonus, quo- } \\
\text { tiens in durum malleus percutitur ferrum. } \\
\text { Aspera uox est rauca, et quae dispergitur } \\
\text { per minutos et indissimiles pulsus. Caeca } \\
\text { uox est, quae, mox emissa fuerit, contices- } \\
\text { cit, atque suffocata nequaquam longius } \\
\text { producitur, sicut est in fictilibus. Vinnola est } \\
\text { uox mollis atque flexibilis. Et uinnola dicta } \\
\text { a uinno, hoc est cincinno molliter flexo. } \\
\text { Perfecta autem uox est alta, suauis et clara: } \\
\text { alta, ut in sublime sufficiat; clara, ut aures } \\
\text { adinpleat; suauis, ut animos audientium } \\
\text { blandiat. Si ex his aliquid defuerit, uox per- } \\
\text { fecta non est. }\end{array}$ \\
\hline
\end{tabular}

\section{Diomède, Ars}

Le $L G$ fait suivre l'extrait des Étymologies d'un passage, attribué à Phocas, mais qui trouve sa source lointaine dans l'Ars de Diomède. Le tableau que l'on trouvera ci-dessous permet de suivre comment la source a été minutieusement découpée, peut-être afin d'éviter des redites, à moins que l'on ait ici aussi affaire à un montage chronologiquement antérieur et analogue à celui de la grammaire Quod (voir supra).

\footnotetext{
30. sonus] lege sonos

31. incudis sonus $\left.L^{\text {p.c. }}\right]$ uac. $P$, inquadis sonus $L^{\text {a.c. }}$

32. conticescit $L]$ conticessit $P$

33. atque $P$ ] ac $L^{\text {p.c. }}$, ad $L^{\text {a.c. }}$

34. longius $V$ ] longus $P$

35. sublime scripsi] -i $P L$

36. adimpleat $L P^{p . c .}$ ] impleat $P^{a . c .}$

37. audientium scripsi] -dium $P L$

38. defuerit $P$ ] infuerit $L$
} 


\begin{tabular}{|c|c|}
\hline $\begin{array}{l}\text { Liber Glossarum } \\
\text { Codd. P 239uc-240rc, L 347uc-348rc }\end{array}$ & Source \\
\hline $\begin{array}{l}\text { Ex regula Foce grammatici } \\
\text { Uox est spiritus tenuis auditus sensibilis }{ }^{39} \text {. } \\
\text { Fit autem uel exilis aeris pulsu uel uerberati } \\
\text { aeris ictu. Igitur interpretatiua uox dicta } \\
\text { est et erit scripturalis sonus uel inscriptu- } \\
\text { ralis. Uox autem dicta PXRUNAUN }{ }^{40} \text { grece } \\
\text { nominata. Vel latine ab eloquio idcirco uox } \\
\text { appellata quod uoluntatem animi enun- } \\
\text { tiat. Sunt qui uocis officia tria designant, } \\
\text { eloquium, tinnitum, sonum. Eloquium est } \\
\text { humane pronuntiationis expressa }{ }^{41} \text { signifi- } \\
\text { catio, facilem sensibus exibens intellectum. } \\
\text { Sonus est corporalis collisio repentinum } \\
\text { auribus inferens fragorem. Tinnitus est } \\
\text { fabricate materiae inlisio tenui sono audi- } \\
\text { tionem [h]ac sensum prestans. Vnde non } \\
\text { inmerito eloquium hominum, tinnitum } \\
\text { inmobilium }{ }^{42} \text {, sonitum corporalium ple- } \\
\text { rique testantur. }\end{array}$ & 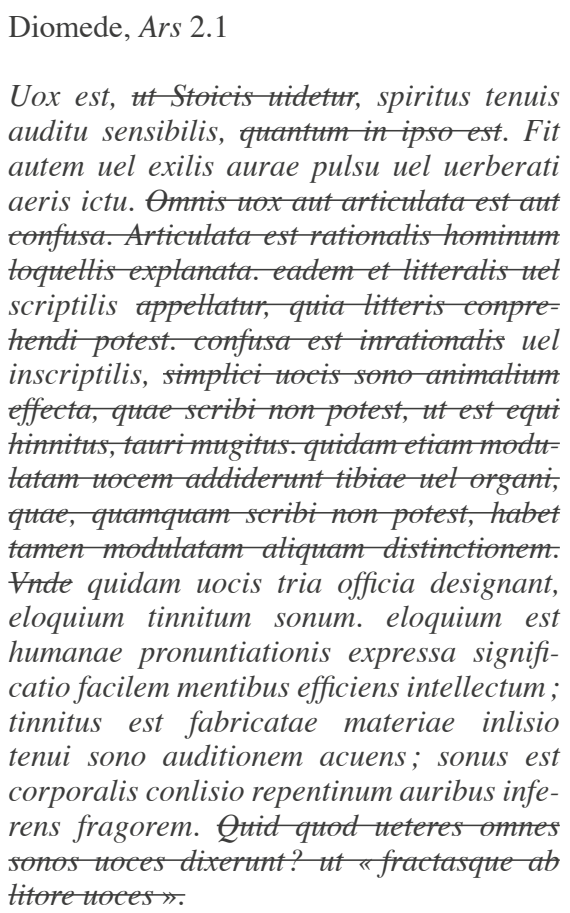 \\
\hline
\end{tabular}

\section{$\underline{\text { Les uoces animantium }}$}

Suit une section, extrêmement longue, consacrée aux verbes latins désignant les cris des animaux, qui s'inscrit dans la riche littérature des uoces animantium. La plus ancienne liste connue de ce type figurait dans les Prata de Suétone (BENEDIKTSON, 1993: 377-447). La reconstitution de cette liste perdue a été tentée par A. REIFFERSCHEID (1860: 247-254) (3) $^{43}$ la base de celle qui figure dans les Deriuationes d'Hugutio de Pise, qui affirme suivre à cet endroit un auteur nommé Sindonius ou Sydonius, que l'on identifie avec Suétone. Il se rencontre cependant bien d'autres listes au Moyen Âge (entre autres celles d'Aldhelm de Malmesbury, Polemius Silvius, Eugène de Tolède ${ }^{44} \ldots$ ), dont il reste pour l'heure difficile

\footnotetext{
39. sensibilis $L]$ insibilis $P$

40. PXRUNAUN $P$ ] PARAPNHOHN $L$

41. expressa $L$ ] expressas $P$

42. inmobilium scripsi] inmolb- $P L$

43. Voir MARCOVICH, 1971 : surtout 409-414).

44. Voir Marcovich, $1971:$ 202, n. 11.
} 
d'apprécier si elles dérivent aussi de celle qu'avait établie Suétone ou de sources non identifiées ${ }^{45}$.

Nous transcrivons ci-dessous l'introduction et les lemmes extrêmes de la liste proposée par le $L G$ (liste G. de ReIfFERSCHEID, 1860 : 250):

Nam uocem [tam] mutorum animalium (quam hominum est add. P) esse declarantes sic efferunt $[\mathrm{V}]$ si afferunt $\mathrm{P}$ )

Aquilas clangere

Accipitres plipiare

Vultures pulpare

...

Edos uebare

Canes latrare

Catulos glattire

Mustelas drinorare

Mures mintare - Sorices desticare

Ranas rabire uel coaxare

\section{$\underline{\text { Priscien }}$}

La série grammaticale se conclut avec Priscien, dont l'extrait a subi de sérieux remaniements. On trouvera dans le tableau ci-dessous la comparaison du passage emprunté à Priscien avec le texte de cette source (les interventions du rédacteur sont indiquées en gras):

\section{Liber Glossarum \\ Codd. P 239uc-240rc, L 347uc-348rc \\ Ex regula Prisciani grammatici \\ Vocis differentiae sunt quattuor, articu- lata, inarticulata ${ }^{46}$, litterata et inlitterata. Articulata ${ }^{47}$ est que quoartata id est copulata cum aliquo sensu eius qui loquitur profertur, ut Arma uirumque cano. Inarticulata est que ab aliquo affectu proficiscitur mentis, ut sibilos ${ }^{48}$ et gemitus hominum. Litterata ${ }^{49}$ est que scribi potest ${ }^{50}$ nihil pene significans ut 'coax' 'ora' ${ }^{51}$ '. Inlitterata est que nec scribi potest nec intelligi ut crepitus, ut mugitus.}

\section{Source}

Priscien, Gramm. 1.1

Vocis autem differentiae sunt quattuor: articulata, inarticulata, literata, illiterata. articulata est, quae coartata, hoc est copulata cum aliquo sensu mentis eius, qui loquitur, profertur. inarticulata est contraria, quae a nullo affectu proficiscitur mentis, literata est, quae scribi potest, illiterata, quae scribi non potest. inveniuntur igitur quaedam voces articulatae, quae possunt scribi et intellegi, ut: Arma virumque cano,

45. Voir PERIS, 1998 (surtout n. 11) pour un répertoire de listes de Voces animantium.

46. inarticulata] add. s. l. $P$

47. articulata $\left.P L^{\text {p.c. }}\right]$ articula $L^{\text {a.c. }}$

48. sibilos $P$ ] -us $L$

49. litterata $\left.V^{p . c .}\right]$ littera $P L^{a . c}$

50. potest scripsi] potes $P L$

51. ora scripsi] era $P L$ 


\begin{tabular}{|c|c|}
\hline $\begin{array}{l}\text { Liber Glossarum } \\
\text { Codd. P 239uc-240rc, L 347uc-348rc }\end{array}$ & Source \\
\hline $\begin{array}{l}\text { 'Uox' autem dicta est a uocando sicut 'dux' } \\
\text { a ducendo. }\end{array}$ & $\begin{array}{l}\text { quaedam, quae non possunt scribi, intelle- } \\
\text { guntur tamen, ut sibili hominum et gemitus: } \\
\text { hae enim voces, quamvis sensum aliquem } \\
\text { significent proferentis eas, scribi tamen non } \\
\text { possunt. aliae autem sunt, quae, quamvis } \\
\text { scribantur, tamen inarticulatae dicuntur, } \\
\text { cum nihil significent, ut 'coax', 'era'. Aliae } \\
\text { vero sunt inarticulatae et illiteratae, quae } \\
\text { nec scribi possunt nec intellegi, ut crepitus, } \\
\text { mugitus et similia. scire autem debemus } \\
\text { quod has quattuor species vocum perficiunt } \\
\text { quattuor superiores differentiae genera- } \\
\text { liter voci accidentes, binae per singulas } \\
\text { invicem coeuntes. } \\
\text { 'uox' autem dicta est vel a vocando, ut } \\
\text { 'dux' a ducendo, vel apo toû boô, ut quibus- } \\
\text { dam placet. }\end{array}$ \\
\hline
\end{tabular}

Priscien avait introduit une nouveauté dans un ensemble complexe, qui était en réalité un héritage d'un stoïcisme plus ou moins bien compris, une nouveauté qui consistait à lier l'articulation à l'émission d'une signification. Pour lui, héritier probablement en cela aussi d'Apollonios Dyscole, comme le suggère F. DesBordes (1990: 106), la condition de l'articulation est la liaison avec une intention de signifier; Priscien justifie cela en donnant comme équivalent d'articulata le terme de coartata, c'est-à-dire coartata sensu. Avant Priscien, articulata était toujours assimilé à litterata et à scriptilis; articulata signifiait ce qui peut se décomposer en articuli - des séquences phoniques identifiables et donc susceptibles de recevoir une transcription écrite: on le voit dans les définitions de Diomède, que n'a pas retenues le $L G$, mais aussi d'Audax, qui figure en bonne place dans le $L G$ (cf. supra 2.1). Audax dit même: dicta articulata quod articulo scribentis comprehendi possit.

Avec Priscien, le changement est radical: un sifflement a beau ne pouvoir recevoir une transcription graphique, il est quand même porteur de signification pour celui qui l'émet, donc il mérite d'être rangé sous la uox articulata. Priscien propose donc de ne plus assimiler des distinctions qui ne sont pas, il est vrai, sur le même plan : il revient ainsi sur l'équivalence articulata $=$ litterata $=$ scriptilis. L'exemple du coax de la grenouille suffit à montrer qu'une voix peut être mise en lettres sans être pour autant signifiante. Il renonce aussi à l'emploi du terme confusa, trop imprécis peut-être, pour lui substituer celui d'inarticulata. Là aussi, inarticulata est lié à la signification, ou plutôt à l'absence de signification: sera dite inarticulata toute voix émise sans intention de signifier. Les rédacteurs du $L G$ sont-ils restés perplexes devant ces innovations qui contredisent ouvertement les définitions compilées plus haut dans la même entrée ? C'est en tout cas un moyen terme qui va être adopté, en même temps qu'un bouleversement formel qui aboutit à faire suivre chaque division de la uox de l'exemple qui lui est attribué par Priscien. 
Divisions de la uox chez Priscien ${ }^{52}$

\begin{tabular}{|l|l|l|}
\hline Scriptible & $\begin{array}{l}\text { Articulée = prove- } \\
\text { nant de la pensée } \\
\text { signifiante (hommes) }\end{array}$ & $\begin{array}{l}\text { Inarticulée = non signifiante } \\
\text { (animaux, objets) }\end{array}$ \\
\hline Non scriptible & $\begin{array}{l}\text { « Je chante les armes et } \\
\text { le héros » }\end{array}$ & «coax » «cra » \\
\hline & Sifflement, gémissement & Craquement, mugissement \\
\hline
\end{tabular}

Divisions de la uox dans le $L G$

\begin{tabular}{|l|l|l|}
\hline Articulata & Ecrit et compris & 《Je chante les armes et \\
le héros »
\end{tabular}

Au plan de la doctrine, la solution retenue par le $L G$ consiste à suivre Priscien sur sa définition de la uox articulata comme une voix liée à la signification: le début de la division est bien repris. C'est ensuite que les choses se compliquent. Manifestement le fait de ranger les sifflements et les gémissements sous la catégorie de l'articulé passe mal; ces manifestations se trouvent donc basculées sous l'inarticulé; mais les termes de Priscien deviennent dès lors hautement problématiques, puisque celui-ci définit l'inarticulé comme ce qui est dépourvu de signification: a nullo affectu proficiscitur mentis. Qu'à cela ne tienne, il suffit de changer deux petits mots de cette définition pour pouvoir la réutiliser de façon satisfaisante, et la définition devient: ab aliquo affectu proficiscitur mentis.

Un autre petit changement, trois fois rien en apparence, intervient un peu plus loin. La uox litterata est maintenant qualifiée de nihil pene significans, «ne signifiant presque rien ». À première vue le changement est minime. On retrouve sous cette rubrique les exemples désormais classiques des coax et autres cra, cris de la grenouille et du corbeau. Et après tout, Priscien admettait aussi que l'on pouvait les écrire. La nuance est cependant dans l'adverbe pene. Alors que Priscien rangeait ces cris dans la catégorie de l'inarticulé, les considérant comme totalement dépourvus de signification - c'est-à-dire d'une signification intentionnelle de la part de leur émetteur -, le $L G$, par un glissement sur le sens de "signifier", réintègre la uox litterata sous la bonne vieille catégorie de l'intelligible: le cri de la grenouille ne signifie presque rien... sauf qu'il y a une grenouille. Il ne signifie

52. Voir Desbordes, 1990: 106. 
rien de la part de l'émetteur mais il est signe de quelque chose, que peut décoder le récepteur.

Quelles sont les motivations de ce remaniement en profondeur? On doit en effet noter qu'aucun autre des extraits retenus pour cette entrée uox n'a subi un tel bouleversement, sinon formel, du moins doctrinal. On peut a priori penser que les rédacteurs ont voulu faire cadrer la division de Priscien avec les définitions compilées plus haut. Mais il ne serait pas impossible d'y lire aussi une certaine influence du Peri Hermeneias de Boèce : la uox significatiua est, dans ce cadre totalement différent et difficilement conciliable avec celui de Priscien, celle qui signifie quelque chose non pas en fonction de l'intention du locuteur, mais pour l'auditeur. Ce double héritage posera d'ailleurs des problèmes difficiles aux commentateurs postérieurs de Priscien qui tenteront dans les Glosulae ${ }^{53}$, au tournant des $\mathrm{XI}^{\mathrm{e}}-\mathrm{XII}{ }^{\mathrm{e}}$ siècles, une lecture des Institutiones Grammaticae à la lumière de Boèce ${ }^{54}$. Pourtant cette hypothèse pose à son tour d'autres problèmes, dans la mesure où Boèce n'apparaît pas dans les sources du $L G$. En supposer une connaissance indirecte nous ramènerait une fois de plus à Alcuin, qui utilise Boèce dans sa Grammatica. Pourtant le passage concordant de celui-ci témoigne d'un respect scrupuleux des divisions de Priscien:

Quatuor sunt differentiae vocis: articulata, inarticulata; litterata, illitterata. Articulata est, quae copulata atque coarctata cum sensu profertur, ut: Arma virumque cano... Inarticulata, quae a nullo sensu proficiscitur, ut crepitus, mugitus. Litterata, quae scribi potest; illitterata, quae scribi non potest (PL 101, col. 854d).

On remarquera toutefois qu'Alcuin effectue le même remaniement, formel et non doctrinal, qui consiste à remonter l'exemple virgilien de uox articulata.

Pour en terminer avec cette question, nous lirons un dernier extrait des Glosulae, portant sur la suite de notre passage, lorsque Priscien divise la uox. Les Glosulae suivent scrupuleusement la lettre du texte, et insistent sur le fait qu'un

53. Pour une présentation etung bibliographie détaillées concernant les Glosulae, voir Rosier, CATACH, 2009²; Grondeux, Rosi 2011.

54. Cf. ms. Metz, Bibl. Mun. 1224, f. 3va: ARticVlata (ad Prisc. I.1.5.5). Diffiniens articulatam significationem et ethimologiam ipsius ostendit. Articulata est quae profertur, id est potentialiter apta est proferri; COARTATA (p. 5.6), id est artata et ligata, hoc quantum ad ethimologiam quod postea apponit est de sensu significationis, scilicet COPVLATA ; et est expositio ethimologiae. Cum quo sit copulata subdit CVM SENSV MENTIS EIVS QVI LOQVITVR (p. 5.6-7), scilicet cum profertur profert eam loquens ad sensum suum designandum, etiam si auditor non intelligat, competenter intelligendum est proferri uocem cum aliquo sensu. Licet enim rusticus proferat hanc uocem 'homo' sine aliquo intellectu significandi, tamen non minus est articulata postquam impositionem significandi suscepit. Et ideo exponimus sic: articulata est quae profertur cum sensu proferentis, idest quae potentialiter apta est proferri ad sensum proferentis demostrandum, licet ille cum aliquo sensu non proferat. Notandum est quod Boethius alio modo accipit significatiuum, quod idem est quod articulatum, alio modo Priscianus; Boethius enim dicit significatiuum quantum ad auditorem, scilicet quod in animo auditoris aliquem generat intellectum, licet prolator sine aliquo intellectu uocem pronuntiet. Priscianus uero quantum ad intentionem proferentis significatiuum dicit. Boethius dicit etiam uoces naturales significatiuas quantum ad auditorem, Priscianus non significatiuas quantum ad prolatorem. 
sifflement, un gémissement, un crachat même, nouvel exemple dans ce contexte, sont articulés dès lors qu'ils sont émis avec l'intention de signifier quelque chose ; dans le cas contraire, ces manifestations seront dites inarticulées.

Nota quia sibilus est uox articulata si ille qui profert eum auditori intendat aliquid per ipsum significare, ut latrones in nemoribus se solent per sibilum conuocare. Similiter gemitus, screatus, si ad aliquid significandum proferantur, articulati sunt. Sin autem natura sola sic exigente fiunt, sunt inarticulatae (Ibid.).

$\mathrm{Au}$ final, il est difficile de dégager une quelconque structure dans cette séquence d'entrées du $L G$ traitant du lemme uox:

- la uox et les uerba: matière et forme

- trois définitions: Audax, Isidore, Diomède

- les cris des animaux

- divisions de la uox

- exemples virgiliens

- une dernière définition, selon laquelle uox dicitur quidquid sonat. Cette brièveté apparaît un peu décevante lorsque l'on songe à tous les raffinements définitionnels qui ont été déployés auparavant.

On a l'impression que l'entrée se compose d'une introduction générale, avec l'extrait d'Augustin, clairement mis à part et invoqué pour sa réflexion sur la matérialité phonique de la uox. On passe ensuite à un corpus de définitions techniques pour lequel les grammairiens sont mis à contribution. Viennent ensuite deux sections périphériques d'inégales importance et longueur, l'une consacrée aux cris des animaux, l'autre aux divisions de la uox. Tout juste peut-on supposer que l'avantage de placer ici la division de Priscien est qu'elle subsume l'ensemble, par la conjonction des voix humaines, animales mais aussi des choses inanimées, ce qui constitue comme un renvoi à la fin de l'extrait de Diomède.

\section{LES PROLONGEMENTS}

On se limitera ici à présenter en parallèle l'entrée uox dans le $L G$ et dans le Vocabularium de Papias, dont l'œuvre, rappelons-le, va éclipser totalement sa source principale, le $L G$.

\begin{tabular}{|l|l|}
\hline Papias, Vocabularium & Sources \\
\hline $\begin{array}{l}\text { Uox materia uerborum est, uerba uero for- } \\
\text { matam nocem indicant. }\end{array}$ & $\begin{array}{l}\text { Liber Glossarum: Uox materia ueruorum } \\
\text { est, uerua uero formatam uocem indicant... }\end{array}$ \\
\hline \begin{tabular}{l} 
Uox dicitur a uocando uel a boo. \\
\hline
\end{tabular} \\
\hline
\end{tabular}




\begin{tabular}{|c|c|}
\hline Papias, Vocabularium & Sources \\
\hline $\begin{array}{l}\text { Uox est aeris ad linguam percussio quae } \\
\text { per quasdam arterias gutturis ab animali } \\
\text { profertur. Sunt enim soni quos lingua non } \\
\text { percutit, ut tussis, ast non sunt uox, nam } \\
\text { de sola linguae percussione uox; sin uero } \\
\text { talis percussio ut in linguam redigat sonum, } \\
\text { locutio est; quod si uis quaedam imagina- } \\
\text { tionis addatur, significatiua uox redditur. }\end{array}$ & $\begin{array}{l}\text { Boece, Periherm. I: Uox est aeris per } \\
\text { linguam percussio quae per quasdam guttu- } \\
\text { ris partes, quae arteriae uocantur, ab animali } \\
\text { profertur. Sunt enim quidam alii soni, qui } \\
\text { eodem perficiuntur flatu, quos lingua non } \\
\text { percutit, ut est tussis... sit linguae sola per- } \\
\text { cussio, uox est; sin uero talis percussio sit } \\
\text { ut in litteras redigat sonum, locutio; quod si } \\
\text { uis quoque quaedam imaginationis addatur, } \\
\text { illa significatiua uox redditur. }\end{array}$ \\
\hline \multicolumn{2}{|l|}{$\begin{array}{l}\text { Uox, uocis, inde uocaliter, } \\
\text { uocalis, seminocalis. }\end{array}$} \\
\hline \multicolumn{2}{|l|}{$\begin{array}{l}\text { Voco, as; uocari id est dici; uocalis uoca- } \\
\text { bilis, unde componitur aduoco aduocatus } \\
\text { ti, euoco, inuoco, reuoco; si uoce compo- } \\
\text { nitur uociferor, aris, aequiuocus, ca, cum, } \\
\text { aequinoco, cas, uniuocus, ca, cum. }\end{array}$} \\
\hline $\begin{array}{l}\text { Uox est aer ad linguam ictus auditu sensi- } \\
\text { bilis. Plato autem non esse uocem corpus } \\
\text { putat. Non enim percussus, inquit, aer sed } \\
\text { plaga ipsaque percussio id est uox. }\end{array}$ & $\begin{array}{l}\text { Liber Glossarum: Uox est haer ictus auditu } \\
\text { sensibilis. [...] Plato autem non esse uocem } \\
\text { corpus putat: 'non enim percussus, inquit, } \\
\text { aer, sed plaga ipsa adque percussio, id est } \\
\text { uox'. [...] }\end{array}$ \\
\hline $\begin{array}{l}\text { Vocis uero species sunt multae, harmonia, } \\
\text { simphonia, euphonia, diastema, dyesis, } \\
\text { tonus, cantus, arsis et thesis. }\end{array}$ & $\begin{array}{l}\text { Liber Glossarum: Proprie autem uox } \\
\text { hominum seu inrationalium animantium, } \\
\text { nam in aliis abusiue non proprie sonitum } \\
\text { uocem uocari, ut 'uox tube infremuit' frac- } \\
\text { tusque ab litore uoces'. Nam proprium est ut } \\
\text { litorei sonant scopoli. Et, At tuba terribilem } \\
\text { sonitum procul aere canoro. } \\
\text { Vocis species multae, armonia, simpho- } \\
\text { nia, euphonia, diastigmee, diesis, thonus, } \\
\text { cantus, arsis et thesis. }\end{array}$ \\
\hline $\begin{array}{l}\text { Uox graece dicta a boo idest sono, uel latine } \\
\text { dicta quod uoluntatem animi adnuntiet. }\end{array}$ & $\begin{array}{l}\text { Liber Glossarum: Uox autem dicta } \\
\text { PXRUNAUN (P] PARAPNHOHN V) grece } \\
\text { nominata. Vel latine ab eloquio idcirco uox } \\
\text { appellata quod uoluntatem animi enuntiat. }\end{array}$ \\
\hline Vel uox a uocando. & Ex Priscien, Gramm. I 1 \\
\hline $\begin{array}{l}\text { Voces mutorum animalium sic declarantes } \\
\text { efferunt. Aquilas clangere... } \\
\text { Ranas rabire uel coaxare }\end{array}$ & $\begin{array}{l}\text { Liber Glossarum: Nam uocem tam mutorum } \\
\text { animalium esse declarantes sic efferunt: } \\
\text { Aquilas clangere... Ranas rabire uel coaxare }\end{array}$ \\
\hline
\end{tabular}


On voit ici comment Papias traite le $L G$, coupant de longs passages (la définition d'Augustin est presque entièrement sacrifiée, ramenée à une seule phrase), supprimant les définitions répétitives des grammairiens, reprenant à son compte les coupes faites dans les Étymologies, gardant aussi l'interminable développement sur les cris d'animaux, riche en vocabulaire. On remarque enfin comment des nouveautés viennent trouver leur place dans l'entrée: les dérivés du mot uox, et surtout Boèce, dont la définition manquait dans le $L G^{55}$.

Nous avons essayé de souligner ici - à notre tour - l'importance de l'encyclopédie carolingienne, afin de rappeler la nécessité d'éditer et d'étudier le Liber glossarum. Le petit passage qui a été sélectionné pose un certain nombre de questions, qui restent pour le moment en suspens, parmi lesquelles s'inscrivent l'inspiration alcuinienne, voire l'emprunt à une source alcuinienne, thèse de G. Barbero. La connaissance du Liber glossarum, ne serait-ce que pour les sources mises en œuvre, permet de mieux saisir le paysage intellectuel carolingien. Il témoigne en particulier de l'accès à une variété de sources qui n'étaient pas matériellement présentes comme unités bibliographiques autonomes dans les bibliothèques contemporaines, mais dont la substance était aisément et largement accessible dans le Liber glossarum ${ }^{56}$.

Inscrire le Liber dans une catégorie déterminée n'est pas une tâche aisée. Il évoque le lexique par son ordre alphabétique et non thématique; il évoque l'encyclopédie par l'ampleur donnée à chaque notice, et par le fait que ses entrées ne se résument pas à des données de nature strictement lexicale. Sa comparaison avec l'Elementarium de Papias fait encore davantage ressortir cette spécificité, dans la mesure où Papias élimine en grande partie, mais pas en totalité il est vrai, les développements non lexicaux. La place du $L G$ dans la tradition de lexicographie médiolatine est donc assez paradoxale, puisque c'est sa double caractéristique d'encyclopédie alphabétique qui en a fait la matrice de lexiques alphabétiques de volume plus réduit. Ses particularités deviennent encore plus nettes si on le compare aux instruments de type dérivationnel du XII ${ }^{\mathrm{e}}$ siècle, comme les œuvres d'Osbern de Gloucester et d'Hugutio de Pise: autant les rédacteurs du Liber ont voulu suivre des chemins balisés et réunir des connaissances effectivement disponibles en une somme à visée encyclopédique, autant les auteurs de Deriuationes veulent faire œuvre de lexicographes, en explorant le lexique de façon méthodique et spéculative. Dans le premier cas les mots renvoient à des choses, dans le second cas les mots renvoient à des mots, qui ne sont parfois que des créations ex integro nées de la méthode dérivationnelle poussée à son extrême.

55. Quelques éléments du $L G$ ont ainsi subsisté dans le Catholicon de Jean de Gênes; cf. Catholicon sous la vedette uox: Uox uocis dicitur a uoco, cas, et produ. o ante c, sed uoco, cas cor. o ante c. Vel uox secundum quosdam dicitur a boo boas, mutato $b$ in u et ultima o subtracta et addita $x$. Et dicitur secundum Papias uox quia uoluntatem anumi annunciat, quia uoces sunt note earum que sunt in anima passionum. Uox componitur ut equiuocus, uniuocus, multiuocus ca cum id est synonimus.

56. Voir, pour la diffusion manuscrite, HugLo, 2001 : 12-25. 


\title{
BIBLIOGRAPHIE
}

\author{
SOURCES PRIMAIRES
}

Adelard De Bath

Burnett C. (éd.), 1998 - Adelard De Bath. Quaestiones naturales, dans Burnett C., Conversations with his nephew, Cambridge/New York/Melbourne (Cambridge Medieval Classics, 9), p. 81-235.

\section{Aelred de Rievaulx}

Raciti G. (éd.), 2005 - Aelred de Rievaulx. Homeliae de oneribus propheticis Isaiae, Turnhout (CC Cont. Med., 2D).

\section{Al-Battani}

Al-Battani, Mahometis Albatenii De scientia stellarum de numeris stellarum et motibus liber [traductus a Plato Tiburtino] cum aliquot additionibus Joannis Regiomontani ex bibliotheca Vaticana transcriptus, Bologne, 1645.

Peyroux J. (trad.), 2003 - Al-Battani. Livre sur la science des étoiles, avec quelques additions de Jean Regiomontanus, trad. du latin en français, d'après la traduction latine de Plato Tiburtinus du ms arabe de la bibliothèque Vaticane, Paris.

Regiomontanus J. (éd.), 1645 - Muhammad Ibn-Ğābir al-Battān. De numeris stellarum et motibus, Bologne.

\section{AL-BITRÛJî}

CARMody F. J. (éd.), 1952 - Al-Bitrûjî. De motibus celorum, critical ed. of the Latin translation of Michael Scot, Berkeley.

\section{Al-Ghunaim}

'Aвdullah Y. (éd.), 2006 - Al-Ghunaim, Arabic Geographic Manuscripts at the Bodleian Library, Oxford.

\section{Al-WațWāṭ, Mựamad ibn Ibrāhīmm}

Al-Ḥarabī, 'Ábd al-Razzāo Ạ̣mad (éd.), 2000 - Al-Waṭwāṭ, Muhamad ibn Ibrāhīmm. Mabāhiğ al-fikar wa-manāhiğ al-'ibar, Beyrouth.

SEZgin F. (éd.), 1990 - Al-Wațwāṭ, Muhamad ibn Ibrāhīmm, Mabāhiğ al-fikar wa-manāhiğ al-'ibar, Frankfurt am Main.

\section{Albert le Grand (Albertus Magnus)}

ANGel M. (trad.), 1995 - Albert le Grand. Le Monde minéral : les pierres, "De mineralibus" livres I et II, Paris (Sagesses chrétiennes).

Borgnet A. (éd.), 1890 - Alberti Magni, Ratisbonensis episcopi, ordinis praedicatorum Opera omnia, ex editione Lugdunensi [1651], religiose castigata [...] etiam revisa et locupletata, vol. 5, Paris (Mineralium libri V), p. 1-116.

Geyer B. (éd.), 1960 - Sancti doctoris ecclesiae Alberti Magni [...] Opera omnia, ad fidem codicum manuscriptorum edenda, apparatu critico notis prolegomenis indicibus instruenda, curavit Institutum Alberti Magni Coloniense, t. 16. I : Metaphysica, libri quinque priores, Aschendorff (Albertus Magnus Institut).

Geyer B. (éd.), 1964 - Sancti doctoris ecclesiae Alberti Magni [...] Opera omnia, ad fidem codicum manuscriptorum edenda, apparatu critico notis prolegomenis indicibus instruenda, curavit Institutum Alberti Magni Coloniense, t 16. II : Metaphysica, libri VI-XIII, Aschendorff (Albertus Magnus Institut). 
Hossfeld P. (éd.), 2003 - Sancti doctoris ecclesiae Alberti Magni [...] Opera omnia, ad fidem codicum manuscriptorum edenda, apparatu critico notis prolegomenis indicibus instruenda, curavit Institutum Alberti Magni Coloniense, t. 6, pars 1 : Meteora, Aschendorff (Albertus Magnus Institut).

Kitchell K. F., ResNick I. M. (trad.), 1999 - Albertus Magnus. On Animals. A Medieval Summa Zoologica, Baltimore,

Meyer E. F., Jessen C. (éd.), 1867 - Albertus Magnus. De vegetabilibus, Berlin (repr. Frankfurt a. M., 1982).

Moulin I. (trad.), 2009 - Albert le Grand. Métaphysique, Livre XI, Traités II et III, Paris (Sic et non).

Stadler H. (éd.), 1916-1921 - Albertus Magnus. De animalibus, 2 vol., Aschendorff, (Beiträge zur Geschichte der Philosophie des Mittelalters, 15-16).

Sтroick C. (éd.), 1968 - Sancti doctoris ecclesiae Alberti Magni [...] Opera omnia, ad fidem codicum manuscriptorum edenda, apparatu critico notis prolegomenis indicibus instruenda, curavit Institutum Alberti Magni Coloniense, t. 7. I : De anima, Aschendorff (Albertus Magnus Institut).

VERNIER J.-M. (éd. et trad.), 2009 - Albert le Grand. Livre sur la nature et l'origine de l'âme [Liber de natura et origine animae], Paris (Epistémologie et philosophie des sciences).

WyскоғF D. (trad.), 1967 - Albert the Great. Book of minerals, Oxford.

\section{Alcuin}

Alcuinus, Grammatica, PL 101, col. 849-902.

\section{Aldhelm de Malmesbury}

Aldhelmus. Epistola ad Acircium sive Liber de septenario, de metris aenigmatibus ac pedum regulis, $P L$ 89, col. 162-238.

Ehwald R. (éd.), 1984 - Aldhelmi opera, Berlin, 1913-1919, 2 vol. (MGH. Auctores antiquissimi, 15, réimpr. fac. simile, Munich).

\section{D'Alembert Jean Le Rond}

Discours Préliminaire De L'encyclopédie, 1976 [1751], Paris

\section{Alexandre de Villedieu}

Reichling D. (éd.), $\mathbf{1 8 9 3}$ - Das Doctrinale des Alexander de Villa-Dei. Kritisch-exegetische Ausgabe mit Einleitung, Verzeichniss der Handschriften und Drucke nebst Registern, Berlin (réimpr. New York, 1974).

\section{Alexandre Neckam (Alexandre Nequam)}

Wright T. (éd.), 1863 - Alexandri Neckam De naturis rerum: libri duo, with the poem of the same author, De laudibus divinae sapientiae, London (Rerum Britannicarum Medii Aevi Scriptores, 34).

\section{Alia Musica}

Chailley J. (éd.), 1964 - Alia Musica (traité de musique du IXe siècle), Paris (Publications de l'Institut de Musicologie, 6).

\section{Alsted J. H.}

Encyclopaedia philosophica, Lyon, 1610.

Encyclopaedia septem tomis distincta, Herborn, 1630.

Scientiarum omnium Encyclopaideia, Lyon, 1649.

Ambroise de Milan (Ambrosius Mediolanensis)

BANTERLE G. (trad.), 2002 - Ambrogio. Esamerone, Rome (Collana di testi antichi, 164). 
Schenkl C. (éd.), 1897 - Ambrosius. Exameron. De Paradiso. De Cain et Abel. De Noe. De Abraham. De Isaac. De Bono mortis, Vienne (CSEL 32, 1), p. 3-261.

ANONYMA DE MUSICA SCRIPTA BELLERMANNIANA

NaJock D. (éd.), 1975 - Anonyma de musica scripta Bellermanniana, Leipzig.

ANONYMi ARS LECTORIA

Sivo V. (éd.), 1979 - Anonymi Ars lectoria e codice Parisino Latino 8499, Bari.

ANonymi MontePESSULANENSIS DictionaRius

Grondeux A. (éd.), 1998 - Anonymi Montepessulanensis Dictionarius. Glossaire latinfrançais du ms. Montpellier H236, Turnhout (CC Cont. Med., Series in-4º, II).

ANONYMi ARTIUM MAGISTRI QUAESTIONES SUPER LIBRUM ETHICORUM ARISTOTELIS

Costa J. (éd.), 2010 - Anonymi artium magistri quaestiones super librum ethicorum Aristotelis (MS Paris, BnF, lat. 14698), Turnhout (Studia Artistarum, 23).

Apollonios Dyscole

Lallot J. (éd. et trad.), 1997 - Apollonios Dyscole. De la construction, Paris (Histoire des doctrines de l'Antiquité classique, 19).

\section{Apulée le Grammairien}

Osann F. (éd.), 1826 - L. Caecilii Minutiani Apuleii De orthographia fragmenta et Apuleii minoris De nota aspirationis et De diphthongis libri duo, Darmstadt.

Aristote

De l'Âme

Jannone A. (éd.), Barbotin E. (éd. et trad.), 20094 - Aristote. De l’Âme, Paris $(C U F, 171)$.

Tricot J. (trad.), 1969 - Aristote. De l'Âme, Paris, 1969.

Éthique à Nicomaque

Barthélemy Saint-Hilaire J., Gomez-Muller A. (trad.), 1992 - Aristote. Éthique à Nicomaque, Paris.

Gauthier R. A., Jolif J. Y. (trad.), 1958-1959 - Aristote. Éthique à Nicomaque, Louvain.

Gauthier R. A. (éd.), 1972a - Aristoteles Latinus. Ethica Nicomachea, translatio antiquissima libri II-III sive "Ethica vetus" et translatio Antiquioris quae supersunt sive "ethica nova", "Hoferiana", "Borghesiana", Leiden/Bruxelles (AL, 26.1-3, fasc. secundus).

Gauthier R. A. (éd.), 1972b - Aristoteles Latinus. Ethica Nicomachea, translatio Roberti Grosseteste Lincolniensis sive "Liber ethicorum" A. recensio pura, Leiden/Bruxelles (AL, 26.1-3, fasc. tertius).

Gauthier R. A. (éd.), 1973 - Aristoteles Latinus. Ethica Nicomachea, translatio Roberti Grosseteste Lincolniensis sive "Liber ethicorum" B. recensio recognita, Leiden/Bruxelles (AL, 26.1-3, fasc. quartus).

Tricot J. (trad.), 1959 - Éthique à Nicomaque, Paris.

Tricot J. (trad. et index), 2007 - Aristote, Éthique à Nicomaque, Paris.

De l'Interpretatione

Minio-Paluello L. et al. (éd.), 1965 - Aristoteles Latinus. De interpretatione vel Peri ermenias, translatio Boethii, specimina translationum recentiorum, Leiden (AL, 2.1-2). 
Métaphysique

Tricot J. (trad.), 1986 - Aristote. Métaphysique, t. II, Paris.

Météorologiques

Groisard J. (trad.), 2008 - Météorologiques, Paris 2008.

Ross W. D., Webster E. W., Forster E. S. (éd. et trad.), 1931 - The Works of Aristotle. Vol. 3. Meteorologica, Oxford.

Parties des Animaux

Folster K. et al. (trad.), 1951 - Aristotle's "De anima" in the version of William of Moerbeke, and the Commentary of St Thomas Aquinas, Londres.

Lennox J. G. (trad.), 2001 - On the parts of Animals, Oxford.

Pellegrin P. (trad.), 2011 - Les Parties des animaux, Paris.

Siwek P. (éd.), 1954 - Aristotelis De anima libri tres, voll. I-III, Roma (Pontificia Universitas Gregoriana, textus et documenta, series philosophica 9).

Parva Naturalia

Tricot J. (trad.), 1999 [1951] - Aristote. Parva naturalia suivi du traité pseudo-aristotelicien De spiritu, Paris.

Physica

Bossier F., Brams J., Mansion A. (éd.), 1990 - Aristoteles Latinus. Physica [translatio vetus et translatio Vaticana], Leyde/New York, 2 vol. $(A L, 7.2)$.

AristoxÈne

DA Rios R. (éd.), 1954 - Aristoxeni elementa harmonica, Rome.

Pighi G. B. (éd. et trad.), 1959 - Aristoxeni rhythmica, Bologne.

Asclépiade de Bithynie

Pagani L. (éd.), 2007 - Asclepiades, of Bithynia: I frammenti degli scritti omerici. Pleiadi 7, Roma.

Asclépiade de Myrléa

Pagani L. (éd.), 2007 - I frammenti degli scritti omerici, Michigan.

Athénée de Naucratis

KaIBEL G. (éd.), 1887-1890 - Athenaei Naucratitae. Dipnosophistarum libri quindecim (3 vol.), Leipzig.

\section{Audax}

KeIL H. (éd.), 1880 - Audacis excerpta de Scauro et Palladio, GL 7, p. 320-361.

\section{Augustin}

Cité de Dieu

Dombart B., Kalb A. (éd.), 1955 - Sancti Avrelii Augustini De civitate Dei libri XI-XXII, Turnhout (CC Ser. Lat., 48).

Hoffmann E. (éd.), 1898 - Sancti Avrelii Avgvstini episcopi De Ciuitate Dei libri XXII, Prague (CSEL 40).

Doctrine chrétienne

Martin J. (éd.), 1962 - Augustin. De doctrina christiana, II, C. 30 et 40, Turnhout (CC Ser. Lat., 32).

Genèse au sens littéral

Zycha J. (éd.), 1894 - Sancti Avrelii Augustini De Genesi ad litteram libri duodecim. [...], Prague-Leipzig-Vindobonae (Corpus scriptorum ecclesiasticorum latinorum; Academiae litterarum Caesareae Vindobonensis, xxviii.sectionis iii pars [ii]). 
Musique

Finaert G., Thonnard F.-J. (éd. et trad. ), 1947 - Augustin. De Musica, in Euvres de Saint Augustin. La Musique, Bruges (Bibliothèque Augustinienne, 1/VII, IV).

Ordre

KNöll P. (éd.), 1922 - Sancti Aureli Augustini Contra Academicos libri tres, De beata vita liber unus, De Ordine libri duo, Vienne-Leipzig (CSEL, 63).

Règles

Martorelli L. (éd.), 2011 - Ps. Aurelii Augustini Regulae, Hildesheim.

Rétractations

KNöLl P. (éd.), 1895 - Sancti Avrelii Augustini Retractationum libri duo, Vienne (CSEL, 36).

\section{Aulu-Gelle}

Hosıus K. (éd.), 1959 - Auli Gellii Noctium atticarum libri XX, Stuttgart.

Julien Y. (éd. et trad.), 1998 - Aulu-Gelle. Les Nuits Attiques, Paris, t. 4 (CUF, 345).

Marache R. (éd. et trad.), 1967-1989 - Aulu-Gelle. Les Nuits Attiques, Paris, t. 1-3 (CUF, 189, 235, 288).

\section{BACON, ROGER}

Nolan E., Hirsch S. A. (éd.), 1902 - The Greek Grammar of Roger Bacon and a Fragment of His Hebrew Grammar Edited from the Mss with Introduction and Notes, Cambridge.

\section{BaRTHÉLEMY L'ANGLAIS}

Bartholomaeus Anglicus. De genuinis rerum coelestium, terrestrium et infrarum proprietatibus libri XVIII, [...] procurante Georgio Bartholdo Pontano a Braitenberg, Frankfurt, 1601 (éd. anast., 1964) .

Corbechon J. (trad.), 1528 - Barthélemy l'Anglais. Le proprietaire en françois, Paris.

van den Abeele B., Meyer H. (éd.), 2005 - Bartholomaeus Anglicus, "De proprietatibus rerum". Texte latin et réception vernaculaire - Lateinischer Text und volkssprachige Rezeption, Turnhout (De diversis artibus, 74, N.S. 37).

van den Abeele B. et al. (éd.), 2007 - Bartholomaeus Anglicus. De proprietatibus rerum. Volume I : Prohemium, Livre I-IV, Turnhout (De diversis artibus 78, N.S. 41).

Ventura I. (éd.), 2007b - Bartholomaeus Anglicus. De proprietatibus rerum.Volume VI: Livre XVII, Turnhout (De diversis artibus 79, N.S. 42).

BÈDE LE VÉNÉRABLE

Burnett C. (éd.), 1985 - Pseudo-Bede. De mundi celestis terrestrisque constitutione, Londres.

Fraipont J. (éd.), 1955 - Bedae venerabilis opera. Pars III, Opera homiletica, Pars IV, Opera rhytmica, 1 vol., Turnhout (CC Ser. Lat., 121).

Jones C. W. (éd.), 1975-1980 - Bedae venerabilis opera. Pars vI, Opera didascalica, 3 vol., Turnhout (CC Ser. Lat., 123A-123C).

\section{Bernard de Clairvaux}

Leclerce J., Talbot C. H. et Rochais H.-M. (éd.), 1975 - Bernard de Clairvaux, Sermones de diversis, dans Sancti Bernardi opera, vol. 6.1, Rome.

\section{Bersuire, Pierre}

Berchorii Repertorium morale, Nuremberg, 1494.

Engels J. (éd.), 1966 - Petrus Berchorius. Reductorium morale, Liber XV: Ovidius moralizatus, cap. I, De formis figurisque deorum. Textus e codice Brux., Bibl. Reg. 863-869 critice editus, Utrecht. 
Huisch J. W. (éd.), 1731 - Petri R. P. Berchorii Pictaviensis Ordinis Benedicti S., Dictionarium, vulgo Reductorium morale (...), Cologne.

KeErberg J. (éd.), 1609 - Opera omnia Petri Berchorii totam S. Scripturae, morum, naturae historia complectentia, Amsterdam.

KoBerger P. (éd.), 1517 - Morale reductorium super totam Bibliam: fratris Petri Berthorii Pictavensis..., Nüremberg.

Reynolds W. (éd.), 1977 - « De formis figurisque deorum/From On the images and figures of the gods », Allegorica, 2.3, 1977, p. 62-89.

vaN Der BiJL M. S. (éd.), 1971 - « Petrus Berchorius, Reductorium morale, liber XV: Ovidius moralizatus, cap. II », Vivarium, 9, p. 25-48.

ZEINER J. (éd.), 1474 - Liber Bibliae moralis, seu Reductorium morale super totam Bibliam F. Petri Berchorii, Ulm.

\section{BIBLE}

Froehlich K. (intro.), Gibson M. T. (éd.), 1992 - Biblia latina, cum glossa ordinaria, facsimile reprint of the editio princeps, [chez] Adoph Rusch of Strassburg, 1480-1481, 4 vol., Turnhout.

BoÈCE

Institution arithmétique

Guillaumin J.-Y. (éd. et trad.), 1995 - Boèce. Institution arithmétique, Paris, $(C U F, 329)$.

Institution musicale

FriedLein G. (éd.), 1867 - Boetii De institutione arithmetica libri II., De institutione musica libri $V$, Leipzig.

Meyer C. (trad. et notes), 2004 - Boèce. Traité de la musique, Turnhout.

\section{BONIFACE}

Gebauer G. J., Löfstedt B. (éd.), 1980 - Bonifatii Ars grammatica, Turnhout (CC Cont. Med., 133B).

\section{BrunetTo Latini}

Baldwin S., Barrette P. (éd.), 2003 - Brunetto Latini. Li livre dou Tresor, Arizona Center for Medieval and Renaissance studies, Tempe (Arizona).

Beltrami P. G., Squillaciotti P., Torri P., Vatteroni S. (éd.), 2007 - Brunetto Latini. Tresor, Torino.

Carmody F. J. (éd.), 1948 - Brunetto Latini. Li livre dou Tresor, Berkeley/Los Angeles, (rééd. Genève, 1998).

Chabaille P. (éd.), 1863 - Li livre dou Tresor par Brunetto Latini, Paris, 1863.

Ribémont B., Menegaldo S. (trad.), 2013 - Brunetto Latini. Le Livre du trésor, livre I, Paris, 2013.

\section{BUFFON}

De la manière d'étudier et de traiter l'Histoire naturelle. Premier discours de l'Histoire naturelle, générale et particulière, avec la description du Cabinet du Roy, Paris, 1986 (1 ${ }^{\text {re éd., } 1749) .}$

\section{CASSIOdore}

Adriaen M. (éd.), 1958 - Cassiodorus. Expositio psalmorum I-LXX, Turnhout (CC Ser. Lat., 97).

FerRÉ, 1999 - Cassiodore. Institutions, livre II : introduction, traduction et commentaire, thèse soutenue en 1999 à l'Université de Saint-Étienne. 


\section{Censorinus}

Rocca-Serra G. (trad.), 1980 - Censorinus. Le jour natal, Paris (Histoire des doctrines de l'Antiquité classique, 5).

Sallmann N. (éd.), 1983 - Censorini de die natali liber ad Q. Caerellium. Accedit Anonymi cuiusdam epitoma disciplinarum fragmentum Censorini, Leipzig.

\section{Chambers E.}

Cyclopaedia, or, An universal dictionary of arts and sciences : Containing the Definitions of the Terms, and Accounts of the Things Signify'd Thereby, in the Several Arts, both Liberal and Mechanical, and the Several Sciences, Human and Divine: the Figures, Kinds, Properties, Productions, Preparations, and Uses, of Things Natural and Artificial; the Rise, Progress, and State of Things Ecclesiastical, Civil, Military, and Commercial: with the Several Systems, Sects, Opinions, etc; among Philosophers, Divines, Mathematicians, Physicians, Antiquaries, Criticks, etc.: The Whole Intended as a Course of Ancient and Modern Learning, Londres, 1728., London, 1571.

\section{Chen Shou}

Chen Shou, Sanguo zhi (Histoire des Trois Royaumes), Weishu (Livre des Wei), Pékin, Zhonghua shuju, 1959.

\section{NOUS DIT}

Blangez G. (éd.), 1979 - Ci nous dit. Recueil d'exemples moraux, Paris, t. 1.

Blangez G. (éd.), 1986 - Ci nous dit. Recueil d'exemples moraux, Paris, t. 2.

\section{Conrad de Hirsau}

Huygens R. B. C., 1955 - Conrad de Hirsau. Dialogus super auctores, Bruxelles (Collection Latomus, 17).

Conrad de Mure

VAN DE Loo T., 2006 - Conradi de Mure Fabularius, Turnhout (Instrumenta lexicologica latina. CC Cont. Med., 210).

\section{Corpus GLOSSARIORUM LATINORUM [= CGL]}

Goetz G., Löwe G. (éd.), 1888-1923 - Corpus glossariorum Latinorum, 7 vol., Leipzig.

\section{Cyrano de Bergerac}

Histoire comique des États et Empires de la Lune, Paris, 1787 [1657].

\section{DiDEROT D.}

Encyclopédie ou Dictionnaire raisonné des sciences, des arts et des métiers, par une société de gens de Lettres, Paris, 1751-1772.

« Prospectus », « Encyclopédie », CEuvres complètes, tome 2, Paris, Le Club Français de Livre, 1970.

\section{Dioscoride (Pedianus)}

Wellmann M. (éd.), 1907 - Pedanii Dioscuridis Anazarbei De Materia Medica Libri quinque, Berlin.

\section{Érotien}

Nachmanson E. (éd.), 1918 - Erotiani Vocum hippocraticarum collectio, Uppsala.

\section{ÉTIENNE DE BouRBon}

BERLIOZ J. (éd.), 2006 - Stephanus de Borbone. Tractatus de diversis materiis predicabilibus. Liber tertius. De eis que pertinent ad donum scientie et penitentiam, Brepols, Turnhout (CC Cont. Med., 214B; Exempla medii aevi, 3).

Berlioz J., Eichenlaub J.-L. (éd.), 2002 - Stephanus de Borbone. Tractatus de diversis materiis predicabilibus. Prologus - Liber primus. De dono timoris (CC Cont. Med., 124). 


\section{EUCHER DE LyON}

Eucherius Lugdonensis Episcopus. Instructionum ad Salonium libri duo, PL 50, col. 773-822.

Mandolfo C. (éd.), 2004 - Eucherii Lugdunensis Opera pars 1. Formulae spiritualis intellegentiae. Instructionum libri duo, Turnhout (CC Ser. Lat., 66).

EugÈne de TolÈde

Alberto P. F. (éd.), 2005 - Eugenii Toletani opera omnia, Turnhout (CC Ser. Lat., 114).

EuSÈbe de CÉSARÉE

Tıмm S. (éd.), 2005 - Eusebius von Caesarea. Das Onomastikon der biblischen Ortsnamen, Berlin.

ÉVRARD DE BÉTHUNE

Wrobel J. (éd.), 1887 - Der Graecismus von Eberhard von Béthune, Breslau.

Évrart de CoNTI

Guichard-Tesson F., Roy B., 1993 - Évrart de Conti. Le Livre des eschez amoureux moralisés, Montréal (CERES Bibliothèque du Moyen français, 2).

Legaré A.-M. (éd.), Guichard-Tesson F., Roy B., 1991 - Le Livre des échecs amoureux: Bibliothèque nationale [ms. fr. 9197], Paris.

Favonius Eulogius

van Weddingen R.-E. (éd.), 1957 - Favonii Eulogii Disputatio de somnio Scipionis, Bruxelles (Latomus, 27).

\section{Festus (Paulus Festus)}

Lindsay W. M. (éd.), 1913 - Sexti Pompei Festi De verborum significatu quae supersunt cum Pauli epitome, Leipzig.

\section{Firmin Le Ver}

Merrilees B., Edwards W. (éd.), 1994 - Firmini Verris Dictionarius: Dictionnaire latinfrançais de Firmin Le Ver, Turnhout (CC Cont. Med., Series in-4 ${ }^{\circ}$, I).

\section{Gervais de Tilbury}

Banks S. E., Binns J. W. (éd. et trad.), 2002 - Gervase of Tilbury. Otia Imperialia. Recreation for an emperor, Oxford (Oxford Medieval Texts).

Duchesne A. (trad.), 1992 - Gervais de Tilbury. Le Livre des merveilles : divertissement pour un empereur (troisième partie), Paris (La Roue à livres).

GiLBERT D'AuXERRE

ANDRÉE A. (éd. et trad.), 2005 - Gilbertus Universalis. Glosa ordinaria lamentationes Ieremie Prophete : Prothemata et Liber I, Stockholm (Acta universitatis Stockholmiensis. Studia latina Stockholmiensia, 52).

GLOSSA ORDINARIA

Dove M. (éd.), 1997 - Glossa ordinaria. Pars 22, In canticum canticorum, Turnhout (CC Cont. Med., 170).

\section{GLOSSARIA LATINA [= GLOSS.L.]}

LindsaY W. M. et al. (éd.), 1926-1931 - Glossaria Latina iussu Academiae Britannicae edita, 5 vol., Paris.

Gossuin de Metz

Connochie-Bourgne C. (éd.), 1999 - Gossuin de Metz. L'Image du monde, une encyclopédie du XIII siècle. Édition critique et commentaire de la première version, thèse d'État, Paris IV-Sorbonne. 
Prior O. H. (éd.), 1913 - L'image du monde de maître Gossuin, rédaction en prose, texte du ms. Bibl. nat. Fr. 574, Lausanne/Paris.

GRAMMATICAE RoMANaE FraGMENTA [= GRF]

Funaioli I. (éd.), 1907 - Grammaticae Romanae Fragmenta, Leipzig.

GRAMMATICI LATINI [= GL]

KeIL H.(éd.), 1855-1880 - Grammatici Latini, 7 vol., Leipzig.

Keil H., Hagen H. (éd.), 1870 - Supplementum continens Anecdota Helvetica, vol. 8, Leipzig.

\section{Gregoire de Montesacro}

Pabst B. (éd.), 2002 - Gregor von Montesacro und die geistige Kultur Süditaliens unter Friedrich II. mit Text- und quellenkritischer Erstedition der Vers-Enzyklopädie Peri ton anthropon theopiisis (De hominum deificatione), Stuttgart (Montesacro-Forschungen, 2).

\section{GréGoIre Le Grand}

Gregorius Magnus. Dialogorum Libri IV De Vita Et Miraculis Patrum Italicorum, PL 77, col. 149-430.

Adriaen M. (éd.), 1979-1985 - Gregorius Magnus. Moralia in Iob, Turnhout (CC Cont. Med., 143-143B).

Gillet R., de Gaudemaris A. (éd.), 1989 - Grégoire le Grand. Morales sur Job, Paris (Sources Chrétiennes, 32 bis).

\section{Guillaume de Conches}

Badia L., Pujol J. (éd.), 1997 - Guillelmis de Conchis Opera omnia, t. I: Dragmaticon philosophiae, éd. Ronca I., Summa de philosophia in vulgari, Turnhout (CC Cont. Med., 152).

CETEDOC (éd.), 2001 - Guillelmis de Conchis "Dragmaticon philosophiae” : [enumeratio, concordantia et index formarum], U. Catholica Lovaniensis, Turnhout (CC Instrumenta lexicologica latina. Series A, 103).

Gratarolus G. (éd.), 1567 - Dragmaticon sive Dialogus de substantiis physicis ante annos ducentos confectus a Vuilhelmo Aneponymo philosopho, Strasbourg (reprod. fac. similé, Francfort, 1967).

Maurach G. (éd.), 1980 - Wilhelm von Conches. Philosophia mundi, Pretoria.

Nauta I. (éd.), 2008 - Guillelmi de Conchis Glosae super Boetium, Turnhout (CC Instrumenta lexicologica latina, Fasc.117 Series A)

Ronca I. (éd.), 1997 - Guillelmi de Conchis Dragmaticon Philosophiae, Turnhout, (CC Cont. Med., 152).

Ronca I., Curr M. (trad.), 1997 - A Dialogue on natural philosophy (Dragmaticon philosophiae), translation of the new Latin critical text with a short intro. and explanatory notes, Notre Dame [Indiana].

Guillaume Durand

Davril A., Thibodeau T. M. (éd.), 1995 - Guillelmi Duranti Rationale divinorum officiorum I-IV, Turnhout (CC Cont. Med., 140).

\section{Guillaume Le Breton}

Daly L. W., Daly B. A. (éd.), 1975 - Summa Britonis sivi Guillelmi Britonis Expositiones vocabulorum Biblie, 2 vol., Padoue.

\section{Henri Bate}

Boese H., Steel C. (éd.), 1990 - Henricus Bate. Speculum divinorum et quorundam naturalium, On Platonic Philosophy, Parts XI-XII, Louvain (Ancient and Medieval Philosophy. Series 1 [AMPh1], 12). 
Guldentops G. (éd.), 2002 - Henricus Bate. Speculum divinorum et quorundam naturalium, Parts XIII-XVI: On Thinking and Happiness, Louvain (AMPhl, 21).

StEel C. (éd.), 1993 - Henricus Bate. Speculum divinorum et quorundam naturalium, Parts IV-V : On the Nature of Matter, on the Intellect as Form of Man, Louvain $(A M P h 1,9)$.

STEel C. (éd.), 1994 - Henricus Bate. Speculum divinorum et quorundam naturalium, Parts VI-VII : On the Unity of Intellect, on the Platonic Doctrine of the Ideas, Louvain (AMPhl, 10).

Steel C., Guldentops G. (éd.), 1996 - Henricus Bate. Speculum divinorum et quorundam naturalium, Parts XX-XXIII : On the Heavens, the Divine Movers, and the First Intellect, Louvain $(A M P h 1,23)$.

van de Vyver E. (éd.), 1960 - Henricus Bate. Speculum divinorum et quorundam naturalium, Introduction ; Littera dedicatoria - Tabula capitulorum - Proemium - Pars I, Louvain-Paris (Philosophes Médiévaux, 4).

van de Vyver E. (éd.), 1967 - Henricus Bate. Speculum divinorum et quorundam naturalium, Partes II-III, Louvain-Paris (Philosophes Médiévaux, 10).

\section{HenRi de Herford}

Palazzo A. (éd.), Sturlese L. (intr.), 2004 - Enrico di Herford, Catena aurea entium. Tabula quaestionum, VIII-X, Pise (Centro di Cultura Medievale, Scuola Normale Superiore di Pisa, 12).

Sturlese L. (éd.), 1987 - Enrico di Herford, Catena aurea entium. Tabula quaestionum, I-VII, Pise (Centro di Cultura Medievale, Scuola Normale Superiore di Pisa, 2).

\section{Hilaire de Poitiers}

Doignon J. et al. (éd.), 1997-2009 - Tractatus super Psalmos (CC Ser. Lat., 61, 61A, 61B).

Smulders P. (éd.), 1979-1980 - De trinitate (CC Ser. Lat., 62, 62A).

\section{HiLdegarde DE Bingen}

Monat P. (trad.), 1988-1989 - Hildegarde de Bingen. Le Livre des subtilités des créatures divines, Grenoble, 2 vol. (Atopia, 7).

Müller I., Schulze C. (éd.), 2008 - collab. Neumann S., Physica, Edition der Florentiner Handschrift (Cod. Laur. Ashb. 1323, ca 1300) im Vergleich mit den Textkonstitution der 'Patrologia Latina' (Migne), Hildesheim-Zurich-New York (éd. antérieure: PL, t. 197, col. 1125-1352).

\section{Honorius Augustodunensis}

Honorius Augustodunensis. De imagine mundi libri tres, PL 172, col. 119-187.

Flint V. (éd.), 1949 - « Honorius Augustodunensis. Imago mundi », dans Archives d'histoire doctrinale et littéraire du Moyen Âge, 82, p. 7-153.

Lucentini P. (éd.), 1974 - Honorius Augustodunensis. Clavis physica, Rome (Temi e testi, 21).

\section{Hucbald de Saint-Amand}

Chartier Y. (trad.), 1995 - Hucbald de Saint-Amand. L'Euvre musicale d'Hucbald de Saint-Amand. Les Compositions et le Traité de musique, Saint-Laurent, Québec (Cahiers d'études médiévales. Cahier spécial, 5).

Hugues de Fouilloy (Hugo de Folieto)

Hugonis opera dogmatica continuatio. De bestiis et aliis rebus, PL 177, col. 15-163. 


\section{Hugutio de Pise (Hugues)}

Cecchini E., Arbizzoni G., Lanciotti S., Nonni G., Sassi M. G., Tontini A. (éd. crit. princeps), 2004 - Uguccione da Pisa. Derivationes, edizione critica princeps, 2 vol., Florence (Edizione nazionale dei testi mediolatini. Serie I, 6).

Cremascoli G. (éd.), 1978 - Huguccione da Pisa. De dubio accentu. Agiographia. Expositio de symbolo Apostolorum, Spoleto.

\section{IBN FADL AlLā̄H AL-'UMARī}

Masālik al-abșār fì mamālik al-amșār fì l-hayawān wa-l-nabāt wa-l-ma'ādin, Al-Qāhira, 1996.

Masālik al-abșār fì mamālik al-amșār, Al- ‘Ayn, 25 vols, 2008.

\section{ISIDORE DE SÉvILLE}

De ecclesiasticis officiis

Lawson C. M. (éd.), 1989 - Sancti Isidori episcopi Hispalensis De ecclesiasticis officiis, Turnhout (CC Ser. Lat., 113).

Étymologies

ANDRÉ J. (éd., et trad.), 1981 - Isidore de Séville. Étymologies XVII. De l'agriculture, Paris.

André J. (éd., et trad.), 1986 - Isidore de Séville. Étymologies XI. Des animaux, Paris.

Cantó Llorca J. (éd., et trad.), 2007 - Isidore de Séville. Étymologies XVIII. De bello et ludis, Paris.

Feáns Landeira J. (éd. et trad.), 2011 - Isidore de Séville. Etimologías xVI. De las piedras y de los metales, Paris.

GaSParotto G. (éd., et trad.), 2004 - Isidore de Séville. Étymologies XIII. De mundo et partibus, Paris.

Gasparatto G. (éd.), Guillaumin J.-Y.(trad.), 2009 - Isidore de Séville. Étymologies ilI. De mathematica, Paris.

GaSTI F. (éd. et trad.), 2010 - Isidore de Séville. Étymologies XI. De homine et portentis, Paris.

Guillaumin J.-Y (éd. et trad.), 2010 - Isidore de Séville. Étymologies Xx. De penu et instrumentis domesticis et rusticis, Paris.

LiNDSAY W. M. (éd.), 1911 - Isidori Hispalensis episcopi Etymologiarum sive Originum libri XX recognovit brevique adnotatione critica instruxit, 2 vol., Oxford.

LindSAY W. M. (éd.), 1911 - Isidorus Hispalensis, "Etymologiarum" sive "Originum" libri XX, Oxford, rééd. 1989-1991.

Marshall P. K. (éd.), 1983 - Isidore de Séville. Étymologies II. Rhetoric, Paris.

Reydellet M. (éd., et trad.), 1984 - Isidore de Séville. Étymologies IX. Les langues et les groupes sociaux, Paris.

Rodriguez-Pantoja M. (éd., trad.), 1995 - Isidore de Séville. Étymologies XIX. De naves, edificios y vestidos, Paris / Cordoue.

SPEvak O. (éd.), 2011 - Isidore de Séville. Étymologies XIV. La terre, Paris.

Liber Differentiarum sive De proprietate sermonum

Sancti Isidori Hispalensis episcopi, Differentiarum sive De proprietate sermonum libri duo, PL 83, col. 9-98.

Andrés Sanz M. A. (éd.), 2006 - Isidori Hispalensis episcopi Liber differentiarum [II], Turnhout (CC Ser. Lat., 111, 1).

Codoñer C. (éd., et trad.), 1992 - Isidoro de Sevilla. "De differentiis", libro I, Paris (Auteurs latins du Moyen Âge, 8). 
De natura rerum

FonTaine J.(éd.), 1960-Isidore de Séville. De natura rerum. Traité de la nature, Bordeaux.

Jacob de Maerlants

VerwiJs E., 1878 - Jacob van Maerlant. Naturen Bloeme, Groningen.

JAMBLique

Pistelli H. (éd.), 1894 - Iamblichi in Nicomachi Arithmeticam Introductionem Liber,

Leipzig, éd. revue par U. Klein, Stuttgart, 1975.

\section{JEAN BELETh}

DouteIL H. (éd.), 1976 - Iohannis Beleth Summa de ecclesiasticis officiis, Turnhout (CC Cont. Med., 41A).

Jean de Garlande

BLATt Rubin B. (trad.), 1981 - The Dictionarius of John de Garlande, Lawrence, 1981.

Haye T. (éd.), 1995 - Johannes de Garlandia. Compendium Gramatice, Cologne/ Weimar/Vienne.

Scheler A. (éd.), 1865 - «Trois traités de lexicographie latine du XII ${ }^{\mathrm{e}}$ et du XIII ${ }^{\mathrm{e}}$ siècle », Jahrbuch für Romanische und Englische Literatur, 6, Leipzig, p. 142-162.

\section{JEAN DE GÊNES}

Summa quae vocatur Catholicon edita a fratre Joanne de Janua, Venise, 1490.

Lichtenstein H. (éd.), 1487 - Catholicon edita a fratre Johanne de Janua Balbi, Cologne.

ZAINER G. (éd.), $\mathbf{1 4 6 0}$ - Summa quae vocatur Catholicon edita a fratre Johanne de Janua Balbi, Moguntiae (réimpr. anast., Farnborough, 1971).

JeAn DE SAint-Victor

Guyot-Bachy I., Poirel D. (éd. et trad.), 2002 - Jean de Saint-Victor. Traité de la division des royaumes. Introduction à une histoire universelle, Turnhout (Sous la règle de saint Augustin), p. 72-74.

JeAn de Salisbury

Hall J. B., Keats-Rohan K. S. B. (éd.), 1991 - Ioannis Saresberiensis. Metalogicon, Turnhout (CC Ser. Med., 98).

\section{JEAN Gerson}

Glorieux P. (éd.), 1973 - Jean Gerson. CEuvres complètes, Contra superstitionem sculpturae leonis, Paris, t. 10.

JÉRôME

S. Eusebii Hieronymi Commentariorum in epistolam Beati Pauli ad Titum liber unus, PL 26, col. 555-599.

de Lagarde P. (éd.), 1959 - Hieronymi Quaestiones Hebraicae in Libro Geneseos, Turnhout (CC Cont. Med., 72).

\section{JiANG SHaOYU}

Jiang Shaoyu, Huangchao leiyuan (Jardin des catégories de la dynastie), réimpr. Kyoto 1981 [éd. japonaise 1615-1624].

Juan Gil de Zamora (Johannes Aegidius Zamorensis)

Domínguez García A., L. García Ballester (éd. et trad.), 1994 - Johannis Aegidii Zamorensis, Historia naturalis, 3 vol., Junta de Castilla y León (Estudios de historia de la ciencia y de la técnica, 11). 


\section{Jean de San Gimignano}

Oldoni M. (éd.), ZapPeri A. (trad.), 1993 - Giovanni da San Gimignano. Un enciclopedismo dell'anima, Città di San Gimignano [traduction partielle du Liber de exemplis et similitudinibus rerum].

Pafraet R. (éd.), 1478-1479 - Johannes de Sancto Geminiano. Liber de exemplis ac similitudinibus rerum.

\section{KonRad von Megenberg}

Pfeiffer F. (éd.), 1861 - Das Buch der Natur von Konrad von Megenberg. Die erste Naturgeschichte in deutsche Sprache, Stuttgart (repr. Hildesheim, 1962 et 1971).

STEer G., Luff R. (éd.), 2003 - Conradus de Megenberg, Buch der Natur, Tübingen, 2003 (Texte und Textgeschichte, 54 ; volume paru: II. Kritischer Text nach der Handschriften)

\section{LACTANCE}

Brandt S., von Laubmann G. (éd.), 1890 - Lactantius. Opera omnia (...) Pars I, Sectio I. Divinae institutiones et epitome divinarum institutionum, Vienne/Prague/Leipzig (CSEL 19).

Jahnke R (éd.), 1898 - Lactantii Placidi qui dicitur Commentarii in Statii Thebaide et Commentarium in Achilleidem, Leipzig.

Pannier L., Paris G. (éd.), 1882 - Les Lapidaires français du Moyen Âge des XII ${ }^{e}$, XIII et XIV siècles, réunis, classés et publiés, accompagnés de préfaces, de tables et d'un glossaire, Paris (réimpr. fac. similé, Genève, 1973).

LeCoy de la MaRche

A. Lecoy de la Marche, Anecdotes historiques, légendes et apologues d'Étienne de Bourbon, Paris, 1877.

\section{Daniel de Morley}

SudHOFF K. (éd.), 1917 - Daniel von Morlay. Liber de naturis inferiorum et superiorum, dans Archiv für Geschichte der Mathematik, der Naturwissenschaften und der Technik, 8, 1917, p. 1-40.

\section{LIBER GLOSSARUM}

Goetz G., 1893 - Der Liber glossarum, Leipzig (Abhandlungen der philologisch-historischen Classe der königlich-sächsischen Gesellschaft der Wissenschaften, XIII [2]).

Goetz G. (éd.), 1894 - Liber glossarum (excerpta), Leipzig (CGL 5, p. 159-255).

\section{LIVRE DE SYDRAC LE PHILOSOPHE, VOIR SYDRAC}

\section{LIU SU}

Liu Su, Sui Tang jiahua (Précieuses paroles des Sui et des Tang), Pékin, 1979.

\section{MaCrobe}

Les Saturnales

Bornecque H., Richard F. (éd. et trad.), 1937 - Macrobe. Les Saturnales, Paris.

GuitTaRd C. (trad.), 1997 - Macrobe, Les Saturnales, Paris, t. 1 (livres 1-3).

KASTER R. A. (éd.), 2011 - Macrobii Ambrosii Theodosii Saturnalia, Oxford / New York.

KASTER R. A. (trad.), 2011 - Macrobius. Saturnalia, Cambridge, 3 vol.

Willis J. A. (éd.), 1963 - Macrobius. Saturnalia, Leipzig, 2 vol.

\section{Songe de Scipion}

Armisen-Marchetti M. (éd. et trad.), 2001-2003 - Macrobe. Commentaire au Songe de Scipion, Paris, 2 vol. (CUF, 360, 373). 


\section{Marc D'OrVieto (Marcus d'Orvieto)}

Etzkonn G. J. (éd.), 2005 - Marci de Urbi Veteri Liber De Moralitatibus, Saint Bonaventure U.P., 3 vol. (Franciscan Institute Publications).

\section{Martianus Capella}

Guillaumin J.-B. (éd. et trad.), 2011 - Martianus Capella. Les Noces de Philologie et de Mercure. Livre IX. L'Harmonie, Paris $(C U F, 401)$.

Willis J. (éd.), 1983 - Martianus Capella, [De nuptiis Philologiae et Mercurii], Leipzig.

\section{Michael Scot (Michaelus Scottus)}

Liber introductorius

Meier H. (éd.), 1928 - [Transcription du manuscrit de Munich, copie au Warburg Institute, Londres, cote FAH 1437, quatre volumes dactylographiés]

\section{Muhammad IBN Mạ̣mūd Ṭūsī}

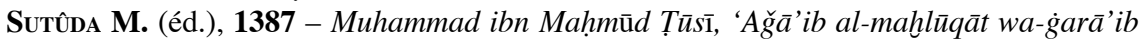
al-mawğūdāt, Téhéran.

\section{MUSICI SCRIPTORES GRAECI}

von JAN C. (éd.), 1895 - Musici scriptores graeci: Aristoteles, Euclides, Nicomachus, Bacchius, Gaudentius, Alypius et melodiarum veterum quicquid exstat, Leipzig, réimpr. fac-similé 1995.

Nicolas de LyRe

Nicolaus de Lyra, [Postilla super totam Bibliam], Venise, 1488, reprod. num. Cambridge, c. 1990 (Italian books before 1601, 418.5).

\section{Nicolas de Strasbourg}

Pellegrino G. (éd.), Sturlese L. (intro.), 2009 - Nikolaus de Strassburg. Summa (II, L. 2, tr. 1-2), Hambourg (CphTMA, 5.2.1).

Pellegrino G. (éd.), 2009 - Nikolaus de Strassburg. Summa (II, L. 2, tr. 3-7), Hambourg (CPhTMA, 5.2.2).

Suarez-Nani T. (éd.), 1990 - Nikolaus de Strassburg. Summa (II, L. 2, tr. 8-14), Hambourg, (CPhTMA, 5.2.3).

\section{Osbern de Gloucester}

Busdraghi P., et al. (éd.), 1996 - Osberno. Derivazioni, 2 vol., Spoleto.

\section{PaPIas}

Ars grammatica

Cervani R. (éd.), 1998 - Papiae Ars grammatica, Bologne.

Elementarium Vocabularium

Elementarium doctrine rudimentum, Milan, 1476 (réimpr. anast., Turin, 1966).

Papias Vocabulista, Elementarium doctrinae rudimentum, Venetiis, 1496 (réimpr. anast., Turin, 1966).

De Angelis V. (éd.), 1977-1978 - Papiae Elementarium Littera A (A-Aequus, AequusAmiferme), 2 vol., Milan (Testi e documenti per lo studio dell'antichità, 58).

RidDER K. (éd.), 1980 - Papiae Elementarium Littera A. Littera A, Ani-Azoni. Milan, 1980 (Testi e documenti per lo studio dell'antichità, 58, III)

\section{von Pforr, Antonius}

GeISLER F., 1960 - Beispiele der alten Weisen des Johann von Capua. Übersetzung der hebräischen Bearbeitung des indischen Pañcatantra ins Lateinische, Berlin. 


\section{Phocas}

KeIL H. (éd.), 1868 - Phocas. Ars de nomine et verbo, Leipzig, GL 5, p. 410-439.

Pierre Helie (Petrus Helias)

Reilly L. (éd.), 1993 - Petrus Helias, Summa super Priscianum, 2 vol., Toronto.

Pierre le Chantre (Petrus Cantor)

Boutry M. (éd.), 2004 - Petrus Cantor. Verbum adbreviatum Textus conflatus, Turnhout (CC Cont. Med., 196).

Sylwan A. (éd.), 1992 - Petrus Cantor. Glossae super Genesim. Prologus et capitula 1-3, Göteborg.

\section{Pierre le Mangeur (Petrus Comestor)}

Scolastica historia magistri Petris Comestoris, Chambéry, 1485 (réimpr. num. Cambridge, c. 1990, French Books before 1601, 345.1).

CTLO (éd.), 2007 - Petrus Comestor Scolastica historia : Liber Genesis. Enumeratio, concordantia et index formarum, Turnhout (CC Instrumenta lexicologica latina. Series $A, 160)$.

Sylwan A. (éd.), 2005 - Petrus Comestor. Scolastica historia. Genesis, Turnhout (CC Cont. Med., 191).

Placidus (Placide)

Götz G., Löwe G. (éd.), 1894 - Placidus. Liber glossarum. Glossaria reliqua (CGL 5, p. 1-158).

Pirie J. W. et Lindsay W. M. (éd.), 1930-1932 - « Placidi glossae », dans Lindsay W. M. (dir.), Glossaria latina, iussu Academiae britannicae edita, 5 vol., Poitiers-Paris, vol. 4.

Placides et TIMÉo

Thomasset C. (éd.), 1980 - Placides et Timéo ou Li secrés as philosophes, Genève/Paris (Textes littéraires français, 289).

VéraRd A. (éd.), 1504 - Le cuer de philozophie, Paris, [ca 1504] (exemplaire consulté : $\mathrm{BnF}, \mathrm{RES}-\mathrm{R}-840$ ).

Platon

Rivaud A. (éd. et trad.), 1925 - Platon. Timée, Paris $(C U F, 30)$.

Pline l'Ancien

BARChIESI A. et al. (éd.), 1982 - Plinio. Storia naturale, Turin.

BeAuJeu J. (éd. et trad.), 1950 - Pline l'Ancien. Histoire naturelle, Livre II, Paris (CUF, 133).

Polemius Silvius

Mommsen T. (éd.), 1857 - Polemii Silvii Laterculus, Leipzig (Abhandlungen der philologisch-historischen Klasse der königlichsächsischen Gesselschaft der Wissenschaften, II.B).

Pollux

BETHE E. (éd.), 1900-1917 - Pollucis Onomasticon, Leipzig.

Priscien de Césarée

Hertz, Keil H. (éd.), 1855-1859 - Prisciani grammati Caesariensis Institutionum grammaticarum libri xviii, ex recensione, 2 vol., Leipzig, GL 2-3.

\section{Quintilien, Aristide}

Mathiesen T. J. (trad.), 1983 - Aristides Quintilianus : On music in three books, New Haven - Londres (Music Theory Translation Series).

Winnington-Ingram R. P. (éd.), 1963 - Aristidis Quintiliani De musica libri tres, Leipzig. 
Winterbottom M. (éd.), 1970 - M. Fabi Quintiliani Institutionis oratoriae libri duodecim, éd. 2 vol., Oxford.

\section{RABan MaUR}

Rabanus Maurus. Commentariorum in Genesim libri quatuor, PL 107, col. 439-669.

Rabanus Maurus. De universo libri duo, PL 111, col. 9-614.

Rabanus Maurus. Excerptio de arte grammatica Prisciani, PL 111, col. 613-678.

Cavallo G. (éd.), Leonardi C., Braga G. et al., 1994 - Rabano Mauro De rerum naturis, Codex Casinensis 132, Archivio dell'Abbazia di Montecassino, Turin, 3 vol. [fac-similé et études].

\section{RaOul le Breton (RAdulphus Brito)}

Costa J. (éd.), 2004 - Le quaestiones di Radulfus Brito sull'Ethica Nicomachea. Introduzione e testo critico, Turnhout (Studia Artistarum, 17).

\section{Remi d’Auxerre (Remigius Autissiodorensis)}

Remigius Autissiodorensis. Commentum Einsidlense in Donati artem maiorem (= Commentum in Donati artem maiorem sec. cod. Einsidlensem 172, libri I-II), GL 8 (Anecdota Helvetica quae ad grammaticam Latinam spectant), p. 219-266.

Huygens R. B. C. (éd.), 2000 - Remi d'Auxerre, Commentarius in Prisciani tractatum De nomine et pronomine et verbo, dans Serta mediaevalia. Textus varii saeculorum X-XIII in unum collecti, Turnhout (CC Cont. Med., 171), p. 11-23.

\section{Richard de SAINT-Victor}

Châtillon J. (éd.), 1958 - Richard de Saint-Victor : Liber exceptionum, Paris.

\section{ROBERT DE BORON}

Мicha A. (éd.), 1979 - Robert de Boron. Merlin, Roman du XIII siècle, Genève.

\section{SAINT JÉrôME}

Hieronymus. Liber nominum Hebraicorum scripturae sacrae, Migne, PL 23, col. 1146-1176.

\section{SALERNITAN QUESTIONS}

Lawn B. (éd.), 1979 - The Prose Salernitan Questions, edited from a Bodleian Manuscript (Auct. F.3.10). An anonymous collection dealing with science and medicine, written by an Englishman c. 1200, with an appendix and ten related collections, Londres/Oxford (Auctores Britannici Medii Aevi, 5).

\section{Scalich, Paul (Skalić, Scaliger)}

Encyclopaedia, seu Orbis disciplinarum, tam sacrarum quam prophanum Epitome, Bâle, 1559.

\section{SCHOLIA BEMBINA}

MountFord J. F. (éd.), 1934 - The Scholia Bembina, Liverpool.

\section{Sedulius Scottus}

LöfSTEDT B. (éd.), 1977 - Sedulius. In Donati artem maiorem, Turnhout (CC Cont. Med., 40B).

SEguin

KneEPKens C. H., Reijnders H. F. (éd.), 1979 - Magister Siguinus Ars lectoria. Un art de lecture à haute voix du onzième siècle, Leyde.

\section{Sergius}

KeIL H. (éd.), 1864 - [Sergii] explanationes in artes Donati, Leipzig, GL 4, p. 486-565.

\section{Servius}

Thilo G., Hagen H. (éd.), 1878-1901 - Servii grammatici qui feruntur in Vergilii carmina commentarii, 4 vol., Leipzig. 


\section{Strabo Walahfrid (STRabus)}

Biblia sacra cum Glossa ordinaria primum quidem a Strabo Fuldensis collecta, novis Patrum, graec. et lat., explicationibus locupletata, et Postilla Nicola Lirani [...] cum additionibus Pauli Burgensis [...] et Matthiae Thoringe replicis, opera et studio Theolog. Duacensium studi emendatis ... omnia denuo recensuit R.P. doctor Leander a San Marino ..., Anvers, 1634.

Walafridus Strabo Fuldensis, liber Genesis, PL 113, col. 67-182 (Liber Genesis cum Walafridi Strabi glossa ordinaria et Anselmi Laudunensis glossa interlineari).

\section{SuÉTONE}

REIFFERSCheId A. (éd.), 1860 - Suetonii, Tranquilli praeter Caesarum libros reliquiae, Leipzig, p. 247-254.

\section{SUMMARIUM HEINRICI}

Hildebrandt R., De Bidder L. (éd.), 1974-1995 - Summarium Heinrici I-III, Berlin / New York (Quellen und Forschungen Sprach- und Kulturgeschichte der Germanischen Völker, neue Folge, 61, 78 et 109).

\section{SunESEN, ANDERS}

Ebbesen S., Mortensen L. B. (éd.), 1985-Andreae Sunonis Filii Hexaemeron, Copenhague.

\section{Sydrac (SYdrach)}

Burton Tl. (éd.), Schaer F., Masters B., Flanagan S. et al., 1998-1999 - Sidrak and Bokkus, a parallel text edition from Bodleian Library, ms Laud, misc 559 and British Library, Ms Lansdowne 793, Oxford (Early english texts society. Original series, 311-312), vol. 1 : Introduction, Prologue and Books I-II, et vol. 2 : Books III-IV, Commentary, Appendices, Glossary, Index.

Du Pré G., Vidoue P. (éd.), 1531 - Sydrach le grant philosophe. La Fontaine de toutes sciences, Paris (exemplaire consulté: BnF, 8-S-1764).

RuHE E. (éd.), 2000 - Sydrac le philosophe. Le Livre de la fontaine de toute science, Wiesbaden (Wissensliteratur im Mittelalter, 34).

Sgrilli P. (éd.), 1984 - Il "Libro di Sidrac" Salentino, Pise (Biblioteca degli studi mediolatini e volgari, Nuova serie, 7).

Steiner S.-M. (éd.), 1994 - Un témoignage de la diffusion encyclopédique au XIII siècle. Le Livre de Sidrach. Édition critique d'après les manuscrits de Paris et de Rome (Premier Prologue. Catalogue des Questions. Second Prologue), Melun (Mémoires, 2).

\section{Synonyma CiCERonis}

GaTti P. (éd.), 1993 - Lexicographica 2, "Synonyma Ciceronis" : arba, humus, Genova (Publicazioni del D.Ar.Fi.Cl.Et, Nuova serie, 149).

Gutti P. (éd.), 1994 - Synonyma Ciceronis. La raccolta Accusat-Lacescit, Trente (Labirinti : collana del Dipartimento di scienze filologische e storische, 9).

\section{Tertullien}

Tertullianus, Liber de praescriptionibus adversus haereticos, PL 2, col. 9-74.

ThLL

WölfFlin E., Leo F. (éd.), 1900-... - Thesaurus linguae Latinae (TL), Leipzig.

\section{Thomas D'AQuin}

Zimmermann A., Kopp C. (éd.), 1988 - Thomas von Aquin: Werk und Wirkung im Licht neutre Forschungen, Berlin/New York (Miscellanea Mediaevalia, 19).

Thomas de Cantimpré

BOESE H. (éd.), 1973 - Thomas Cantimpratensis, Liber de natura rerum secundum diversos philosophos, Berlin/New York. 


\section{VARRON}

Collart J. (éd.), 1954 - Varron. De lingua Latina livre V, Paris.

\section{VinCENT de BeAuVAIS}

Bibliotheca Mundi. Vincentii Burgundi... Speculum quadruplex siue Speculum maius, 4 vol., Douai, 1624 (éd. anast., Graz, 1961-1965).

\section{Vincente Coronelli}

CORONElli V., 1701-1706 - Biblioteca universale sacro-profana, antico-moderna: in cui si spiega con ordine alfabetico ogni voce, anco straniera, che può avere significato nel nostro idioma italiano, appartenente a'qualunque materia, Venise.

\section{Vita Aristotelis Marciana}

Gigon O., 1962 - Vita Aristotelis Marciana, Berlin (Kleine Texte für Vorlesungen and Übungen, Heft, n. 81).

\section{VITRUVE}

Saliou C. (éd. et trad.), 2009 - Vitruve. De l'Architecture. Livre V, Paris $(C U F, 393)$.

\section{WENYING}

Wenying, Yuhu qinghua (Propos distingués à Yuhu), Pékin, 1984.

\section{WOWERN, JOHANN VON}

Wower J. A. De polymathia tractatio, Basel, 1603. 


\section{SOURCES SECONDAIRES}

Abramov D., 2002 - « Die moralisierende Enzyklopädie Liber de naturis rerum von PseudoJohn Folsham », dans Die Enzyklopädie im Wandel vom Hochmittelalter bis zur frühen Neuzeit. Akten des Kolloquiums des Projekts D im Sonderforschungsbereich 231 (29.11.1996-01.12.1996), Munich (Münstersche Mittelalter-Schriften, 78), p. 123-154

ACKermann S., 2009 - Sternstunden am Kaiserhof: Michael Scotus und sein Buch von den Bildern und Zeichen des Himmels, Frankfurt am Main.

Adorno F., 1998 - «Vivere secondo natura : natura e ragione nello Stoicismo », dans UGLIONE R. (éd.), L'uomo antico e la natura, Turin, p. 129-146.

Aertsen J. A. et al., 2001 - Nach der Verurteilung von 1277. Philosophie an der Universität von Paris im letzten Viertel des 13. Jahrhunderts. Studien und Texte, Berlin/New York (Miscellanea Mediaevalia, 28).

Afshar I., 1985 - « 'Ajā’eb al-maklūqāt » dans Yarshater E. (éd.) Encyclopaedia Iranica, I, London, p. 698-699.

AL-NuwaYrī, 1923-1998 - Nihāyat al-arab fì funūn al-adab, Al-Qāhira, 33 vols.

D’Alverny M.-T., 1965 - Alain de Lille, Textes inédits, Paris.

Amelung I., 2007 - « New Maps for the Modernizing State: Western Cartographic Knowledge and its Application in 19th and 20th Centuries », dans Bray F., DorofeEva-Lichtmann V., MÉTAILIÉ G. (dir.), Graphics and Text in the Production of Technical Knowledge in China: The Warp and the Weft, Leiden.

Amsler M. E., 1989 - Etymology and Grammatical Discourse in Late Antiquity and the Early Middle Ages, Amsterdam/Philadelphie.

Anderson G., 1997 - «The Sophistic Environment », dans Aufstieg und Niedergang der römischen Welt, 2, 34.3, p. 2173-2185.

Anderson G., 2000 - « The Banquet of Belles-Lettres. Athenaeus and the Comic Symposium », dans Braund D. \& WiLkins J. (dir.), Athenaeus and his World, Exeter, p. 316-326.

ANDRÉ J., 1955 - «Pline l'Ancien botaniste », REL, 33, p. 297-318.

ANDRÉ J., 1959 - «Erreurs de traduction chez Pline l'Ancien », REL, 37, p. 203-215.

ANDRÉ J., 1971 - Emprunts et suffixes nominaux en latin, Genève, 1971.

Anzulewicz H., Senner W. et al. (éd.), 2001 - Albertus Magnus. Zum Gedenken nach 800 Jahren. Neue Zugänge, Aspekte und Perspektiven, Berlin (Quellen und Forschungen zur Geschichte des Dominikanerordens, 10).

Anzulewicz H., 2009 - «Albertus Magnus und die Tiere », dans Obermaier S. (éd.), Tiere und Fabelwesen im Mittelalter, Berlin-New York, p. 29-54.

Arnar A. S., 1990 - Encyclopedism from Pliny to Borges, Chicago.

ARnOLD K., 1976 - « Konrad von Megenberg als Kommentator der Sphaera des Johannes von Sacrobosco », Deutsches Archiv für Erforschung des Mittelalters, 32.1, p. 147-186.

Astarita M. L., 1993 - La cultura nelle Noctes Atticae, Catane.

Aujac G., 1993 - La Sphère, instrument au service de la découverte du monde d'Autolycos de Pitanè à Jean de Sacrobosco, Caen.

JaIL C., 2001 - L'étrange et le merveilleux en terres d'Islam, Paris.

Bagley P. J., 1992 - « On the Practice of Esotericism », Journal of the History of Ideas, 53.2, p. 231-247.

BaIER T., 1997 - Werk und Wirkung Varros im Spiegel seiner Zeitgenossen: von Cicero bis Ovid, Stuttgart. 
Baillaud B., de Gramont J., Hüe D. (éd.), 1999 - Discours et savoirs : Encyclopédies médiévales, Paris.

BaIN E., 2007 - «"Homme et femme il les créa" (Gen. 1, 27) : le genre féminin dans les commentaires de la Genèse au XII ${ }^{\mathrm{e}}$ siècle », Studi Medievali, 48.1, p. 229-270.

BaKhtine M., 1978 - Esthétique et théorie du roman, Paris.

Balansard A., 2001 - 'Techné' dans les Dialogues de Platon. L'empreinte de la sophistique, Sankt Augustin.

Balazs E., 1968 - La Bureaucratie céleste, Paris.

BALME D. B., 1962 - « Development of Biology in Aristotle and Theophrastus: Theory of Spontaneous Generation », Phronesis, 7, p. 91-104.

Balme D. M., 1987 - « The place of biology in Aristotle's philosophy », dans Gotthelf A., Lennox J. G. (dir.), Philosophical issues in Aristotle's biology, p. 9-20.

Baratin M., Desbordes F., 1981 - L'Analyse linguistique dans l'Antiquité classique. I. Les théories, Paris.

Barbéris J.-M., 2005 - « Le processus dialogique dans les phénomènes de reprise en écho », dans Bres J., Haillet P. P., Mellet S., Nølke H., Rosier L. (dir.), Dialogisme et polyphonie. Approches linguistiques, Bruxelles, p. 157-172.

Barbero G., 1990 - « Contributi allo studio del Liber glossarum », Aevum, 64, p. 151-174.

Barbero G., 1993 - «Per lo studio delle fonti del Liber Glossarum: il MS. Amploniano F.10 », Aevum, 67, p. 253-278.

BAUER U., 1983 - Der Liber introductorius des Michael Scotus in der Abschrift CLm 10268 der Bayerischen Staatsbibliothek München. Ein illustrierter astronomisch-astrologische Codex aus Padua, 14. Jahrhundert, München.

Baumann A., 1995 - Weltchronistik in the Outgoing Middle Ages. Heinrich of Herford, Gobelinus Person, Dietrich Engelhus, Francfort (Europäische Hochschulschriften, Reihe $3,653)$.

Baumgartner E., Harf-Lancner L. (dir.), 2002 - Seuils de l'œuvre dans le texte médiéval, Paris.

Bausani A., 1978 - L'enciclopedia dei fratelli della purità, Napoli.

Bausani A., 1985 - «L'enciclopedia e il mondo arabo-islamico medievale », Rivista critica de storia della filosofia Firenze, 40.1, p. 137-146.

Bazàn B. C., Wippel J. W., Fransen G., Jacquart D. (dir.), 1985 - Les Questions disputées et les questions quodlibétiques dans les Facultés de théologie, de droit et de médecine, Turnhout (Typologie des Sources du Moyen Âge Occidental, 44-45).

Beagon M., 2007 - «Situating Nature's Wonders in Pliny's Natural History », dans BisPham E. et Howe G. (éd.), avec Matthews E., 'Vita vigilia est'. Essays in Honour of Barbara Levick, Londres, p. 19-40.

Becq A. (éd.), 1991 - L'Encyclopédisme. Actes du Colloque de Caen (1987), Paris.

Belardi W., 2002 - L'etimologia nella storia della cultura occidentale, 2 vol., Rome.

Belaval Y., 1985 - «Diderot et l'encyclopédisme », Encyclopaedia Universalis, p. 437.

BÉLis A., 1986 - Aristoxène de Tarente et Aristote. "Le traité d'harmonique”, Paris.

Bélis A., 1996 - « Harmonique », dans Brunschwig J., Lloyd G. (éd.), Le Savoir grec. Dictionnaire critique, Paris, p. 352-367.

BÉLIS A., 2005 - «Musicales grecques (Théories) » dans LeClant J. (éd.), Dictionnaire de l'Antiquité, Paris, p. 1475-1479.

Bellino F., 2008 - Le Meraviglie del creato et le stranezze degli esseri, Milano. 
Benatouïl T., 2002 - «Logos et scala naturae dans le stoïcisme de Zénon et Cléanthe », Elenchos, 23, 2, p. 297-331.

Bénatouïl T., Draelants I. (dir.), 2011 - Expertus sum: l'expérience par les sens dans la philosophie naturelle médiévale, Firenze (Micrologus' Library, 40).

Benedetti M. (éd.), 2001 - Fare etimologia. Presente, passato e futuro nella ricerca etimologica. Atti del Convegno Università per Stranieri, Siena, 2-3 ottobre 1998, Roma.

Benediktson D. T., 1993 - « A Survey of Suetonius Scholarship, 1938-1987 », The Classical World, 86, p. 377-447.

Berlekamp P., 2011 - Wonder, Image and Cosmos in Medieval Islam, Yale, 2011.

Berlioz J., Polo de Beaulieu M. A., 2000 - « Les prologues des recueils d'exempla », dans Hamesse J. (éd.), Les Prologues médiévaux. Actes du Colloque international organisé par l'Academia Belgica et l'École française de Rome avec le concours de la F.I.D.E.M. (Rome, 26-28 mars 1998), Turnhout (Textes et études du Moyen Âge, 15), p. 275-321.

Berndt R., 1987 - « Note sur la tradition manuscrite et l'édition du Tractatus in Hexaemeron de Hugues de Rouen », Revue d'Histoire des Textes, 17, p. 353-367.

BernT G., 1986 - « Enzyklopädie II.1: Lateinisches Mittelalter », Lexikon des Mittelalters, 3, col. 2032-2033.

Bernt G., Jung M.-R., 1986 - « Enzyklopädie III.1: Romanische und niederländische Literaturen », Lexikon des Mittelalters, 3, col. 2034;

Berteloot A., Hellfaier D., 2001 - Jacob van Maerlants Der naturen bloeme und das Umfeld. Vorläufer-Redaktionen-Rezeption, Münster/New York (Niederlande-Studien, 23).

Bertini F., 1981 - « La tradizione lessicografica latina fra tardo antico e alto medioevo », La cultura in Italia fra tardo antico e alto medioevo, I, Roma, Herder, p. 397-409.

Bertrand P., van den Abeele B., 2006 - « Recyclage de contenus et récupération de pièces d'archives dans Claassens G. H. M., Verbeke W. (éd.), le Macrologus encyclopédique de Saint-Laurent de Liège (c. 1470-1480) », dans Medieval Manuscripts in Transition. Tradition and Creative Recycling, Leuven (Mediaevalia lovaniensia. Series 1, studia, 36), p. 37-59.

BEsNier B., 1999 - « La conception stoïcienne de la nature », dans Cusset C. (éd.), La nature et ses représentations dans l'Antiquité, Paris, p. 119-131.

BEYER DE RYKe B., 2003 - « Le miroir du monde: un parcours dans l'encyclopédisme médiéval », Revue belge de philologie et d'histoire, 81 (4), p. 1243-1275.

Bianchi L., 1990 - Il vescovo e i filosofi. La condanna parigina del 1277 e l'evoluzione dell'aristotelismo scolastico, Bergame (Quodlibet, 6).

Binkley P. (éd.), 1997 - Pre-Modern Encyclopedic Texts. Proceedings of the second COMERS Congress, Groningen, 1-4 July 1996, Leiden/New York/Köln.

BIONDI L., 2011 - Recta scriptura. Ortografia ed etimologia nei trattati mediolatini del grammatico Apuleio, Milan, 2011.

Bischoff B., 1966 - « Die Kölner nonnenhandschriften und das Scriptorium von Chelles », dans Bischoff B. (éd.), Mittelalterliche Studien, I, Stuttgart, p. 16-34.

Bischoff B., 1981 - « Die Bibliothek im Dienste der Schule », dans Bischoff B. (éd.), Mittelalterliche Studien, III, Stuttgart, p. 213-233.

BitTerling K., 1986 - «Enzyklopädie III.2: Englische Literatur », Lexikon des Mittelalters, 3, col. 2034-2035.

BLACHÈRE R., 1975 - «Quelques réflexions sur les formes de l'encyclopédisme en Égypte et en Syrie du VIII $/ \mathrm{XIV}^{\mathrm{e}}$ siècle à la fin du $\mathrm{IX}^{\mathrm{e}} / \mathrm{Xv}^{\mathrm{e}}$ siècle », dans BLACHĖRE R. (éd.), Analecta, Damas, p. 521-540. 
BlaIR A., 1999 - « Authorship in the Popular "Problemata Aristotelis" », Early Science and Medicine, 4, p. 190-227.

Boissat D., 1971 - «Questions de classe: question de mise en scène, question de mise en demeure », dans Kerbrat-OrecChioni C. (dir.), La Question, Lyon (Linguistique et sémiologie), p. 263-294.

Boisson C., Kirtchuk P., BÉJoInt H., 1991 - « Aux origines de la lexicographie : les premiers dictionnaires monolingues et bilingues », International Journal of Lexicography, p. 261-315.

Bolton Holloway J., 1986 - Brunetto Latini : an Analitic Bibliography, London (Research Bibliographies \& checklists, 44).

Bolton Holloway J., 1993 - Twice-told Tales : Brunetto Latini and Dante Alighieri, New York.

Bona I., 1991 - Natura terrestrium (Plin. NH VIII), Gênes.

Bonnelli M., 2004 - « La lexicographie philosophique antique », dans Darbo-Peschanski C. (dir.), La citation dans l'antiquité, Grenoble, p. 85-93.

Borst A., 1994 - Das Buch der Naturgeschichte. Plinius und seine Leser im Zeitalter des Pergaments, Heidelberg.

Bos A. P., 1989 - «Exoterikoi logoi and enkyklioi logioi in the Corpus Aristotelicum and the Origin of the Idea of the enkykios paideia », Journal of the History of Ideas, 1, p. 179-198.

Bottero J., 1997 - « L'écriture, le développement et la diffusion du savoir en Mésopotamie ancienne ", dans SchaER R., Tous les savoirs du monde. Encyclopédies et bibliothèques, de Sumer au XXIe siècle, Paris, p. 26-31.

DE BoÜARD M., 1930 - « Les encyclopédies médiévales : sur "la connaissance de la nature et du monde" au Moyen Âge », Revue des questions historiques, 112, p. 258-304.

DE BouÄRD M., 1932 - «Une encyclopédie médiévale jusqu'à présent inconnue, le Compendium philosophiae », Revue Thomiste, 15, p. 118-143 et p. 301-330.

DE BouäRD M. (éd. partielle), 1939 - Une nouvelle encyclopédie médiévale. Le Compendium philosophiae, Paris, p. 121-206.

DE Boüard M., 1991 - «Réflexions sur l'encyclopédisme médiéval », dans Beck A. (éd.), L'encyclopédisme. Actes du colloque de Caen, 12-16 janvier 1987, Paris, p. 281-90.

Bouchet F., 2008 - Le discours sur la lecture aux XIV et $X V^{e}$ : pratiques, poétique, imaginaire, Paris.

Bourgain P., 1989 - «Le sens de la langue et des langues chez Roger Bacon», dans Contamine G. (éd.), Traducteurs et traductions au Moyen Âge. Actes du Colloque International du CNRS, Paris, p. 317-331.

Bourgain P., 2001 - «Les verbes en rapport avec le concept d'auteur », dans Zimmermann M. (éd.), Auctor et auctoritas. Invention et conformisme dans l'écriture médiévale. Actes du colloque tenu à l'Université de Versailles-Saint-Quentin-en-Yvelines (14-16 juin 1999), Paris (Mémoires et documents de l'École des Chartes, 59), p. 361-374.

Braun L., 1973 - « Hellenistische Erklärungen des Nestorbechers », Mnemosyne, 26, p. 47-54.

BraY L., 1990 - Dictionnaires. Encyclopédie Internationale de lexicographie, vol. 2, Berlin/New York, p. 1796-1798 et 1800-1801.

Bres J., 2005 - « Savoir de quoi on parle : dialogue, dialogal, dialogique; dialogisme, polyphonie... », dans Bres J., Haillet P. P., Mellet S., Nølke H., Rosier L. (dir.), Dialogisme et polyphonie. Approches linguistiques, Bruxelles, p. 47-61.

BrinKER-von DER Heyde C., 1999 - « Durch Bildung zur Tugend: Zur Wissenschaftslehre des Thomasin von Zerclære », dans Schaefer U., Artes im Mittelalter, Formationen und transformationen des Wissens, Berlin, p. 34-52. 
Brunschwig J., 1996 - « La connaissance », dans Brunschwig J., Loyd G. E. R. (dir.), Le Savoir grec: dictionnaire critique, Paris, p. 112-131.

Buffière F., 1958 - Les mythes d'Homère et la pensée grecque, Paris.

Bullough V. L., Brundage J. A. (éd.), 1996 - Handbook of Medieval Sexuality, New York, (Garland Reference Library of the Humanities).

Buridant C., 1986 - « Lexicographie et glossographie médiévales. Esquisse de bilan et perspectives de recherche », dans BURIDANT C. (éd.), Lexique, 4 (La Lexicographie au Moyen Âge), p. 9-46.

Buridant C., 1990 - « Définition et étymologie dans la lexicographie et la lexicologie médiévales », dans Chaurand J., Mazière F. (éd.), La Définition. Actes du Colloque la Définition organisé par le CELEX de l'Université Paris-Nord (Paris 13, Villetaneuse) à Paris, le 18 et 19 novembre 1988, Paris, p. 43-59.

Buridant C., 1998 - « Les paramètres de l'étymologie médiévale », dans Buridant C. (éd.), Lexique, 14 (L'Étymologie, de l'Antiquité à la Renaissance), p. 11-56.

Burnett C. S. F., 1990 - «Innovations in the Classification of the Sciences in the Twelfth Century », dans Asztalos M., Murdoch J. E., Niiniluoto I. (éd.), Knowledge and the Sciences in Medieval Philosophy. Proceedings of the eight International Congress of Medieval Philosophy, Helsinki 24-29 August 1987, t. 2, Helsinski (Publications of LutherAgricola Society. Series B, 19), p. 25-42.

Burnett C., 1995 - « Master Theodore, Frederick II's Philosopher », Federico II e le nuove culture, atti del XXXI Convegno Storico internazionale, Todi, 9-12 ottobre, 1994, Spoleto, p. 225-285.

Burnett C., 2005 - « Michael Scot », dans Glick T. F., Livesey St. J., Wallis F. (éd.), Medieval Science, Technology, and Medecine. An Encyclopedia, p. 344-345.

Burton T. L. (éd.), 1998 - Sidrak and Bokkus. A parallel-text edition from Bodleian Library, MS Laud Misc. 559 and British Library, MS Lansdowne 793, Vol. I: Introduction, Prologue, and Books I-II, Oxford (EETS No. 311) (Early English Text Society, t. 311).

CAdDEn J., 1999 - Meaning of Sex Difference in the Middle Ages : Medicine, Science, and Culture, Cambridge (Cambridge History of Medicine).

Cadden J., 2001 - « Nothing natural ist shameful : vestiges of a debate about sex and science in a group of late-medieval manuscripts », Speculum, 76, p. 66-89.

de Callataÿ G., van den Abeele B. (éd.), 2008 - Une lumière venue d'ailleurs. Héritages et ouvertures dans les encyclopédies d'Orient et d'Occident au Moyen Âge. Actes du colloque de Louvain-la-Neuve, 19-21 mai 2005, Louvain-la-Neuve, p. 141-176.

Cambiano G., 1991 - Platone e le tecniche, Rome et Bari (1éd. 1971).

Canto Llorca J., 1991 - « La erudición virgiliana a fines del s. IV : Macrobio, Saturnalia, 6 », dans Ramos Guerra A. (éd.), Homenaje Codoñer C., Salamanque, p. 29-44.

Capelli L. M., 1897 - Primi studi sulle enciclopedie medioevali. Le fonti delle enciclopedie latine del XII secolo, Modène.

Capitani U., 1972 - «Celso, Scribonio Largo, Plinio il Vecchio e il loro attegiamento nei confronti della medicina popolare », Maia, p. 120-140.

Capponi F., 1987 - « Cultura scientifico-naturalistica di Plinio », dans Pigeaud J., Oroz J. (éd.), Pline l'Ancien, témoin de son temps, Salamanque/Nantes, p. 131-146.

CapPONI F., 1990 - 'Natura Aquatilium' (Plin. NH IX), Gênes.

CapPoni F., 1994 - 'Entomologia pliniana' (NH, XI, 1-120), Gênes.

Cardelle De Hartmann C., 2007 - Lateinische Dialoge 1200-1400: literaturhistorische Studie und Repertorium, Leyde/Boston (Mittellateinische Studien und Texte, 37). 
Cardini F., 1994 - « Parole introduttive », dans Picone M. (éd.), L'Enciclopedismo medievale, Ravenna, p. 9-14.

Carruthers M., 2002 (traduction française) - Le Livre de la Mémoire. La mémoire dans la culture médiévale, Paris (éd. angl. : The Book of Memory, Cambridge, 1990).

della Casa A., 1981 - « Les glossaires et les traités de grammaire du Moyen Âge », dans LEFEVRE Y. (éd.), La Lexicographie du latin médiéval et ses rapports avec les recherches actuelles sur la civilisation du Moyen-âge, Paris, p. 35-46.

CAssin B., 2006 - Google-moi. La deuxième mission de l'Amérique, Paris.

CÉARD J., 1997 - « Le commentaire, ou l'encyclopédisme non méthodique de la Renaissance », dans Bouffartigue J., Melonio F. (éd.), L'entreprise encyclopédique, Littérales 21, p. 79-101.

Chailley J., 1960 - L'Imbroglio des modes, Paris.

Chailley J., 1979 - La Musique grecque antique, Paris (Collection d'études anciennes).

Chapoutot-Remadi M., 1990 - « Les encyclopédies arabes de la fin du Moyen Âge », dans BecQ A. (dir.), L'encyclopédisme. Actes du Colloque de Caen 12-16 janvier 1987, Paris, p. 267-279.

Chapoutot-Remadi M., 1995 - « Nuwayrī », dans Encyclopédie de l'Islam, 2éd., Leiden, VIII, p. 158-162.

Charaudeau P., Maingueneau D. (dir.), 2002 - Dictionnaire d'analyse du discours, Paris.

Charlet J.-L., 2004-2005 - «L'encyclopédisme latin humaniste: de la lexicographie à l'encyclopédie ( $\mathrm{Xv}^{\mathrm{e}}$-début XvI ${ }^{\mathrm{e}}$ s.) », Moderni e antichi, 2-3, p. 285-306.

Châtillon J., 1948 - «Le contenu, l'authenticité et la date du Liber exceptionum et des Sermones centum de Richard de Saint-Victor », Revue du Moyen Âge latin, 4, p. 23-52 et 343-366.

Châtillon J., 1966 - «Le Didascalicon d'Hugues de Saint Victor », Cahiers d'histoire mondiale, ${ }^{\circ}$ spécial Encyclopédies et civilisations, 9, p. 539-552.

Chenu M.-D., 1976 - La théologie au douzième siècle, Paris.

Citroni-Marchetti S., 1982 - « Juvare Mortalem. L'ideale programmatico della NH di Plinio nei rapporti con il moralismo stoico-diatribico », Atene e Roma, 27, p. 124-148.

Citroni-Marchetti S., 1991 - Plinio il Vecchio e la tradizione del moralismo romano, Pise.

Citroni-Marchetti S., 1992 - « Filosofia e ideologia nella Naturalis historia di Plinio », ANRW, II, 36. 5, p. 3249-3306.

Codoñer C., 1985 - «La etimología en Isidoro de Sevilla », dans Melena J. L. (éd.), Symbolae Ludovico Mitxelena septuagenario oblatae, 1, Vitoria, p. 275-286.

Codoñer C., 1986 - «Antecedentes del diccionario. El libro x de Etymologiae », Los Visigodos. Historia y civilización, Alcalá de Henares, p. 351-371.

Codoñer C., 1991 - « De l'Antiquité au Moyen Âge: Isidore de Sévile », dans BECQ A. (dir.), L'Encyclopédisme. Actes du colloque de Caen, 12-16 janvier 1987, Paris, p. 19-35.

Codoñer C., 1998 - « Evolución de la lexicografía latina medieval », dans Pérez GonZÁlez M. (éd.), Actas II Congreso Hispánico de Latín Medieval (León, 11-14 de Noviembre de 1997), 1, León, p. 39-50.

Codoñer C., 2012 - « La enciclopedia. Un género sin definición. Siglos I a. C. - VII d. C. », Giornate Filologiche Genovese, L'enciclopedismo dall'Antichità al Rinascimento, Gênes, p. 115-153.

Coitier D., de Brabanter P., Dendale P., 2009 - « La notion de prise en charge: mise en perspective », Langue Française, 162, p. 3-27.

Collart J., 1978 - Varron, grammaire antique et stylistique latine, Paris. 
Collinot A., 1985 - « L'ouverture des dictionnaires. Remarques sur les titres et préfaces des dictionnaires français du $\mathrm{XVI}^{\mathrm{e}}$ siècle », Lexique 3, p. 11-31.

Coluison R., 1964 - Encyclopaedias: Their History troughout the Ages, New York.

Congar Y.-M., 1963 - « Le thème de Dieu-créateur et les explications de l'Hexaemeron dans la tradition chrétienne », L’homme devant Dieu. Mélanges offerts au Père Henri de Lubac, 1, Paris, p. 189-222.

Connochie-Bourgne C., 1996 - « Je, qui cest escrit en fis... Brunet Latin et Gossuin de Metz font entendre leurs voix », Cahiers Diderot, 8, p. 57-79.

Connochie-Bourgne C., 1999 - L'Image du monde, une encyclopédie du XIII siècle, édition critique et commentaire de la $1^{r e}$ version, thèse d'état, s. dir. C. thomasset, Univ. de Paris IV.

Connochie-Bourgne C., 2005 - « La tour de Boctus le bon roi dans le Livre de Sydrach », dans Gingras F., Laurent F., Le Nan F., Valette J.-R. (éd), « Furent les merveilles pruvees et les aventures truvees ». Hommage à Francis Dubost, Paris, p. 163-176.

Connochie-Bourgne C., 2006 - « Mise en récit et discours scientifique : les encyclopédies du XIII ${ }^{\mathrm{e}}$ siècle en langue vulgaire », dans THOMASSET C. (dir.), L'écriture du texte scientifique au Moyen Âge, Paris, p. 117-132

Conte G. B., 1991 - « L'inventario del mondo. Forma della natura e progetto enciclopedico nell'opera di Plinio il Vecchio », dans ConTe G. B, Generi e lettori, Lucrezio, l'elegia d'amore, l'enciclopedia di Plinio, Milan, p. 95-144.

Copeland R., Sluiter I. (éd.), 2009 - Medieval Grammar \& Rhetoric. Language Arts and Literary Theory, $A D$ 300-1475, Oxford.

Corbin H., 1964 - Histoire de la philosophie islamique, Paris.

Del Corno D., 1998 - « L'uomo e la natura nel mondo greco », dans Uglione R. (éd.), L'uomo antico e la natura, Turin, p. 93-104.

Cotta Ramosino L., 2004 - Plinio il Vecchio e la tradizione storica di Roma nella Naturalis Historia, Alessandria.

Courcelle P. (éd.), 1939 - « Étude critique sur les commentaires de Boèce », AHDLMA, 12, 1939, p. 5-140.

Craemer-Ruegenberg I., Anzulewicz H. (éd.), $\mathbf{2 0 0 5}^{2}$ - Albert der Große, Leipzig (Dominikanische Quellen und Zeugnisse, 7).

Cremascoli G., 2001 - « Intorno alle Derivationes di Osberno di Gloucester », dans LunARDINI V. (éd.), Pan, 18-19 (Miscellanea di studi in memoria di Cataldo Roccaro), p. 171-184.

Crubellier M., Pellegrin P., 2002 - Aristote. Le philosophe et les savoirs, Paris.

da Cruz Pontes J. M., 1986 - « Astrologie et apologétique au Moyen Âge », dans Wenin C. (éd.) L'homme et son univers au Moyen Âge. Actes du septième Congrès international de philosophie médiévale (30 août - 4 septembre 1982), Louvain-la-Neuve, p. 631-37.

Cureton G., Rieu C., 1843 - Codices Arabicos Amplectens, Londres.

Cusset C., 1999 - La nature et ses représentations dans l'Antiquité, Paris.

Dahan G., 1987 - «Une introduction à l'étude de l'Écriture au XII ${ }^{\mathrm{e}}$ s.: le Prologue du Commentaire du Pentateuque de Rainaud de Saint-Eloi », Recherches de théologie ancienne et médiévale, 54, p. 27-51.

DaHAN G., 1990 - « La classification des savoirs aux XII et XIII ${ }^{e}$ siècles », L'enseignement philosophique, 40.4, p. 5-27.

Dahan G., 1992 - «L'exégèse de Genèse 1, 26 dans les commentaires du XII siècle », Revue des études augustiniennes, 38, p. 124-153. 
Dahan G., 1995 - « Nommer les êtres: exégèse et théories du langage dans les commentaires médiévaux de Genèse 2, 19-20 », dans Ebbesen S. (éd.), Sprachtheorien in Spätantike und mittelalter, Tübingen, p. 55-74.

DAHAN G., 1999a - «Encyclopédies et exégèse de la Bible aux XII ${ }^{\mathrm{e}}$ et XIII ${ }^{\mathrm{e}}$ siècles », Cahiers de Recherches Médiévales (XIII $-X V^{e}$ s.), 6, p. 1-23.

Dahan G., 1999b - L'exégèse chrétienne de la Bible en Occident médiéval XII ${ }^{e}$-XIV siècle, Cerf, Paris.

Dahan G. (éd.), 2013 - Pierre le Mangeur ou Pierre de Troyes, maître du XII siècle, Turnhout (Bibliothèque d'Histoire culturelle du Moyen Âge, 12).

Dalmedico A. D., Pestre D., 1998 - « Comment parler des sciences aujourd'hui », dans Jourdant B. (dir.), Impostures scientifiques. Les malentendus de l'affaire Sokal, Paris, p. 77-105.

DALY L. W., 1967 - Contributions to a history of alphabetization in Antiquity and the Middle Ages, Bruxelles.

Darnton R., 1982 - L'Aventure de l'Encyclopédie, Paris.

DeGregorio S., 2002 - «"Nostrorum socordiam temporum": The reforming impulse of Bede later esegesi", Early Medieval Europe, 11: 2, p. 117-122.

DeGregorio S., 2010 - « The Venerable Bede and Gregory the Great: exegetical connections, spiritual departures », Early Medieval Europe, 18: 1, p. 43-60.

Deleuze G., 1988 - Abécédaire (réalisation, Boutang P.-A.).

Demiéville P., 1925 - «Compte rendu de Che-yin Song Li Ming-tchong Ying tsao fa che », Bulletin de l'École française d'Extrême-Orient, 25, p. 213-264.

Denifle H., Châtelain E. (éd.), 1889 - De proprietatibus: Chartularium universitatis Parisiensis, I, Paris, p. 644.

Denifle H., Châtelain E. (éd.), 1891 - De proprietatibus: Chartularium universitatis Parisiensis, II, sectio 1, Paris.

Derolez A., 1998 - The Autograph Manuscript of the Liber floridus. A Key to the Encyclopedia of Lambert of Saint-Omer, Turnhout (CC Autographa Medii Aeui, 4).

Derrida J., 1972 - La Dissémination, Seuil.

Desbordes F., 1990 - Idées romaines sur l'écriture, Paris-Lille.

Desbordes F., 1998 - «La pratique étymologique des Latins », dans Buridant C. (éd.), Lexique, 14 (L'Étymologie, de l'Antiquité à la Renaissance), p. 69-79.

Desrousseaux A.-M., 1956 - Athénée de Naucratis. Les Deipnosophistes. Livres 1-2, Paris $(C U F, 126)$.

Detienne M., 1981 - L'invention de la mythologie, Paris.

Détrie C., Siblot P., Vérine B., 2001 - Termes et concepts pour l'analyse du discours. Une approche praxématique, Paris (Lexica, 7$)$.

Deus J., 1998 - Der «Experimentator» - eine anonyme lateinische Naturenzyklopädie des frühen 13. Jahrhunderts, Hamburg.

Diesner H.-J., 1976 - « Lexikographie und Enzyklopädie in der Antike », dans Diesner H.-J., GuRSt G. (dir.), Lexika gestern und heute, Leipzig, p. 11-60.

Dionisotti A. C., 1996 - « On the Nature and Transmission of Latin Glossaries », dans Hamesse J. (éd.), les Manuscrits et glaissaires de l'Antiquité Tardive à la fin du Moyen Âge, Louvain-la Neuve, p. 202-252.

Dodvy A., 2010 - Pliny's Encyclopedia. The Reception of the Natural History, Cambridge. 
Dorion L.-A., 1997 - « La "dépersonnalisation" de la dialectique chez Aristote », Archives de philosophie, 60 (4), p. 597-561.

Draelants I., 1992 - «Une mise au point sur les oeuvres d'Arnold de Saxe, $1^{\mathrm{e}}$ partie », Bulletin de philosophie médiévale, 34, p. 164-180.

Draelants I., 1993 - «Une mise au point sur les oeuvres d'Arnold de Saxe, $2^{\mathrm{e}}$ partie », Bulletin de philosophie médiévale, 35, p. 130-149.

Draelants I., 2002 - «Introduction à l'étude d'Arnoldus Saxo et aux sources du De floribus rerum naturalium », dans MeIER C. (éd.), Die Enzyklopädie im Wandel vom Hochmittelalter bis zur frühen Neuzeit. Akten des Kolloquiums des Projekts D im Sonderforschungsbereich 231 (29.11.-01.12.1996), Munich (Münstersche MittelalterSchriften, 78), p. 85-122.

Draelants I., 2005 - « La science naturelle et ses sources chez Barthélemy l'Anglais et les encyclopédistes contemporains », dans van den Abeele B., MeYer H. (éd.), Bartholomäus Anglicus, De proprietatibus rerum. Texte latin et réception vernaculaire, Lateinischer Text und volkssprachige Rezeption, Turnhout, (De diversis artibus, 74, N.S. 37), p. 43-99.

Draelants I., 2010 - « La science encyclopédique des pierres au 13 $3^{\text {e }}$ siècle: l'apogée d'une veine minéralogique », dans Thомasset Cl., Ducos J., ChAmbon J.-P. (éd.), Aux origines de la géologie de l'Antiquité à l'âge classique. Actes du Colloque de la Sorbonne, 10-12 mars 2005, Paris, p. 91-139.

Draelants I., Paulmier-Foucart M., 2004 - « Échanges dans la societas des naturalistes au milieu du XIII ${ }^{\text {e }}$ siècle: Arnold de Saxe, Vincent de Beauvais et Albert le Grand », dans James-Raoul D., Soutet O. (s. dir.), Par les mots et par les textes..., Mélanges de langue, de littérature et d'histoire des sciences médiévales offerts à Claude Thomasset, Paris, Presses de la Sorbonne, p. 219-231.

DrèGe J.-P., 1991 - Les bibliothèques en Chine au temps des manuscrits (jusqu'au Xe siècle), Paris, École française d'Extrême-Orient.

DRÈGEJ.-P.,2007-«Des ouvrages classés par catégories : les encyclopédies chinoises », ExtrêmeOrient Extrême-Occident, Saint-Denis, Presses universitaires de Vincennes, p. 19-38.

DrèGe, J.-P., à paraître - «Les encyclopédies », dans DREGE J.-P. (dir.), La fabrique du lisible : La mise en texte des manuscrits chinois, Paris.

Dreyer M., 1998 - « Ethik als Wissenschaft nach Albertus Magnus», dans Aertsen J. A., SPEer A. (éd.), Was ist Philosophie im Mittelalter? Qu'est-ce que la philosophie au Moyen Âge? What is Philosophy in the Middle Ages? Akten des X. Kongresses für Mittelalterliche Philosophie der Société Internationale pour l'Étude de la Philosophie, Berlin/New York (Miscellanea Mediaevalia, 26), p. 1017-1023.

Dronke P. (éd.), 1988 - A History of Twelfth-Century Western Philosophy, Cambridge.

Ducatez G., 1985 - « La Tuhfa al-albāb d'Abū Ḥāmid al-Andalusī al-Ġarnāṭ̂̄ », Revue des études islamiques, 53, p. 141-241.

DuCÈnE J.-C., 2005 - « Soufisme et cosmographie musulmane auX XII ${ }^{\mathrm{e}}$ et XIII ${ }^{\mathrm{e}}$ siècles: convergence ou influence à propos d'une conception commune du monde? », dans DiERKENS A., Beyer de Ryke B. (éd.), Mystique: la passion de l'Un, de l'Antiquité à nos jours, Bruxelles, p. 205-214.

DuCÈNE J.-C., 2006a - « Le Hortus rerum mirabilium (Rome, 1584-85): une cosmographie arabe oubliée », Zeitschrift der Deutschen Morgenländischen Gesellshaft, 156, p. 81-93.

DucÈnE J.-C., 2006b - De Grenade à Bagdad. La relation de voyage d'Ab̂̂ Hâmid al-Gharnâtî (1080-1168), Paris.

Ducos J., 1995 - « Le clerc et les météores : constitution et évolution d'une culture encyclopédique », Senefiance, 37 (Le clerc au Moyen Age), p. 151-164. 
Ducrot O., 1980 - Dire et ne pas dire, Paris.

Ducrot O., 1981 - «La valeur argumentative de la phrase interrogative », dans BANGE P. et al. (éd.), Logique, argumentation, conversation. Actes du Colloque de Pragmatique, Fribourg (Sciences pour la communication, 5), p. 79-110.

Ducrot O., 1984 - Le Dire et le dit, Paris.

Ducrot O., 1989 - «Énonciation », Encyclopedia Universalis, VIII, p. 388-392.

Düring I. (éd.), 1930 - Die Harmonielehre des Klaudios Ptolemaios, Göteborg (Göteborgs Högskolas Arsskrift, 36).

DüRING I., 1957 - Aristotle in the Ancient Biographical Tradition, Göteborg.

Duval F., Vielliard F., 2007 - Miroir des classiques, Paris, (Éditions en ligne de l'École des chartes, 17), http://elec.enc.sorbonne.fr/miroir/.

Edwards G., 1985 - « The Two Redactions of Michael Scot's Liber introductorius », dans Traditio, 41, p. 329-340.

Eluis A. G., Edwards E., 1912 - A Descriptive list of the Arabic Manuscripts aquired by the trustess of the British Museum since 1894, London.

Engelhardt C. M., 1818 - Herrad von Landsperg und ihr Werk : "Hortus deliciarum », ein Beytrag zur Geschichte des Mittelalters, Stuttgart/Tübingen.

ENGLISCH B., 1994 - Die Artes liberales im frühen Mittelalter (5.-9. Jh.). Das Quadrivium und der Komputus als Indikatoren für Kontinuität und Erneuerung der exakten Wissenschaften zwischen Antike und Mittelalter, Stuttgart (Sudhoffs Archiv. Beihefte, 33).

Englisch B., 1999 - « Artes und Weltsicht bei Roger Bacon », dans Schaefer U., Artes im Mittelalter, Formationen und transformationen des Wissens, Berlin, p. 53-67.

Ernst U., 1989 - « Neu aufgefundene Handschriften des "Elucidarium" von Honorius Augustodunensis », Scriptorium, 43, p. 289-312.

Eyвl F. et al. (éd.), 1995 - Enzyklopädien der frühen Neuzeit. Beiträge zu ihrer Erforschung, Tübingen.

Fant C., 1886 - L'Image du monde, poème inédit du milieu du XIII siècle, étudié dans ses diverses rédactions françaises d'après les manuscrits des bibliothèques de Paris et de Stockholm, Uppsala.

Fedeli P., 1998 - « L'uomo e la natura nel mondo romano », dans Uglione R. (éd.), L'uomo antico e la natura, Turin, p. 105-125.

Fernandez M., 2007 - «Wikipédia, le rêve de Diderot? », Philosophie Magazine, 9.

Ferrari M., 1972 - « Il "Liber glossarum" e la cultura ecclesiastica a Monza e Milano in età carolingia », Ricerche storiche sulla Chiesa Ambrosiana, 3, p. 45-53.

Finzi V., 1894 - « Di un inedito volgarizzamento dell'Imago mundi di Onorio d'Autun », ZrP, 18 , p.1-75

Flasch K. (éd.), 1984 - Von Meister Dietrich zu Meister Eckhart, Hambourg (CphTMA, 2).

Flasch K., 2006 - Meister Eckhart. Die Geburt der deutschen Mystik aus dem Geist der arabischen Philosophie, Munich.

Flasch K., Iмвасн R., 2003 - Meister Eckhart in seiner Zeit, Düsseldorf (Schriftenreihe der Identity Foundation, 7).

FuINT V., 1982 - « Honorius Augustodunensis Imago Mundi», AHDLMA, 49, p. 7-153.

Flint V., 1995 - « Honorius Augustodunensis of Regensburg », dans GEary P. (éd.), Authors of the Middle Ages. Historical and Religious Writers of the Latin West, vol. II, 5-6, Variorum, Aldershot-Brookfield, p. 91-183. 
FLÜELER C., 2004 - « Ethica in Wien anno 1438. Die Kommentierung der Aristotelischen Ethik an der Wiener Artistenfakultät », dans Knapp F. P., MiethKe J., NieSner M. (éd.), Schriften im Umkreis mitteleuropäischen Universitäten um 1400. Lateinische und volkssprachige Texte aus Prag, Wien und Heidelberg: Unterschiede, Gemeinsamkeiten, Wechselbeziehungen, Leyde / New York /Cologne (Education and Society in the Middle Ages and the Renaissance, 20), p. 92-140.

FöGEN T., 2005 - Antike Fachtexte, Ancient Technical Texts, Berlin/ New York.

Fögen T., 2010 - « Plinius der Ältere zwischen Tradition und Innovation: Zur,Ideologie' der Naturalis historia », dans Kramer N., Reitz C. (éd.), Tradition und Erneuerung. Mediale Strategien in der Zeit der Flavier, Berlin/ New York, p. 41-61.

Fontaine J., 1966 - « Isidore de Séville et la mutation de l'encyclopédisme antique », Cahiers d'histoire mondiale, 9, Paris-Neufchâtel, p. 519-538.

FonTaine J., 1978 - « Cohérence et originalité de l'étymologie isidorienne », dans RodRíGuEz E., Iturriaga J. (éd.), Homenaje a Eleuterio Elorduy, Miscelanea S. J. en honor de E.E., S.J. con ocasión de su 80 aniversario, Bilbao, p. 113-144.

FonTaine J., 1979 - « La situation de la rhétorique dans la culture tardive; observations sur la théorie isidorienne de l'étymologie (Étym., I, 29)», dans Chevallier R. (éd.), Colloque sur la rhétorique Calliope I, Paris (Caesarodunum, 14 bis), p. 197-205.

Fontaine J., 1981 - «Aux sources de la lexicographie médiévale: Isidore de Séville, médiateur de l'étymologie ancienne », dans LefÈvre Y. (éd.), La Lexicographie du latin médiéval et ses rapports avec les recherches actuelles sur la civilisation du Moyen Âge, Paris, p. 97-103.

Fontaine J., 1983 [1959] - Isidore de Séville et la culture classique dans l'Espagne wisigothique, Paris, 3 vol. (éd. revue, $1^{\text {re }}$ éd. 1959).

Fontaine J., 1986 - «Cassiodore et Isidore: l'évolution de l'encyclopédisme latin du vi au VII ${ }^{\mathrm{e}}$ siècle », dans Leanza S. (éd.), Flavio Magno Aurelio Cassiodoro. Cosenza - Squillace 19-24 settembre 1983, Soveria, p. 72-91.

Fontaine J., 2000 - Isidore de Séville. Genèse et originalité de la culture hispanique au temps des Wisigoths, Turnhout.

DE Fontenelle B., 1991 - Entretiens sur la pluralité des mondes habités, dans De Fontenelle B. (éd.), Euvres complètes, t. II, Paris (Corpus des auvres de philosophie en langue française, 43).

Fornara W., 1983 - The Nature of History in Ancient Greece and Rome, Berkeley/ Los Angeles/Londres.

Forster R., 2006 - Das Geheimnis der Geheimnisse. Die arabischen und deutschen Fassungen des pseudo-aristotelischen Sirr al-asrar/Secretum secretorum, Wiesbaden (Wissensliteratur im Mittelalter, 43).

Forster R., 2007 - « Enzyklopädie oder Fürstenspiegel? Arabische, lateinische und deutsche Fassungen des pseudo-aristotelischen Secretum Secretorum », dans Michel P., Herren M., RÜESCH M. (éd.), Allgemeinwissen und Gesellschaft. Akten des internationalen Kongresses über Wissenstransfer und enzyklopädische Ordnungssysteme, Aachen, p. 257-273.

Foucault M., 1966 - Les mots et les choses, Paris.

Fowler R. L., 1997 - «Encyclopaedias: Definitions and Theoretical Problems », dans Binkley P. (éd.), Pre-Modern Encyclopaedic Texts. Proceedings of the Second COMERS Congress, Groningen, 1-4 July 1996, Leiden/New York/Köln, p. 3-29.

Franco L., 1994 - «Vincenzo Coronelli : Vita e opere. Aggiornamenti », Nuncius, 9.2, p. 517-541.

French R., 1994 - Ancient Natural History, Londres / New York.

French R., Greenaway F., 1986 - Science in the Early Roman Empire. Pliny the Elder, his Sources and Influence, Londres/Sydney. 
Friedman J.-B., 1989 - « Peacocks and Preachers : Analytic Technique in Marcus of Orvietos' Liber de moralitatibus, Vatican lat. Ms. 5933 », dans Clark W. B., McMunn M. (éd.), Beasts and Birds in the Middle Ages. The Bestiary and its Legacy, Philadelphia (The Middle Ages), p. 179-196.

Frunzeanu E., 2007 - Les configurations de la natura dans le Speculum maius de Vincent de Beauvais, thèse de doctorat, Montréal, Faculté des études supérieures.

Fuchs H., 1962 - «Enkyklios Paideia », Reallexikon für Antike und Christentum, 5, p. 365-398.

Fumagalli M., Boenio-Brocchieri T., 1981 - Le Encyclopedie dell' Occidente medioevale, Turin (Pedagogia, 20).

Fumagalli M., Parodi M., 1985 - « Due enciclopedie dell'occidente medievale: Alessandro Neckam e Bartolomeo Anglico », Rivista di storia della filosofia, 40, p. 51-90.

Fürbeth F., 1999 - «Die Stellung der artes magicae in den hochmittelalterlichen Divisiones philosophiae », dans Schaefer U., Artes im Mittelalter, Wissen und Magie, Berlin, p. 249-262.

GaIDE F., 2003 - « Aspects divers des principes de sympathie et d'antipathie dans les textes thérapeutiques latins », dans PALMIERI N. (éd.) Rationnel et irrationnel dans la médecine ancienne et médiévale, Saint-Étienne, p. 129-144.

Gaillard-Seux P., 1994 - La médecine chez Pline l'Ancien. Ses rapports avec la magie, thèse de l'Université de Paris IV-Sorbonne.

Gaillard-Seux P., 1998 - «A propos des livres XXVIII-XXIX-XXX de l'Histoire naturelle de Pline l'Ancien », Latomus, 57.2, p. 625-633.

Gaillard-Seux P., 2003 - « Sympathie et antipathie dans l'Histoire naturelle de Pline l'Ancien », dans PALmieri N. (éd.), Rationnel et irrationnel dans la médecine ancienne et médiévale, Saint-Etienne, p. 113-128.

Galimberti-Biffino G., 2007 - «Loquere uerbis praesentibus (1, 10, 4) : il criterio dell'elegantia in Gellio », Latomus, 66, 2007, p. 929-941.

DE Gandillac M., 1966a - « Encyclopédies prémédiévales et médiévales », Cahiers d'Histoire mondiale, 9.3, p. 483-518.

DE Gandilliac M. et al., 1966b - La Pensée encyclopédique au Moyen Âge, Paris / Neufchâtel (Cahiers d'histoire mondiale, 9).

Ganz D., 1991 - « Heiric d'Auxerre, glossateur du Liber glossarum », dans Iogna-Prat D., Jeudy C., Lobrichon G. (éd.), L'École carolingienne d'Auxerre de Murethach à Remi, 830-908: Entretiens d'Auxerre 1989, Paris, p. 297-312.

GatTI P., 2001 - Studi osberniani, Genova.

Gautier Dalché P., 1991 - « La Descriptio mappe mundi de Hugues de Saint-Victor: retractatio et addimenta », dans LongÈre J. (éd.), L'abbaye parisienne de Saint-Victor au Moyen Âge, Turnhout (Bibliotheca victorina, I), p. 143-179.

Gavoille E., 2000 - 'Ars'. Étude sémantique de Plaute à Cicéron, Louvain/Paris.

Genette G., 1987 - Seuils, Paris.

Gerosa M., 1911 - La prima enciclopedia romana: i libri ad Marcum filium di Catone Censorio, Pavia.

Giacone R., 1973 - « Sul concetto di "Enciclopedia" nel pensiero classico e medioevale: nota introduttiva », Rivista di studi classici, 21, p. 1-7.

Giacone R., 1974 - «Arti liberali e classificazione delle scienze: l'esempio di Boezio e Cassiodoro », Aevum, 48, p. 58-72.

Gigon O., 1966 - « Plinius und der Zerfall der antiken Naturwissenschaft », Arctos, 4, p. 23-45.

Guick T. F., Livesey S. J., Waluis F. (éd.), 2005 - Medieval Science, Technology, and Medicine- An Encyclopedia, New York. 
Godin C., 1998 - La Totalité, 2, Les Pensées totalisantes, Paris.

GoDin C., 2002 - La Totalité, 6, La totalité réalisée, Paris.

Goetz W., 1936 - « Die Enzyklopädien des 13. Jhs. Ein Beitrag zur Entstehung der Laienbildung », Zeitschrift für deutsche Geistergeschichte, 2, p. 227-256.

GoETz W., 1937 - « Die Enzyklopädien des 13. Jhs. Ein Beitrag zur Entstehung der Laienbildung », Zeitschrift für deutsche Geistergeschichte, 3, p. 1-24.

Goetz W., 1942 - Italien im Mittelalter, 2, Leipzig, p. 62-107.

Golduust B., 2008 - « Macrobe Vergiliomastix? (à propos de Sat., 5, 2, 1) », Latomus, 67, 4, p. 1049-1050.

GoldLuST B., 2009 - « Un manifeste sur l'organicité littéraire: la préface des Saturnales de Macrobe », dans Galand-Hallyn P., Zarini V. (éd.), Manifestes littéraires dans la latinité tardive. Poétique et rhétorique. Actes du colloque international de Paris, Paris, p. 275-293.

GoldLust B., 2010 - Rhétorique et poétique de Macrobe dans les Saturnales, Turnhout.

Goldlust B., 2012 - « Cnaius Gellius ou Aulu-Gelle? Cnaius Gellius et Aulu-Gelle ? À propos de Macr., Sat., 3, 17, 3 », Latomus, 71.4, p. 1151-1155.

Goldstein-Préaud T., 1981 - «Albert le Grand et les questions du XIII ${ }^{\mathrm{e}}$ siècle sur le $D e$ Animalibus d'Aristote », History and Philosophy of the Life Sciences, 3.1, p. 61-71.

GoMEs J., 2005 - «L'Exégèse monastique au XII siècle: tropologie, intériorité et subjectivité chez Guibert de Nogent », Bulletin du centre d'études médiévales d'Auxerre BUCEMA, 9.

Gontero-Lauze V., 2010 - Sagesses minérales. Médecine et magie des pierres précieuses au Moyen Âge, Paris.

GotTschall D., 2004 - Konrad von Megenbergs "Buch von den natürlichen Dingen". Ein Dokument deutschsprachiger Albertus Magnus-Rezeption im 14. Jahrhundert, LeydeBoston (STGgM, 83).

Granger G. G., 1976 - La théorie aristotélicienne de la science, Paris.

Gregory T., 1955 - Anima Mundi : la filosofia di Guglielmo di Conches e la scuola di Chartres, Florence.

Gregory T., 1975 - « La nouvelle idée de nature et de savoir scientifique au XII ${ }^{\mathrm{e}}$ siècle », dans Murdoch J. E., Sylla E. D. (éd.), The cultural context of medieval learning, Dordrecht/ Boston, p. 193-218.

Gregory T., 1992 - Mundana Sapientia : forme di conoscenza nella cultura medievale, Roma.

Grellard C., Morel P.-M., 2010 - Les Parva naturalia d'Aristote, Fortune antique et médiévale, Paris.

Grente G. (éd.), 1954 - Dictionnaire des lettres françaises. Le dix-septième siècle, Paris.

GrÉvin B., 2002 - « Systèmes d'écriture, sémiotique et langage chez Roger Bacon », Histoire Épistémologie Langage, 24.2, p. 75-111.

Griffin M., 2007 - « The Elder Pliny on Philosophers », dans Bispham E., Howe G. (éd.), avec Matthews E., 'Vita vigilia est'. Essays in Honour of Barbara Levick, Londres, p. 85-101.

Grimal P., 1966 - «Les encyclopédies antiques », Cahiers d'histoire mondiale, 9, Paris/Neufchâtel, p. 459-482.

Grimal P., 1987 - «Pline et les philosophes », dans Pigeaud J. et Oroz J. (éd.), Pline l'Ancien, témoin de son temps, Salamanque/Nantes, p. 239-249.

Grondeux A., 2000 - Le Graecismus d'Évrard de Béthune à travers ses gloses. Entre grammaire positive et grammaire spéculative $d u X_{I I I^{e}}^{e}$ au XV siècle, Turnhout. 
Grondeux A., 2009 - «Liber glossarum », dans Stammerjohann H. (éd.), Lexicon Grammaticorum. A Bio-bibliographical Companion to the History of Linguistics, Tübingen, p. 905-906.

Grondeux A., Rosier-Catach I., 2011 - «Les Glosulae super Priscianum et leur tradition », dans Rosier-CATACH I. (éd.), Arts du langage et théologie aux confins des XI et XII siècles. Textes, maîtres, débats, Turnhout, p. 107-179.

Gros P., 1994 - « Munus non ingratum: le traité vitruvien et la notion de service », Le projet de Vitruve, Objet, destinataires et réception du 'De Architectura', Rome, p. 75-90.

GuesPin L., 1985 - «Nous, la langue et l'interaction », Mots, 10, p. 45-61.

Guillaumin J.-B., 2009 - « La place et le statut de la musique dans l'encyclopédisme de Martianus Capella », Bulletin de l'Association Guillaume Budé, 2009.1, p. 169-185.

Guillaumin J.-B., 2012 - « De l'hapax littéraire au néologisme scientifique: les fonctions de l'invention verbale dans le livre IX de Martianus Capella », dans Biville F., Lhommé M.-K., VAllat D. (éd.), Latin vulgaire - Latin tardif IX. Actes du IX colloque international sur le latin vulgaire et tardif, Lyon, 2-6 septembre 2009, Lyon (Collection de la Maison de l'Orient et de la Méditerranée, 49), p. 573-584.

Guldentops G., 1997 - « Henry Bate's Encyclopaedism », dans Binkley P. (éd.), Pre-Modern Encyclopaedic Texts. Proceedings of the Second COMERS Congress, Groningen, 1-4 July 1996, Leiden/New York/Köln, p. 227-237.

Guldentops G., 2001a - «Henry Bate's Theory of sensible Species », Recherches de Théologie et Philosophie Médiévales, 68, p. 75-110.

Guldentops G., 2001b - "Albert's Influence on Bate's Metaphysics and Noetics », dans Senner W. et al. (éd.), Albertus Magnus. Zum Gedenken nach 800 Jahren : Neue Zugänge, Aspekte und Perspektiven, Berlin (Quellen und Forschungen zur Geschichte des Dominikanerordens, Neue Folge, 10), p. 195-206.

Guldentops G., 2001c - « Averroes in Henry Bate's Metaphysics », Documenti e Studi sulla Tradizione Filosofica Medievale, 12, p. 523-547.

Guldentops G., 2001d - « Henry Bate's aristocratic Eudaemonism », dans AerTSEn J. A., EMERY K. Jr., SPEER A. (éd.), Nach der Verurteilung von 1277. Philosophie an der Universität von Paris im letzten Viertel des 13. Jahrhunderts. Studien und Texte, Berlin/New York (Miscellanea Mediaevalia, 28), p. 657-681.

Guldentops G., 2002 - «Beyond Averroism and Thomism : Henry Bate on the Potential and the Agent Intellect », Archives d'Histoire Doctrinale et Littéraire du Moyen Âge, 69 , p. 115-152.

Guldentops G., 2005 - «'Famous Expositor...'. On Bate's (Anti-) Thomism », dans Recherches de Théologie et Philosophie Médiévales, 72, p. 191-231.

GuTZWiLler K., 2007 - A Guide to Hellenistic Literature, Oxford.

Guyot-BaChy I., 1993 - «Les prologues du Memoriale temporum de Jean de Saint-Victor », Journal des savants, 2.2, p. 235-254.

Guyot-Bachy I., 2000 - Le Memoriale historiarum de Jean de Saint-Victor. Un historien et sa communauté au début du XIV siècle, Turnhout (Bibliotheca victorina, XII).

Guyot-Bachy I., 2009 - « La Bible dans le "Memoriale historiarum" de Jean de Saint-Victor: autorité, source et fondement de l'histoire », dans BERNDT R. (éd.), Bibel und Exegese in der Abtei Saint-Victor zu Paris. Form und Funktion eines Grundtextes im europaïschen Raum, Münster, Aschendorff (Corpus victorinum, Instrumenta, 3), p. 473-490.

HAas M., 1999 - « Über die Funktion der ars musica im Mittelalter », dans SCHAEFER U., Artes im Mittelalter, Formationen und transformationen des Wissens, Berlin, p. 13-33. 
Hadot P., 1982 - «La préhistoire des genres littéraires philosophiques médiévaux dans l'Antiquité », dans Les Genres littéraires dans les sources théologiques et philosophiques médiévales : définition, critique et exploitation. Actes du colloque international de Louvain-La-Neuve, 25-27 mai 1981, Louvain-La-Neuve, (Publication de l'Institut d'études médiévales, $2^{\mathrm{e}}$ série, 5), p. 1-9.

НАDOт I., 1984 - Arts libéraux et philosophie dans la pensée antique, Paris.

НАDот P., 1998 - « La figure du sage dans l'Antiquité gréco-latine », dans HaDOt P., Études de philosophie ancienne, Paris, p. 233-257.

НаDOт I., 2005 [1984] - Arts libéraux et philosophie dans la pensée antique, Paris (Textes et traditions, 11).

Hamel J., 2006 - « Johannes de Sacroboscos Sphaera. Text- und frühe Druckgeschichte eines astronomischen Bestsellers », Gutenberg Jahrbuch, 81, p. 113-136.

Hamesse J., 1990 - « Les dossier Aristote dans l'œuvre de Vincent de Beauvais. À propos de l'Éthique », dans Paulmier-Foucart M., Lusignan S. et Nadeau A. (éd.), Vincent de Beauvais. Intentions et réceptions d'une œuvre encyclopédique au Moyen Âge. Actes du XIV Colloque de l'Institut d'Études médiévales, 27-30 avril 1988, Saint Laurent/Paris (Cahiers d'études médiévales. Cahier spécial, 4), p. 197-217.

Hankinson R. J., 1995 - «Philosophy of science », The Cambridge Companion to Aristotle, p. 109-139.

HäRING N., 1955 - « The Creation and Creator of the World according to Thierry of Chartres and Clarenbaldus of Arras », AHDLMA, 30, p. 137-216.

HARris-McCoy D. E., 2008 - Varieties of encyclopedism in the early Roman Empire : Vitruvius, Pliny the Elder, Artemidorus.

DE Hartmann C. C., 2007 - Lateinische Dialoge 1200-1400. Literarhistorische Studie und Repertorium, Leiden/Boston.

Hartog F., 2002 - Régimes d'historicité. Présentisme et expériences du temps, Paris.

Harvey St. (éd.), 2000 - The Medieval Hebrew Encyclopedias of Science and Philosophy. Proceedings of the Bar-Ilan University Conference, Dordrecht.

Haskins C. H., 1927 - The Renaissance of the twelfth century, New York.

HaSSE D. N., 2000 - Avicenna's De anima in the Latin West. The Formation of the Peripatetic Theory of the Soul, 1160-1300, Londres/Turin (Warburg Institute Studies and Texts, 2000).

Hasse D. N., 2008 - «The early Albertus Magnus and his Arabic sources on the Theory of the soul », dans PERLER D. (éd.), Transformation of the Soul. Aristotelian psychology, 12501650, Vivarium, 46.3, p. 232-252.

Havelock E., 1963 - Preface to Plato, Cambridge.

Hegel G. W. F., 1952 [1817] - Précis de l'encyclopédie des sciences philosophiques, Paris.

Hellmann O., 2010 - «Antike Verkürzungen biologischer Texte », dans Horster M., Reitz C. (dir.), Condensing texts - Condensed texts, Stuttgart, p. 555-583.

Hemmerdinger B., 1989 - « L'art d'éditer Athénée », Bollettino dei Classici, 10, p. 106-117.

Henne P., 2006 - Introduction à Hilaire de Poitiers, suivie d'une anthologie, Paris (Initiations aux Pères de l'Église).

Henningsen J., 1966 - « Enzyklopädie ». Zur Sprach- und Bedeutungsgeschichte eines pädagogischen Begriffs (Archiv für Begriffsgeschichte, 10), p. 271-362.

Henkel H., 1991 - « Der Promptus des Dietrich Engelhus und seine Stellung innerhalb der mittelalterlichen enzyklopädischen Tradition », dans Honemann V. (éd.), Dietrich Engelhus. Beiträge zu Leben und Werk. Actes du Congrès de Einbeck, 28 sept.-1er oct. 1989, Köln/Weimar/Wien, p. 179-202. 
Hoenen M. J. F. M., De Libera A. (éd.), 1995 - Albertus Magnus und der Albertismus. Deutsche philosophische Kultur des Mittelalters, Leyde/New York/Cologne, 1995 (STGgM, 48).

Holford-Strevens L., 2003 [1988] - Aulus Gellius. An Antonine scholar and his achievement, Oxford.

Holtz L. (éd.), 1981 - Donat et la tradition de l'enseignement grammatical : étude sur l' "Ars Donati” et sa diffusion (IVe-IX siècle), Paris (Documents, études et répertoires - IRHT).

Holtz L., 1996 - « Glossaires et grammaire dans l'Antiquité », dans Hamesse J. (éd.), Les Manuscrits des lexiques et glossaires de l'Antiquité tardive à la fin du Moyen Âge. Actes du Colloque international organisé par le "Ettore Majorana Centre for Scientific Culture", Erice, 23-30 septembre 1994, Louvain-la-Neuve, p. 1-21.

Holtz L., 2000 - « Priscien dans la pédagogie d'Alcuin », dans de Nonno M., De Paolis P., Holtz L. (éd.), Manuscripts and tradition of grammatical texts from Antiquity to the Renaissance, Cassino, p. 289-326.

Holtz L., 2004 - « Le dialogue de Franco et de Saxo », dans Depreux P., Judic B. (éd.), Alcuin, de York à Tours: écriture, pouvoir et réseaux dans l'Europe du haut Moyen Âge, Annales de Bretagne et des Pays de l'Ouest, 111: 3, p. 133-145.

Honnefelder L. et al. (éd.), 2005 - Albertus Magnus und die Anfänge der AristotelesRezeption im lateinischen Mittelalter : von Richardus Rufus bis zu Franciscus de Mayronis /Albertus Magnus and the beginnings of the medieval reception of Aristotle in the Latin West, Münster (Subsidia Albertina, 1).

Honnefelder L. et al. (éd.), 2009 - Via Alberti. Texte - Quellen - Interpretationen, Münster (Subsidia Albertina, 2).

Hossfeld P., 1980 - « Der Gebrauch der aristotelischen Übersetzungen in den Meteora des Albertus Magnus », Medieval Studies, 42, p. 395-406.

Hossfeld P., 2001 - «Das zweite Buch der Meteora des Albertus Magnus », dans Anzulewicz H., Senner W. et al. (éd.), Albertus Magnus. Zum Gedenken nach 800 Jahren. Neue Zugänge, Aspekte und Perspektiven, Berlin (Quellen und Forschungen zur Geschichte des Dominikanerordens, 10), p. 413-426.

HüE D., 1990 - « Encyclopédisme et Moralisation », Cahier Diderot, 3, p. 17-56.

HüE D., 1993 - «Tracé, écart: le sens de la carte chez Opicinus de Canistris ». Colloque d'Orléans, Terres Médiévales, avril 1990 (coll. Sapience), p. 129-158.

HüE D., 1995 - « Pour la lettre et pour le trait: Formes et formation de l'Europe ». Colloque d'Orléans, De la Chrétienté à l'Europe, Mai 1993, Orléans, p. 105-131.

HüE D., 1999 - « Espace et Paysage chez Pierre Bersuire et quelques Avignonnais », Cahiers de Recherches Médiévales, 6, p. 41-57.

Huglo M., 2001 - «Les arts libéraux dans le Liber glossarum », Scriptorium, 55, p. 3-33.

Hugonnard-Roche H., 1984 - « La classification des sciences de Gundissalinus et l'influence d'Avicenne », dans Jolivet J., Rashed R. (éd.), Études sur Avicenne, Paris (Sciences et philosophie arabes, Études et reprises), p. 41-75.

HüNEMÖRdER C., 1987 - « Die Vermittlung medizinisch-naturwissenschaftlichen Wissens in Enzyklopädien », dans WoLF N. R. (éd.), Wissensorganisierende und Wissens-vermittlende Literatur im Mittelalters. Perspektiven ihrer Erforschung. Kolloquium (5.-7. Dez. 1985), Wiesbaden, p. 255-277.

Hünemörder C., 1994 - « Des Zisterziensers Heinrich von Schüttenhofen Moralitates de naturis animalium. Beobachtungen $\mathrm{zu}$ seiner Quellenbenutzung und zur frühen Rezeptionsgeschiche von Bartholomäus Anglicus und Thomas III ", dans Domes J., GerabeK W. E., Haage B. D. et al. (éd.), Licht der Natur. Medizin in Fachliteratur und Dichtung. Festschrift für G. Keil zum 60. Geburtstag, Göppingen, p. 195-224. 
HüNEMÖRDER C., 1997 - «John Folsham », Lexikon des Mittelalters, 5, München / Berlin, p. 576.

Hunt R. W., 1950 - « Hugutio and Petrus Helias », Mediaeval and Renaissance Studies, 2, p. $174-178$.

Hunt R. W., 1958 - «The "Lost" Preface to the Liber derivationum of Osbern of Gloucester », Mediaeval and Renaissance Studies, 4, 1958, p. 267-282.

Hunt R. W., Gibson M., 1984 - The Schools and the Cloister. The Life and Writings of Alexander Nequam (1157-1217), Oxford.

Hunzinger C., 1995 - « La notion de thôma chez Hérodote », Ktèma, p. 20.

Huot S., 1994 - « The Courtly Lover and Job in Machaut's Motets 2 and 3 », Medium Aevum, 63, p. 222-238.

Huygens R. B. C., 1953 - « Accessus ad auctores », Latomus, 12, p. 296-311, 460-484.

Huygens R. B. C., 1991 - La tradition manuscrite de Guibert de Nogent, La Haye.

Iмвасн R., Flüeler C. (éd.), 1985 - « Albert der Große und die deutsche Dominikanerschule. Philosophische Perspektiven ", Freiburger Zeitschrift für Philosophie und Theologie, 32.

IMBACH R., LindBLAD U., 1985 - « 'Compilatio rudis ac puerilis'. Hinweise und Materialien zu Nikolaus von Strassburg O.P. und seiner Summa» dans IмBACH R., FlüEleR C. (éd.), Albert der Grosse und die deutsche Dominikanerschule. Philosophische Perspektiven (Freiburger Zeitschrift für Philosophie und Theologie, 32), p. 155-233.

IsAger J., 1991 - Pliny on Art and Society. The Elder Pliny's Chapters on the History of Art, Londres.

Isnardi Parente M., 1966 - Techne. Momenti del pensiero greco da Platone ad Epicuro, Florence.

JАСов C., 1992 - Alexandrie, III' siècle av. J.-C.: tous les savoirs du monde, ou Le rêve d'universalité des Ptolémée, Paris.

JACOB C., 1996 - « Athènes-Alexandrie », dans SCHAER R., Tous les savoirs du monde. Encyclopédies et bibliothèques, de Sumer au XXIe siècle, Paris, p. 44-53.

Јасов С., 2004a - «La citation comme performance dans les Deipnosophistes d'Athénée », dans Darbo-Peschanski C. (dir.), La citation dans l'antiquité, Grenoble, p. 147-174.

JACOB C., 2004b - « La construction de l'auteur dans le savoir bibliographique antique: à propos des Deinosophistes d'Athénée », CALAME C., CHARTIER R. (dir.), Identités d'auteur dans l'antiquité et la tradition européenne, Grenoble, p. 127-158.

Јасов С., 2004c - «Questions sur les questions: Archéologie d'une pratique intellectuelle et d'une forme discursive », dans Volgers A., Zamagni C. (éd.), Erotapokriseis. Early Christian Question-and-Answer Literature in Context, Leuven/Paris/Dudley, p. 25-54.

JaCoвi D., 1986 - Diffusion et vulgarisation. Itinéraires du texte scientifique, Paris (Annales littéraires de l'Université de Besançon, Série Linguistique et sémiotique, 5).

JACOBi D., Schiele B. (dir.), 1988 - Vulgariser la science : le procès de l'ignorance, Seysel.

Jacquemard C., Gauvin B., 2013 - Autour de l'Hortus sanitatis : Médecine et sciences naturelles aux premiers temps du livre imprimé, Kentron, 29.

JaCques F., 1979 - Dialogiques. Recherches logiques sur le dialogue, Paris (Philosophie d'aujourd'hui, 12).

JäGER W., 1997 [1923] - Aristote : fondements pour une histoire de son évolution, Paris.

JAHN O., 1850 - « Über römische Encyclopädien », Berichte über die Verhandlungen der Kön. Sächsischen Gesellschaft der Wissensch. zu Leipzig, Phil.-hist. Kl., 2, p. 263-287.

James-Raoul D., 1997 - La Parole empêchée dans la littérature arthurienne, Paris (Nouvelle bibliothèque du Moyen Âge, 40). 
JANSEN-Sieben R. (éd.), 1989 - Artes mechanicae en Europe médiévale, Bruxelles (Archives et bibliothèques de Belgique, N.S., 34).

Jeanneret Y., 1994 - Écrire la science. Formes et enjeux de la vulgarisation, Paris.

JEAUneau E., 1973 - Lectio philosophorum. Recherches sur l'école de Chartres, Amsterdam.

Jeauneau E., 1995 - L'âge d'or des écoles de Chartres, Chartres.

Joly H., 1974 - Le renversement platonicien. 'Logos, Episteme, Polis', Paris.

JoLY R., 1960 - Recherches sur le traité pseudo-hippocratique 'Du régime', Paris.

JourJon D., 1992 - Trois entretiens sur les Pères de l'Église de France: Hilaire, Sidoine Apollinaire, Césaire, Lyon.

Kaderas C., 1998 - Die Leishu der imperialen Bibliothek des Kaisers Qianlong, Wiesbaden.

KaYlor N. H. Jr., 1999 - « Boethius' De Consolatione Philosophiae didaktisch aufbereitet: Die anonyme mittelenglische Übersetzung von Buch I (...) », dans Schaefer U., Artes im Mittelalter, Fortschreibungen von Wissenbeständen, Berlin, p. 187-197.

Kedar B. Z., Kohlberg E., 1995 - « The Intercultural Career of Theodore of Antioch », Mediterranean Historical Review, 10, p. 165-176.

KelLermann K., 1999 - «Zwischen Gelehrsamkeit und Information : Wissen und Wahrheit im Umbruch vom Mittelalter zur Neuzeit », dans Schaefer U., Artes im Mittelalter, Formationen und transformationen des Wissens, Berlin, p. 124-140.

Kerbrat-Orecchioni C., 1971 - «Introduction », dans Kerbrat-Orecchioni C. (dir.), La Question, Lyon (Linguistique et sémiologie), p. 5-37.

Kerbrat-Orecchioni C., 1978 - « Déambulation en territoire aléthique », Stratégies discursives. Actes du Colloque du Centre de Recherches linguistiques et sémiologiques de Lyon, 20-22 mai 1977, Lyon, p. 53-102.

Kerbrat-Orecchioni C., 1992 - Les Interactions verbales, t. II, Paris.

Kerbrat-Orecchioni C., 2005 - Les Actes de langage dans le discours. Théorie et fonctionnement, Paris.

KLEPPER D. C., 2007 - The insight of unbelievers : Nicholas of Lyra and Christian Reading of Jewish Texts in the Later Middle Ages, Philadelphia.

KuINCK R., 1970 - Die lateinische Etymologie des Mittelalters, Munich (Medium Aevum, 17).

KNoch W., 1999 - «Die theologische Summa: Zur Bedeutung einer hochmittelalterlichen Literaturgattung ", dans Schaefer U., Artes im Mittelalter, Fortschreibungen von Wissenbeständen, Berlin, p. 151-160.

KöHLER T. W., 2000 - Grundlagen des philosophisch-anthropologischen Diskurses im dreizehnten Jahrhundert. Die Erkenntnisbemühung um den Menschen im zeitgenössichen Verständnis, Leyde/Boston/Cologne (Studien und Texte zur Geistesgeschichte des Mittelalters [STGgM], 71).

KÖHLER T. W., 2008 - "Homo animal nobilissimum" Konturen des spezifisch Menschlichen in der naturphilosophischen Aristoteleskommentierung des dreizehnten Jahrhunderts, Teilband I, Leyde/Boston/Cologne (STGgM, 94).

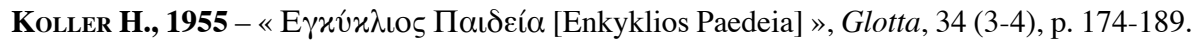

Kowalska M., 1967 - « Remarks on the unindentified cosmography Tuhfat al-garā’ib », Folia Orientalia, 9, p. 11-18.

Krey P. D., Sмith L. J. (éd.), 2007 - Nicholas of Lyra : the Senses of Scripture, Leyde / Boston / Cologne (Studies in the History of the Christian Thought, 40).

Kunz J.-L., 2001 - « The Politics of Collecting Knowledge: Song Taizong's Compilations Project », T'oung Pao, 87, 4-5, p. 289-316. 
Kurz J.-L., 2007 - «The Compilation and Publication of the Taiping yulan and the Cefu yuangui », Extrême-Orient Extrême-Occident, Hors série, p. 39-76.

LabBÉ D., 1985 - « Nous, les communistes », Mots, 10, p. 133-146.

LaChenaud G., 1997 - «L'enkuklios paideia et l'esprit encyclopédique dans l'Antiquité », Revue de Philologie, 71, p. 65-101.

Lacoste F., 1958 - «Un commentaire scripturaire du XII ${ }^{\mathrm{e}}$ siècle : le Tractatus in Hexaemeron de Hugues d'Amiens », AHDLMA, 25, p. 227-294.

Langlois C. V., 1911 - La connaissance de la nature et du monde au Moyen Âge, d'après quelques écrits français à l'usage des laïcs, Paris.

Langlois C.-V., 1926-1928 - La connaissance de la nature et du monde au Moyen Âge, Paris 1926-1928 [réimp., Genève, 1970], t. III.

LARGIER N., 2000 - « Time and Temporality in the German Dominican School. Outlines of a Philosophical Debate between Nicolaus of Strasbourg, Dietrich of Freiberg, Eckhart of Hoheim and Iohannes Tauler », dans Porro P. (éd.), The Medieval Concept of Time. The Scholastic Debate and Its Reception in Early Modern Philosophy, Leyde / Boston/Cologne (Studien und Texte zur Geistesgeschichte des Mittelalters, 75), p. 221-254.

Larreya P., 1979 - Énoncés performatifs. Présupposition, Paris.

LAW V., 1982 - The insular Latin grammarians, Woodbridge.

Lawn B., 1963 - The Salernitan Questions. An introduction to the History of Medieval and Renaissance Problem Literature, Oxford.

Lawn B., 1993 - The Rise and Decline of the Scholastic 'Quaestio Disputata' with Special Emphasis on its Use in the Teaching of Medicine and Science, Leyde/New York/Cologne (Education and Society in the Middle Ages and Renaissance, 2).

LE BLond J.-M., 1939 - Logique et méthode chez Aristote, Paris.

LE GoFf J., 1957 - Les intellectuels au Moyen Âge, Paris.

LE GoFf J., 1964 - La Civilisation de l'occident médiéval, Michigan (Les Grandes civilisations, 3).

LE GoFf J., 1994 - « Pourquoi le XIII ${ }^{e}$ siècle a-t-il été un siècle d'encyclopédisme? », dans Picone M. (éd.), L'enciclopedismo medievale, Ravenne, p. 23-40.

Le GofF J., 1995 - Saint Louis, Paris.

LEAR J., 1990 - Aristotle. The Desire to understand, Cambridge.

Lebel M., 1991 - Le concept de l'Encyclopedia. Acta Conventus Neo-latini Torontonensis, Bighampton.

LefÈvre Y., 1954 - L'Elucidarium et les lucidaires. Contribution, par l'histoire d'un texte, à l'histoire des croyances religieuses en France au Moyen Âge, Paris.

LEJBowicz M., 1988 - « Le choc des traductions arabo-latines du XII ${ }^{\mathrm{e}}$ siècle et ses conséquences dans la spécialisation sémantique d'astrologia et d'astronomia: Dominicus Gundissalinus et la scientia iudicandi », dans Louss P., ROGER J. (dir.), Transfert de vocabulaire dans les sciences, Paris, p. 213-76.

LeJBowicz M., 1991 - «Les antécédents de la distinction isidorienne astrologia/astronomia », dans Ribémont B. (dir.), Observer, lire, écrire le ciel au Moyen Âge, Paris, p. 173-212.

Lemerle P., 1971 - Le premier humanisme byzantin. Notes et remarques sur enseignement et culture à Byzance des origines au $X^{\mathrm{e}}$ siècle, Paris.

LEMoINe M., 1998 - Théologie et platonisme au XII siècle, Paris.

Lemorne M., 2004 - Théologie et cosmologie au XII siècle, Paris.

Lenoble R., 1969 - Histoire de l'idée de nature, Paris. 
Letronne A., 1833 - Observations philologiques et archéologiques sur les noms des vases grecs, Paris.

Letrouit J., 1991 - « À propos de la tradition manuscrite d'Athénée », Maia, 43, p. 33-40.

LeVY C., 1996 - Le concept de nature à Rome. La physique, Paris.

Lewicki T., 1978 - «Al-Kazwīn̄ī », Encyclopédie de l'Islam, Leiden, 2éd., Vol. 4, p. 898-900. DE LibERA A., 1999 - Maître Eckhart et la mystique rhénane, Paris (Initiations au Moyen Âge).

LiDAKA, 1997 - «Bartholomaeus Anglicus in the Thirteenth Century », dans BinkLey P. (éd.), Pre-Modern Encyclopedic Texts. Proceedings of the second COMERS Congress, Groningen, 1-4 July 1996, Leiden/New York/Köln, p. 393-406.

Lindgren U., 1992 - Die Artes liberales in Antike und Mittelalter. Bildungs- und Wissenschaftsgeschichtliche Entwicklungslinien, München (Algorismus, 8).

Linke H., 1880 - Quaestiones de Macrobii Saturnaliorum fontibus, diss. Breslau.

LITT T., 1963 - Les corps célestes dans l'univers de saint Thomas d'Aquin, Paris/Louvain.

Lochrie K. D., Mccracken P., Schultz J. A. (éd.), 1998 - Constructing Medieval Sexuality, Minneapolis, 1998 (Medieval Culture, 11).

Loewe R., 1958 - «Alexander Neckam's Knowledge of Hebrew », Medieval and Renaissance Studies, 4, p. 17-34.

Long A. A., Sedley D. N., 2001 - Les philosophes hellénistiques, II, Paris.

Long J., 2007 - « livres III et livre IV », dans VAN DEN AbEele et al. (éd), Bartholomaeus Anglicus. De proprietatibus rerum. Volume I : Prohemium, Livre I-IV, Turnhout (De diversis artibus 78, N.S. 41), p. 135-199.

Lous P., 1955 - «Le mot ioto@í $\alpha$ chez Aristote », Revue de philologie, 81, p. 39-44.

Louyest B., 2009 - Athénée de Naucratis. Mots de poissons. Le banquet des sophistes. Livres VI et VII, Villeneuve d'Ascq.

Love I., 1968 - « Kantharos or Karchesion », dans SANDLER L. (éd.), Essays in Memory of Lehmann K., Marsyas, suppl. 1, p. 204-222.

LuFF R., 1999 - Wissensvermittlung im europaischen Mittelalter: 'Imago-mundi'-Werke und ihre Prologe, Tübingen.

Lukinovich A., 1985 - « La poikilia chez Athénée », REL, 63, p. 14-16.

Lukinovich A., 1990 - «The Play of Reflection between Literary Form and the Sympotic Theme in the Deipnosophists of Athenaeus », dans Murray O. (dir.), Sympotica. A Symposion on the Symposion, Oxford, p. 263-271.

Lusignan S., 1979 - Préface au Speculum maius de Vincent de Beauvais : réfraction et diffraction, Montréal/Paris.

Lynch C. H., 1938 - Saint Braulio, bishop of Saragossa (631-651): his life and writings, Washington.

LyotaRd J.-F., 1979 - La condition postmoderne. Rapport sur le savoir, Paris.

Maffia Scariati I. (éd.), 2008 - A scuola con Ser Brunetto. Indagini sulla ricezione di Brunetto Latini dal Medioevo al Rinascimento. Atti del Convegno Internazionale di Studi, Università di Basilea, 8-10 Giugno 2006, Firenze (Archivio Romanzo, 14).

Magallón García A.-I., 1996 - La tradición gramatical de differentia y etymologia hasta Isidoro de Sevilla, Saragosse.

Mâle E., 1958 - L'Art religieux du XII siècle en France, tome 1, Paris.

MaLtby R., 1991 - A Lexicon of Ancient Latin Etymologies, Leeds.

Manco A., Silvestri D. (éd.), 2011 - L'etimologia. Atti del XXXV Convegno della Società Italiana di Glottologia, Napoli, 21-23 ottobre 2010, Roma. 
Mandosio J.-M., 2005 - « Encyclopédies en latin et encyclopédies en langue vulgaire (XIIIXVIII ${ }^{\mathrm{e}}$ siècle) », dans BuRY E. (éd.), Tous vos gens à latin: le latin, langue savante, langue mondaine (XIV'-XVII ${ }^{e}$ s.), Genève, p. 113-136.

ManetTi G., 1988 - « Perception, Encyclopedia, and Language Among the Stoics in Signs of Antiquity/Antiquity of Signs », Versus : Quaderni di Studi Semiotici, 50-51, p. 123-144.

Mar Jonsson E., 1990 - «Le sens du titre Speculum aux XII et XIII ${ }^{\mathrm{e}}$ siècles et son utilisation par Vincent de Beauvais », dans Vincent de Beauvais : Intentions et réceptions d'une oeuvre encyclopédique au Moyen Âge. Actes du XIV colloque de l'Institut d'Études Médiévales, 27-30 avril 1988, Saint-Laurent/Paris, p. 11-32.

Marcovich M., 1971 - « Voces animantium and Suetonius », Ziva Antika, 21, p. 399-416.

Marguin-Hamon E., 2003 - L'Ars lectoria Ecclesie de Jean de Garlande. Une grammaire versifiée du XIII siècle et ses gloses, Turnhout.

Marinoni A. (éd.), 1955 - Dal Declarus di A. Senisio : I vocaboli siciliani, Palerme.

Marinoni A., 1988 - « Per una edizione delle Derivationes di Uguccione da Pisa », dans Cornagliotti A., Fontanella L., Piccat M., Rossebastiano A., Vitale-Brovarone A. (éd.), Miscellanea di studi romanzi offerta a G. GASCA Queirazza per il suo $65^{\circ}$ compleanno, Alessandria, p. 637-644.

Marquet Y., 1990 - «Ikhwān al-ṣafā’”, Encyclopédie de l'Islam, 2e éd., Leiden, 3, p. 1098-1103.

Marrou H. I., 1958 - Saint Augustin et la fin de la culture antique, Paris.

Martin J., 1931 - Symposion. Die Geschichte einer literarischen Form, Studien zur Geschichte und Kultur des Altertums, 17, Padeborn.

Massé H., 1944 - Le livre des merveilles du monde, Paris.

McGeachy J. A. Jr., 1938 - « The Glossarium Salomonis and Its Relationship to the Liber Glossarum », Speculum, 13, p. 309-318.

MehrenA. F., 1874-Manuel de la cosmographie du Moyen Âge, traduit de l'arabe, Copenhague.

MeIER C., 1979 - Gemma spiritalis. Methode und Gebrauch der Edelsteinallegorese vom frühen Christentum bis ins 18. Jahrhundert, Munich (Münstersche Mittelalter-Schriften, 34).

Meier-Staubach C., 1984 - « Grundzüge der mittelalterlichen Enzyklopädik. Zu Inhalten, Formen und Funktionen einer problematischen Gattung », dans Grenzmann L., Starkman K. (éd.), Literatur und Laienbildung im Spätmittelalter und in der Reformationszeit. Symposium Wolfenbüttel, 1981, Stuttgart (Germanistische Symposien. Berichtsbände, 5), p. 467-500.

MeIEr C., 1988 - «Cosmos politicus. Der Funktionswandel der Enzyklopädie bei Brunetto Latini », Frühmittelalterliche Studien, 22, p. 315-356.

MeIER C., 1992 - « Vom homo caelestis zum homo faber. Reorganisation der mittelalterlichen Enzyklopädie für neue Gebrauchsfunktionen bei Vinzenz von Beauvais und Brunetto Latini », dans Keller H., Grubmüller K., Staubach N. (éd.), Pragmatische Schriftlichkeit im Mittelalter. Erscheinungsformen und Entwicklungsstufen, München (Münstersche Mittelalterschriften, 65), p. 157-175.

MeIEr C., 1995 - « Der Wandel der Enzyklopädie des Mittelalters von Weltbuch zum Thesaurus sozial gebundenen Kulturwissens : am Beispiel der Artes mechanicae », dans EyBl F. et al. (éd.), Enzyklopädien der frühen Neuzeit. Beiträge zu ihrer Erforschung, Tübingen, p. 19-42.

MeIER C., 1997 - « Organisation of Knowledge and Encyclopedic ordo : Functions and Purposes of a Universal Literary Genre », dans Binkley P. (éd.), Pre-Modern Encyclopaedic Texts. Proceedings of the Second COMERS Congress, Groningen, 1-4 July 1996, Leiden/New York/Köln, p. 103-216.

MeIER C., 2002 - «Enzyklopädischer Ordo und sozialer Gebrauchsraum. Modelle der Funktionalität einer universalen Literaturform », dans MeIER C. (éd.), Die Enzyklopädie im Wandel vom Hochmittelalter bis zur Frühen Neuzeit, München, p. 511-532. 
Meier C., Schuler S., Heckenkamp M. (éd.), 2002 - Die Enzyklopädie im Wandel vom Hochmittelalter bis zur frühen Neuzeit. Akten des Kolloquiums des Projekts D im Sonderforschungsbereich 231, 29.11.-01.12.1996, München.

MeINECKe B., 1991 - «Glossae iussu Salomonis... sub breuitate collectae », Sprachwissenschaft, 16, p. 459-469.

MeINecke B., 1994 - Liber Glossarum und Summarium Heinrici. Zu einem Münchener Neufund, Götttingen.

Melczer W., 1988 - «Les encyclopédies », L'époque de la Renaissance 1400-1600. L'avènement de l'esprit nouveau, vol. I, Budapest, p. 337-347.

Melzer A., 2007 - « On the pedagogical motive for esoteric writing », Journal of Politics, 69, p. 1015-1031.

Meschonnic H., 1997 - «L'encyclopédie sortant de son mot pour se voir », dans SCHAER R., Tous les savoirs du monde. Encyclopédies et bibliothèques, de Sumer au XXIe siècle, Paris, p. 19-25.

MetTe H. J., 1960 - « Enkyklios paideia », Gymnasium, 67, p. 300-307.

Meyer C., 1998 - « Métaphore instrumentale et représentation du système acoustique à l'époque carolingienne », dans Hentschel F. (éd.), Musik und die Geschichte der Philosophie und Naturwissenschaften im Mittelalter: Fragen zur Wechselwirkung von Musica und Philosophia im Mittelalter, Leyde/Boston/Cologne (Studien und Texte zur Geistesgeschichte des Mittelalters, 62), p. 141-149.

Meyer H., 1990 - «Zum Verhältnis von Enzyklopädik und Allegorese im Mittelalter », Frühmittelalterlische Studien, 24, p. 290-313.

MeYer H., 1991 - «Ordo rerum und Registerhilfen in mittelalterlichen Enzyklopediehandschriften », Fruhmittelalterlichen Studien, 25, p. 315-339.

Meyer H., 2000 - Die Enzyklopädie des Bartholomäus Anglicus. Untersuchungen zur Überlieferungs- und Rezeptionsgeschichte von 'De proprietatibus rerum', Münster (Münstersche Mittelalter-Schriften, 77).

Meyer H., 2001 - « Die Problematik und Leistungen der Allegoriedefinitionen Beda Venerabilis », Frühmittelalterliche Studien, 35, p. 183-200.

Meyer H., 2002 - « Die Predigerenzyklopädie. Textsorte und Gebrauch unter methodischen Aspekten », dans Keller H., Meier C., Suntrup R. (éd.), Pragmatische Dimensionen mittelalterlicher Schriftkultur. Akten des Internationalen Kolloquiums 26.-29. Mai 1999, München (Münstersche Mittelalterschriften, 79), p. 177-190.

Michaud-Quantin P., 1966 - « Les petites encyclopédies du XIII siècle », Cahiers d'Histoire mondiale, 3, p. 580-595.

Michel P. éd., 2006 - All you need to know: Encyclopaedias and the Idea of General Knowledge. Conference, Prangins, Switzerland, 18-20 Sept. 2003, www.enzyklopaedie.C.

Michel P., Herren M., 2007 - « Unvorgreifliche Gedanken zu einer Theorie des Enzyklopädischen », dans Michel P., Herren M., RÜESCH, Allgemeinwissen und Gesellschaft, p. 9-74.

Minervini V., 1977 - « Schede sulla tradizione manoscritta del "Livre de Sidrach" », dans Annali dell' Istituto universitario orientale-sezione romana, XIX, 2, Naples, p. 539-570.

Moatti C., 1997 - La raison de Rome. Naissance de l'esprit critique à la fin de la République, Paris.

Moeschler J., 1985 - Argumentation et Conversation. Éléments pour une analyse pragmatique du discours, Paris (Langues et apprentissage des langues, 11).

Mojsisch B., 1991 - « Hugo Ripelin von Straßbourg OP, Theologe und Philosoph », Lexikon des Mittelalters, 5, Munich, col. 176. 
Monjou P., 2008 - La Vulgarisation théologique du XIIIe au xvIe siècle d'après le "Compendium theologicae veritatis" de Hugues Ripelin de Strasbourg, 2 vol., [Thèse non éditée], sous la direction de CAROzzi C., Aix-Marseille.

Morel P. M., 1997 - Aristote et la notion de nature, Bordeaux.

Moreton J., 1994 - « John of Sacrobosco and the Calendar », Viator, 25, p. 225-244.

Mortier G., 1991 - « Préface », dans BecQ A., L'Encyclopédisme. Actes du colloque de Caen, 12-16 janvier 1987, Paris, p. 13-15.

Morton A. G., 1986 - « Pliny on Plants : his Place in the History of Botany », dans French R., Greenaway F. (éd.), Science in the Early Roman Empire. Pliny the Elder, his Sources and Influence, Londres / Sydney.

Moulis M., 1993 - «Éducation, apprentissages, initiation au Moyen Âge », Les Cahiers du CRISIMA, 1, p. 333-346.

Mudry P., 1986 - « Science et conscience. Réflexions sur le discours scientifique à Rome », Sciences et techniques à Rome, Etudes de Lettres, p. 74-86.

Murphy T., 2004-Pliny the Elder's « Natural History ». The empire in the Encyclopedia, Oxford.

Murray O. (dir.), 1990 - Sympotica. A Symposion on the Symposion, Oxford.

NAAS V., 2000 - « L'Histoire naturelle, œuvre scientifique? », dans CAllebat L., Desbordes O. (éd.), Science antique, science médiévale, Hildesheim/Zürich/New York, p. 255-271.

NaAs V., 2002 - Le projet encyclopédique de Pline l'Ancien, Roma (Collection de l'École Française de Rome 303).

NAAS V., 2004 - «Ratio ... multis inuoluta miraculis (Pline l'Ancien, NH, II, 62): autour de la ratio plinienne », dans NAAS V. (éd.), En-deçà et au-delà de la 'ratio', Lille, p. 29-37.

NaAs V., 2008 - «Pline l'Ancien a-t-il cru à ses mythes? » Pallas, 78, p. 133-151.

NAAS V., 2011a - « L'Histoire naturelle de Pline l'Ancien, texte fondateur de l'encyclopédisme? » dans Groult M. (éd.), Les encyclopédies. Construction et circulation du savoir de l'Antiquité à Wikipédia, Paris, p. 25-45.

NAAS V., 2011b - «Imperialism, Mirabilia and Knowledge. Some Paradoxes in the Naturalis Historia », dans Gibson R. K., Morello R. (éd.), Pliny the Elder. Visions and Context, Leyde, p. 57-70.

NaAs V., 2011c - «Philhellénisme et identité romaine chez Pline l'Ancien (nat. VII, 81-130) », dans Bonadeo A., CAnobbio A., Gasti F. (éd.), Filellenismo e identità romana in età flavia, Pavie, p. 35-58.

NADDAF G., 1992 - L'origine et l'évolution du concept grec de 'phusis', Lewiston.

Nicolet C., 1996 - L'inventaire du monde. Géographie et politique aux origines de l'empire

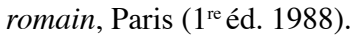

NiEderEHE H.-J., 1976 - « Friedrich Diez und die Etymologie des 13. Jahrhunderts », dans Niederehe H. J., HaArmann H. (éd.), In Memoriam Friedrich Diez. Akten des Kolloquiums zur Wissenschaftsgeschichte der Romanistik, Trier, 2.-4.Oktober 1975, Amsterdam, p. 21-31.

Nifadopoulos C. (éd.), 2003 - Etymologia. Studies in Ancient Etymology. Proceedings of the Cambridge Conference on Ancient Etymology, 25-27 September 2000, Münster.

Nølke H., 2005 - « Le locuteur comme constructeur de sens », dans Bres J., Haillet P. P., Mellet S., Nølke H., Rosier L. (dir.), Dialogisme et polyphonie. Approches linguistiques, Bruxelles, p. 111-124.

Obrist B., Cainzzo I. (éd.), 2011 - Guillaume de Conches. Philosophie et science au XII siècle, Firenze (Micrologus' Library, 42).

O’NeIL M.,2009-«Wikipédia ou la fin de l'expertise », Le Monde Diplomatique, avril 2009, p. 20. 
Oldoni M., 1994 - « Giovanni da San Gimignano », dans Picone M. (éd.), L'enciclopedismo medievale. Atti del convegno "l'enciclopedimo medievale », San Gimignano 8-10 ottobre 1992, Ravenna (Memoria del tempo, 1), p. 213-228.

Olson S., Sens A., 2000 - Archestratos of Gela, Greek Culture \& Cuisine in the Fourth Century, Oxford.

Ouy G., 1999 - Les manuscrits de l'abbaye de Saint-Victor. Catalogue établi sur la base du répertoire de Claude de Grandrue (1514), 2 vol., Turnhout (Bibliotheca victorina, X).

Palmer N., 1989 - « Kapitel und Buch. Zu den Gliederungsprinzipien mittelalterlicher Bücher », Frühmittelalterliche Studien, 23, p. 43-88

Palmieri N. (éd.), 2003 - Rationnel et irrationnel dans la médecine ancienne et médiévale, Saint-Étienne.

Panckoucke C.-J., 1783 - Encyclopédie méthodique ou par ordre des matières ou Bibliothèque complete de toutes les conoissances humaines, Liège.

PaPadoyannakis Y., 2006 - «Instruction by Question and Answer: The Case of Late Antique and Byzantine Erotapokriseis », dans JoHnson S. F. (éd.), Greek Literature in Late Antiquity, Aldershot, p. 91-106.

Paret R., 1966 - «Contribution à l'étude des milieux culturels dans le Proche-Orient médiéval: "l'encyclopédisme" arabo-musulman de 850 à 950 de l'ère chrétienne », Revue historique, 477, p. 47-100 .

Parroni P., 1989 - « Scienza e produzione letteraria », dans Cavallo G., Fedeli P., Giardina A. (dir.), Lo Spazio letterario di Roma antica, I, Rome, p. 469-505.

Parrot G. F., 1821 - Entretiens sur la physique, t. IV, Dorpat.

Paulmier-Foucart M., 1980 - « Jean Hautfuney, Tabula super Speculum historiale fratris Vincentii. Présentation - Édition A-L », Spicae - Cahiers de l'Atelier Vincent de Beauvais, 2, p. 19-263.

Paulmier-Foucart M. (éd.), 1981 - « Jean Hautfuney, Tabula super Speculum historiale fratris Vincentii. Présentation de la deuxième partie de l'édition - Édition M-Z - Édition de la Table des Flores - Exemple de traitement informatisé... », Spicae - Cahiers de l'Atelier Vincent de Beauvais, 3, p. 7-208.

Paulmier-Foucart M., Lusignan S., Nadeau A. (éd.), 1990 - Vincent de Beauvais : Intentions et réceptions d'une oeuvre encyclopédique au Moyen Âge. Actes du XIV colloque de l'Institut d'Études Médiévales, 27-30 avril 1988, Saint-Laurent/Paris, 1990.

Paulmier-Foucart M., 1994 - «Une des tâches de l'encyclopédiste: intituler, les titres des chapitres du Speculum naturale de Vincent de Beauvais », dans Picone M. (éd.), L'enciclopedismo medievale, Ravenne, p. 147-162.

Paulmier-Foucart M., 2001 - « L'actor et les auctores. Vincent de Beauvais et l'écriture dans le Speculum majus », dans Zimmermann M. (éd.), Auctor et auctoritas. Invention et conformisme dans l'écriture médiévale. Actes du colloque tenu à l'Université de VersaillesSaint-Quentin-en-Yvelines (14-16 juin 1999), Paris (Mémoires et documents de l'École des Chartes, 59), p. 145-160.

Paulmier-Foucart M., Duchenne M.-C., 2004 - Vincent de Beauvais et le Grand Miroir du monde, Paris (Témoins de notre Histoire).

Pedersen O., 1985 - «In quest of Sacrobosco », Journal of the History of Astronomy, 16, 47, p. $175-221$.

Pellat C., 1990 - «Mawsū‘a. Encyclopédie », Encyclopédie de l'Islam, $2^{\mathrm{e}}$ éd., Leiden, 6, p. 894-898.

Pellicer A., 1966 - 'Natura'. Etude sémantique et historique du mot latin, Paris. 
Percival W. K., 1998 - « Saussure on Etymology », dans Liver R., Werlen I., Wunderli P. (éd.), Sprachtheorie und Theorie der Sprachwissenschaft. Geschichte und Perspektiven. Festschrift für R. ENGLER zUm 60. Geburstag, Tübingen.

Perelman C., 1955 - «La méthode dialectique et le rôle de l'interlocuteur dans le dialogue », Revue de Métaphysique et de Morale, 60, p. 26-31.

Perelman C., Olbrechts-Tyteca L., 1970 - Traité de l'Argumentation. La nouvelle rhétorique, Bruxelles (Collection de sociologie générale et de philosophie sociale).

Pérez Rodríguez E., 1998 - « La Summa artis gramatice de Hugutio y la gramática del s. XII ", dans Leonardi C. (éd.), Gli Umanesimi medievali. Atti del il Congresso dell' «Internationales Mittellateinerkomitee »Firenze, Certosa del Galluzzo, 11-15 settembre 1993, Florence, p. 479-484.

Perifano A., 2011 - « Pline à la Renaissance. Transmission, réception et relecture d'un encyclopédiste antique », dans Perifano A. (éd.), Archives Internationales d'Histoire des Sciences, 166-167.

Peris A., 1998 - « La lista de Voces animantium del Matritensis B.N. 19: estudio de sus fuentes y nueva edición », Cuadernos de Filología Clásica. Estudios Latinos, 15, p. 405-427.

Peruzzi E., 1976 - « Lat. lupa », dans Pisani V., SAntoro C. (éd.), Italia linguistica nuova ed antica. Studi linguistici in memoria di Parlangèli O., vol. 1, Galatina, p. 173-177.

Peters F. E., 1968 - Aristotle and the Arabs, New York.

Petrt A., 1997 - « 'L'art imite la nature': les fins de l'art et les fins de la nature », dans Morel P. M. (éd.), Aristote et la notion de nature, Bordeaux, p. 35-43.

Piccione R.-M., 2002 - « Encyclopédisme et enkyklios paideia. À propos de Jean Stobée et de son Anthologion », Philosophie antique, 2, p. 169-197.

Picone M. (éd.), 1994 - L'enciclopedismo medievale. Atti del convegno "l'enciclopedimo medievale », San Gimignano 8-10 ottobre 1992, Ravenna (Memoria del tempo, 1).

Pigeaud J., 1988 - « La greffe du monstre », REL, 66, p. 197-218.

PInÈs S., 1985 - «Une encyclopédie arabe du $x^{\mathrm{e}}$ siècle. Les Épîtres des Frères de la Pureté Rasā'il Ikhwān al-Șafā' », Rivista critica de storia della filosofia Firenze, 40 (1), p. 131-136.

Pizzani U., 1990 - « L'enciclopedismo tardoantico e le discipline del quadrivio : prospettive metodologiche », dans GARZYA A. (éd.), Metodologie della ricerca sulla tarda antichità : atti del primo Convegno dell'Associazione di studi tardoantichi, Atti dei Convegni: Associazione di studi tardoantichi, 1, Napoli, p. 49-69.

Pons A., 1986 - Introduction aux extraits de l'Encyclopédie de Diderot, 1, Paris.

del Punta F., Donati S., Trifogli C., 2000 - « Commentaries on Aristotle's Physics in Britain, 1250-1270 », dans Marenbon J. (éd.), Aristotle in Britain during the Middle Ages and the Renaissance. Proceedings of the International Conference at Cambridge, 8-11 April 1991, Turnhout (Rencontres de Philosophie Médiévale, 5), p. 265-283.

QuaIn E. A., 1945 - « The Medieval Accessus ad Auctores », Traditio, 3, p. 215-264.

RADTKE B., 1987 - « Die älteste islamische Kosmographie Muhammad-i Țūsīs 'Ağā’ib ul-mahlūqāt », Der Islam, 64, p. 279-288.

RadtKe B., 1998 - « Persian Cosmography, Early Tafsir and Nestorian Exegesis », dans Vesel Z. (éd), La science dans le monde iranien, Téhéran, p. 323-335.

ReIJNDERS H. F., 1971 - « Aimericus Ars lectoria », Vivarium, 9, p. 119-137.

ReiJnders H. F., 1972 - «Aimericus Ars lectoria », Vivarium, 10, p. 41-101 et 124-176.

Reinink G. J., 1997 - « Communal Identity and the Systematisation of Knowledge in the Syriac "Cause of all causes" », dans BinKLEY P. (éd.), Pre-modern Encyclopaedic Texts. 
Proceedings of the Second Comers Congress, Groningen, 1-4 July 1996, Leiden/New York / Köln, p. 275-288.

DE RENTIIS D., 1999 - « Für eine neue Geschichte der Nachahmungskategorie : Imitatio morum und lectio auctorum in Policraticus VII, $10 »$ dans SchaEfer U., Artes im Mittelalter, "Fortschreibungen von Wissenbeständen », Berlin, p. 161-173.

REY A., 1982 - Encyclopédies et dictionnaires, Paris.

REY A., 2006 - Antoine Furetière : un précurseur des Lumières sous Louis XIV, Paris.

REY A., 2007 - Miroirs du monde: une histoire de l'encyclopédisme, Paris.

Reynolds P. L., 1999 - Food and the Body. Some Peculiar Questions in High Medieval Theology, Leyde / Boston/Cologne (STGgM, 69).

Reynolds S., 1996 - Medieval Reading : Grammar, Rhetoric and the Classical Text, Cambridge.

RibÉmont B., 1991 - « Statut de l'astronomie et évolution des connaissances sur le cosmos au Moyen Âge », Observer, lire, écrire le ciel au Moyen Âge, Paris, Klincksieck, p. 283-300.

Ribémont B., 1995a - De natura rerum: études sur les encyclopédies médiévales, Orléans.

RibÉmont B., 1995b - «Les encyclopédies médiévales. Une première approche du genre », dans Guichard P. et AleXandre-Bidon D. (dir.), Comprendre le xiI ${ }^{e}$ siècle. Études offertes à M.-T. Lorcin, Lyon, p. 237-252.

RibÉmont B., 1997 - « On the definition of an encyclopaedic genre in the Middle Ages », dans Binkley P. (éd.), Pre-Modern Encyclopaedic Texts. Proceedings of the Second COMERS Congress, Groningen, 1-4 July 1996, Leiden/New York/Köln, p. 47-61.

Ribémont B., 1999a - «Repères bibliographiques sur les encyclopédies médiévales de l'Occident latin (XII -XIV s.) », Cahiers de Recherches Médiévales (XIII ${ }^{e}-{ }^{\mathrm{e}}{ }^{e}$ S. $)$, 6, p. 99-109.

Ribémont B. (dir.), 1999b - Vulgariser la science : les encyclopédies médiévales, Paris.

RiвÉmont B., 1999c - Bartholomaeus, Le livre des propriétés des choses: une encyclopédie au XIV siècle, Paris.

RibÉmont B., 2001 - Les origines des encyclopédies médiévales d'Isidore de Séville aux Carolingiens, Paris.

RibÉmont, 2002a - La «renaissance » du XII siècle et l'encyclopédisme, Paris.

RibÉmont, 2002b - Qui des sept arz set rien entendre... Études sur le Roman de Thèbes, Orléans.

Rich A., 1867 [1859] - Dictionnaire des antiquités Romaines et Grecques, Paris (1859).

Richelet P., 1694 - Dictionnaire françois, contenant generalement tous les mots et plusieurs remarques sur la langue françoise; les expressions Propres, figurées et burlesques, la Pronontiation des Mots les plus difficiles, le Genre des Noms, la Conjugaison des Verbes, leur régime, celui des adjectifs \& des Prépositions. Avec les Termes les plus connus des Arts \& des Sciences. Le tout tiré de l'usage et des bons auteurs par P. Richelet, Cologne.

Riessner C., 1965 - Die «Magnae derivationes » des Uguccione da Pisa und ihre Bedeutung für die romanische Philologie, Rome (Temi e testi, 11).

RiEu C., 1894 - Supplement to the catalogue of the Arabic manuscripts in the British Museum, London.

Riffaterre M., 1980 - «La trace de l'intertexte », La Pensée, 215, p. 4-18.

Riнa O., 1993 - « Ein Buch machen aus allen Büchern. Die Konzeption von Ortolfs "Arzneibuch" », dans KeIL G. (éd.), "Ein teutsch puech machen”. Untersuchungen zur landessprachlichen Vermittlung medizinischen Wissens. Ortolf-Studien I, Wiesbaden, p. 15-38.

DE RIJK L. M., 1965 - « 'Egkuklios paideia'. A Study of its Original Meaning », Vivarium, 3, p. 24-93. 
Robbins F. E., 1912 - The Hexaemeral Litterature. A study of Greek and Latin Commentaries on Genesis, Chicago.

Robrieux J.-J., 1998 - Les Figures de style et de rhétorique, Paris (Les Topos).

Rohault J., 1671a - Entretiens sur la philosophie, Paris.

Rohault J., 1671b - Traité de physique, Paris.

Romano E., 1994 - « Verso l'enciclopedia di Plinio. Il dibattito scientifico fra I. a.C. e I. d.C. », dans SABbah G., Mudry P. (éd.), La médecine de Celse. Aspects historiques, scientifiques et littéraires, Saint-Étienne, p. 11-27.

RoMeri L., 2002 - Philosophes entre mots et mets. Plutarque, Lucien et Athénée autour de la table de Platon, Grenoble.

Ronquist E. C., 1997 - « Patient and impatient encyclopedism », dans BinkLey P. (éd.), PreModern Encyclopaedic Texts. Proceedings of the Second COMERS Congress, Groningen, 1-4 July 1996, Leiden/New York/Köln, p. 31-46.

Rosen E., 1949 - «A Review of Lynn Thorndike, The Sphere of Sacrobosco and its Commentators », Isis, 121, p. 257-264.

Rosen V., 1881 - Notices sommaires des manuscrits arabes du Musée asiatique, Saint-Pétersbourg.

Rosier-CATACH I., 1997 - « Roger Bacon and Grammar », dans Hackett J. (éd.), Roger Bacon and the Sciences. Commemorative Essays, Leiden, p. 67-102.

Rosier-CataCh I., 1998a - « La Grammatica practica du ms. British Museum V A IV. Roger Bacon, les lexicographes et l'étymologie », dans Buridant C. (éd.), Lexique, 14 (L'étymologie, de l'Antiquité à la Renaissance), p. 97-125.

Rosier-Catach I., 1998b - «Quelques textes sur l'étymologie au Moyen Âge », dans Buridant C. (éd.), Lexique, 14 (L'étymologie, de l'Antiquité à la Renaissance), p. 221-229.

Rosier-Catach I., 2009 - « Glosule in Priscianum », dans Stammerjohann H. (éd.), Lexicon Grammaticorum. A Bio-bibliographical Companion to the History of Linguistics, Tübingen, p. 547-547.

Roulet E., 1982 - « De la structure dialogique du discours monologal », Langues et Linguistique, 8 : 1, p. 65-84.

Roulet E. et al., 1991 - L'Articulation du discours en français contemporain, Berne (Sciences pour la communication, 11).

Rouse M. A., Rouse R. H., 1982 - « Alphabetization », Dictionary of the Middle Ages, Bd. I, p. 204-207.

Rouse R.H., Rouse M. A., 1971 - « The text called Lumen anime », Archivum Fratrum Predicatorum, 41, p. 5-113.

Roux G., Laharie M., 1997 - Art et Folie au Moyen Âge. Aventures et Énigmes d'Opicinus de Canistris (1296-1351?), Paris.

Rubincam C., 1997 - « The Organisation of Material in Graeco-Roman World Histories », dans Binkley P. (éd.), Pre-Modern Encyclopedic Texts, Leyde/New York/Cologne, p. 127-136.

Ruн K. (éd.), 1997 - Initiation à Maître Eckhart. Théologien, prédicateur, mystique, Fribourg (Vestigia, 23).

RuHE D., 1994 - « La Roe d'astronomie. Le livre de Sidrac et les encyclopédies françaises du Moyen Âge », Picone M. (éd.), L'enciclopedismo medievale, p. 293-310.

RuHE D., 2003 - « Ratgeber. Hierarchie und Strategien der Kommunikation », dans SpIEss K.-H. (éd.), Medien der Kommunikation im Mittelalter, Wiesbaden (Beiträge zur Kommunikationsgeschichte, 15), p. 63-82.

Ruhe D., 2007 - « La divination au Moyen Âge. Théories et pratiques », dans TrACHSLER R. (éd.), Moult obscures paroles. Études sur la prophétie médiévale, Paris, p. 17-28. 
RuHE E., 1968 - Untersuchungen zu den altfranzösischen Übersetzungen der Disticha Catonis, München (Beiträge zur romanischen Philologie des Mittelalters, 2).

RuHE E., 2007 - «L'invention d'un prophète: Le livre de Sydrac », dans TraChSLER R. (éd.), Moult obscures paroles. Etudes sur la prophétie médiévale, Paris, p. 65-78.

Ruitenbeek K., 1996 - Carpentry and Building in Late Imperial China: A Study of the Fifteenth-Century Carpenter's Manual Lu Ban jing, Leiden.

Ruiz de Elvira A., 1998 - « Universitas y Encyclopaedia », Habis, 29, p. 349-369.

RungGaldiER E., 2010 - Die menschliche Seele bei Albertus Magnus : ein nicht-reduktionistischer Beitrag zum Leib-Seele-Problem, Münster/Aschendorff (Lectio Albertina, 11).

Salomon R. G., 1936 - Opicinus de Canistris. Weltbild und Bekenntnisse eines Avignonesicher Klerikers des 14. Jahrunderts, Londres, 2 tomes.

Salvan G., 2005 - « Dites-vous ou le dialogisme à l'épreuve du dialogal (et vice versa) », dans Bres J., Haillet P. P., Mellet S., Nølke H., Rosier L. (dir.), Dialogisme et polyphonie. Approches linguistiques, Bruxelles, p. 265-279.

Salvat M., 1995 - «Les incursions de l'histoire chez Barthélémy l'Anglais et ses traducteurs », dans Baillaud B., de Gramont J., Hüe D. (éd.), L'histoire, le savoir et le temps, discours encyclopédiques. Actes du colloque de Mortagne-au-Perche, avril 1994, Rennes (Cahiers Diderot, 7), p. 323-335.

Samaran C., Monfrin J., 1962 - «Pierre Bersuire, prieur de Saint-Éloi de Paris », Histoire littéraire de la France, Paris, 39, p. 259-450.

Sánchez Martínez C., 2002 - La etimología latína. Concepto y métodos, Murcie.

SANDQvist S., 2004-2005 - Le Bestiaire et le lapidaire du Rosarius (BNF fr. 12483), Lund, 1996 (Études Romanes de Lund, 55).

SANFord E. M., 1949 - « Famous Latin Encyclopaedias. Compilers of universal knowledge from Varro to Vincent of Beauvais », Classical Journal, 44, p. 462-467.

Sarnowsky J., 1999 - « Die Artes im Lehrplan der Universitäten », dans SchaEFER U., Artes im Mittelalter, Formationen und transformationen des Wissens, Berlin, p. 68-82.

Scarborough J., 1986 - «Pharmacy in Pliny's Naturalis historia: Some Observations on Substances and Sources », dans French R., Greenaway F. (éd.), Science in the Early Roman Empire. Pliny the Elder, his Sources and Influence, Londres/Sydney, p. 59-85.

SChaEFER U., 1999 - Artes im Mittelalter, Formationen und transformationen des Wissens, Berlin.

SCHAER R., 1996 - Tous les savoirs du monde. Encyclopédies et bibliothèques, de Sumer au XXIème siècle, Paris.

Schipper K. M. et al., 1981 - Index du Yunji qiqian, Paris, École française d'Extrême-Orient.

SснміDт C., 1899 - Quaestiones de musicis scriptoribus Romanis, inprimis de Cassiodoro et Isidoro, diss. Giessen, Darmstadt.

Sснміdт P. L., 1977 - « Zur Typologie und Literarisierung des frühchristlichen lateinischen Dialogs », Christianisme et formes littéraires de l'antiquité tardive en occident (Entretiens sur l'antiquité classique, XXIII), p. 101-180.

Sснмітт P., 1986 - « Enzyklopädie III.3 : Deutsche Literatur », dans Lexikon des Mittelalters, 3, col. 2035-2036.

Schмiтz T., 1997 - Bildung und Macht. Zur sozialen und politischen Funktion der zweiten Sophistik in der griechischen Welt der Kaiserzeit, Munich.

Schmuki K., Ochsenbein P., Dora C., 1998 - Cimelia Sangallensia. Hundert Kosbarkeiten aus der Stifstbibliothek St. Gallen, St Gall, p. 100-101. 
SCHNEIDER H., 1986 - Das griechische Techniskverständnis, von den Epen Homers bis zu den Anfängen der technologischen Fachliteratur, Darmstadt.

Sconocchia S., 1993 - « L'opera di Scribonio Largo e la letteratura medicina latina del I. sec. d. C. », dans HaAse W. (éd.), ANRW II, 37-1, Berlin/ New York, p. 843-922.

SeEck G. A., 1985 - «Plinius und Aristoteles als Naturwissenschaftler », Gymnasium, 92, p. 419-434.

Sellheim R., 1976 - Materialien zur arabischen Literaturgeschichte, I, Wiesbaden, p. 176-186.

SeZgin F., 2011 - Anthropogeographie, Teil 2, Frankfurt am Main.

Sezgin F. Amawî M. et al. (éd.), 1998 - Al-Farghânî (fl. c. 850) and Al-Battânî (d. 929). Texts and Studies, Francfort (Publications of the Institute for the History of Arabic-Islamic Science. Islamic Mathematics and Astronomy, 68).

Sezgin F., Ehrig-Eggert F., Neubauer E., 2006 - The reception and assimilation of Islamic mathematics and astronomy in the Occident : texts and studies, Frankfurt.

Sharples R., 1998 - Theophrastus of Eresus: Sources for His Life, Writings, Thought and Influence, Commentary. Volume 3.1, Sources on Physics, Leiden.

Shank M. H., 1988 - “Unless You Believe, You Shall Not Understand”. Logic, University, and Society in Late Medieval Vienna, Princeton.

Sherwood-Sмiтh M. C., 2000 - Studies in the reception of the "historia scholastica" of Peter Comestor: the "Schwarzwälder Predigten", the "Weltchronik" of Rudolf von Ems, the "Scolastica" of Jacob von Maerlant and "Historiebijbel van 1360", Oxford (Medium aevum monographs. New series, 20).

Sicard P., 1991 - Hugues de Saint-Victor et son École, Paris.

SiCARD P., 1997 - « Savoir et sagesse dans une école médiévale: le cas de Saint-Victor de Paris », dans SchaER R., Tous les savoirs du monde. Encyclopédies et bibliothèques, de Sumer au XXI' siècle, Paris, p. 99-106.

Siebenborn E., 1976 - Die Lehre von der Sprachrichtigkeit und ihren Kriterien. Studien zur antiken normativen Grammatik, Amsterdam.

SiEMERS K., 2006 - Möglichkeiten und Grenzen des gemeinsamen Wissens in der Onlineenzyklopädie Wikipedia, Karlsruhe (http://www.karinsche.de/files/wikipedia.pdf).

SILVI C., 2003a - «Les "petites encyclopédies" du XIII siècle en langue vulgaire. Bibliographie sélective (1980-2000) », Le Moyen Âge, 2, p. 345-361.

SiLvi C., 2003b - Science médiévale et vérité. Étude linguistique de l'expression du vrai dans le discours scientifique en langue vulgaire, Paris (Bibliothèque de grammaire et de linguistique, 15).

SiLvi C., 2006 - « Fausses et vraies objections dans le discours encyclopédique scientifique au XIII" siècle », dans Thomasset C. (dir.), L'Écriture du texte scientifique. Des origines de la langue française au XVIII siècle, Paris (Cultures et civilisations médiévales, 35), p. 49-78.

Sımon M., 1966 - « Zur Abhängigkeit spätrömischer Enzyklopädien der Artes liberales von Varros Disciplinarum libri », Philologus, 110, p. 88-101.

Smalley B., 1946 - « Two Biblical Commentaries of Simon of Hinton », Recherches de Théologie Ancienne et Médiévale, 13, p. 57-85.

Smalley B., 1948a - « Some More Exegetical Works of Simon of Hinton », Recherches de Théologie Ancienne et Médiévale, 15, p. 97-106.

Smalley B., 1948b - «The Quaestiones of Simon of Hinton », dans Hunt R. W., Pantin W. A., SOUTHERn R. W. (éd.), Studies in Medieval History presented to Frederick Maurice Powicke, Oxford, p. 209-222.

Smalley B., 1983 [1941]- The Study of the Bible in the Middle Ages, Oxford. 
Sмiтн L. J., 2009 - The Glossa ordinaria : the making of a medieval Bible commentary, LeydeBoston/Cologne (Commentaria, 3).

Southern R., 1970 - « Humanism and the School of Chartres », Medieval Humanism and Other Studies, Oxford, p. 61-85.

Southern R., 1982 - « The School of Paris and the School of Chartres » dans Benson R. L., Constable G. (éd.), Renaissance and Renewal in the Twelfth Century, Cambridge, p. 113-137.

SPARKLes B., 1991 - Greek Pottery : an Introduction, Manchester.

Speer A. et Wegener L. (éd.), 2005 - Meister Eckhart in Erfurt, Berlin/New York (Miscellanea Mediaevalia, 32).

Speer A., Wegener L. (éd.), 2006 - Wissen über Grenzen, Berlin/New York (Miscellanea Mediaevalia, 33).

SPYra U., 2005 - Das "Buch der Natur" Konrads von Megenberg. Die illustrierten Handschriften und Inkunabeln, Cologne/Weimar/Vienne (Pictura et poësis, 19).

STAdLer H., 1912 - « Vorbemerkungen zur neuen Ausgabe der Tiergeschichte des Albertus Magnus », Sitzungsberichte der königlich Bayerischen Akademie des Wissenschaften, Philosophisch-philologische und historische Klasse, Abhandlung 1.

Stannard J., 1979 - « Identification of the Plants described by Albertus Magnus, De vegetabilibus, 1. VI », Res Publica litterarum, Studies in the Classical Tradition, 2, p. 281-318.

Starobinski J., 1970 - «Remarques sur l'Encyclopédie », Revue de métaphysique et de morale, 257, p. 284-291

Steel C., 1996 - « The Individuation of the human Intellect : Henry Bate's PlatonicNominalistic Position », dans AertSen J. A., SPeEr A. (éd.), Individuum und Individualität im Mittelalter, Berlin/New York (Miscellanea Mediaevalia, 24), p. 230-248.

Steel C., Guldentops G. et Beullens P. (éd.), 1999 - Aristotle's animals in the Middle Ages and Renaissance, Congrès international, Institute of Medieval Studies, mai 1997, Louvain (Mediaevalia Lovaniensia, series 1, Studia 27).

STEER G., 1981 - Hugo Ripelin von Strassburg : zur Rezeptions-und wirkungsgeschichte des "Compendium theologicae veritatis" in deustschen Spätmittelalter, Tübingen (Texte und Textgeschichte, 2).

STEer G., 1995 - « Das Compendium theologicae veritatis des Hugo Ripelins von Straßbourg: Anregungen zu Bestimmung seines Verhältnisses zu Albertus Magnus », dans HoEnEN M. et De Libera A. (éd.), Albertus Magnus und der Albertismus. Deutsche philosophische Kultur des Mittelalters, Leyde/New York/Cologne (STGgM, 48), p. 133-154.

Stegmüller F., Reinhardt K., 1940-1980-Repertorium biblicum medii aevi, Madrid/Barcelone, 1950-1980 (11 vol.).

Steneck N. H., 1976 - Science and Creation in the Middle Ages. Henry of Langenstein (d. 1397) On Genesis, Notre Dame/Londres.

Stevenson A. J., 2004 - « Gellius and the Roman Antiquarian Tradition », dans HolfordStrevens L., Vardi A. (éd.), The Worlds of Aulus Gellius, Oxford.

Sтотz P., 1996 - Handbuch zur lateinischen Sprache des Mittelalters. Lautlehre, vol. 3, Munich.

Sun Jen I-Tu, Sun HsüEh-Chuan (trad.), 1966 - Thien Kung Khai Wu, Chinese Technology in the Seventeenth Century, by Sung Yin-hsing, Philadelphie/Londres.

Swiggers P., 2004 - «Alcuin et les doctrines grammaticales », dans Depreux P. et Judic B. (éd.), Alcuin, de York à Tours : écriture, pouvoir et réseaux dans l'Europe du haut Moyen $\hat{A}$ ge, Annales de Bretagne et des Pays de l'Ouest, 111.3, p. 147-161.

Tанмі M., 1998 - L'encyclopédisme musulman à l'âge classique, Paris. 
Tarabochia Canavero A., 1981 - Esegesi biblica e cosmologia. Note sull'interpretazione patristica e medievale di Genesi 1-2, Milan.

TAuer F., 1950 - Annotations critiques au texte du Tuhfat al-albāb d'Abū Hāmid al-Māzin̄̄ édité par G. Ferrand, Archiv Orientání, 18, p. 298-316.

TesniÈre M.-H., 1993 - «Le Reductorium morale de Pierre Bersuire », L'encyclopédisme médiéval. Actes du Colloque San Gimignano, 8-10 octobre 1992, Ravenna, p. 225-242.

TesniÈre M.-H., 1997 - « De l'Écriture, "jardin de la Sagesse”, au Livre des merveilles du monde: six modèles d'esprit encyclopédique médiéval », dans Schaer R., Tous les savoirs du monde. Encyclopédies et bibliothèques, de Sumer au XXI siècle, Paris, p. 57-98.

Tesnière M.-H., 2000 - « Pierre Bersuire, un encyclopédiste au XIv ${ }^{\mathrm{e}}$ siècle », Plein Chant, 69-70, p. 7-24.

ThÉRY P. G., 1939 - Thomas Gallus : aperçu biographique, Paris.

Thomasset C., Jacquart D., 1985 - Sexualité et savoir médical au Moyen Âge, Paris.

Thorndike L., 1949 - The "Sphere of Sacrobosco" and its Commentators, Chicago (Corpus of medieval scientific Texts, 2).

Torrell J.-P., 2002² - Initiation à Saint Thomas d'Aquin: sa personne et son æeuvre, Fribourg (Vestigia: pensée antique et médiévale, 13).

Traina G., 1994 - La tecnica in Grecia e a Roma, Bari.

Trifogli C., 2000 - Oxford Physics in the Thirteenth Century. Motion, Infinity, Place and Time, Berlin/New York $(S T G g M, 72)$.

Trifogli C. (éd.), 2008 - Liber quartus Physicorum Aristotelis. Repertorio delle questioni. Commenti inglesi ca. 1250-1270, Firenze (Corpus Philosophorum Medii Aevi, Subsidia, 16).

Tuo Tuo (éd.), 1977 - Songshi (Histoire des Song), Pékin.

TÜRK E., 1965 - « Macrobe et les Nuits Attiques », Latomus, 24, p. 381-406.

TürK M., 2000 - «Lucidaire de grant sapientie ». Untersuchung und Edition der altfranzösischen Übersetzung 1 des « Elucidarium » von Honorius Augustodunensis, Tübingen (Beihefte zur Zeitschrift für Romanische Philologie, 307).

Twomey M. W., 1988 - « Medieval Encyclopedias », Medieval Christian literary imagery. A guide to interpretation, Toronto/Buffalo/London, p. 182-315.

Twomey M. W., 1996 - « Towards a reception history of western medieval encyclopaedias in England before $1500 »$ dans BinKLEY P. (éd.), Pre-Modern Encyclopaedic Texts. Proceedings of the Second COMERS Congress, Groningen, 1-4 July 1996, Leiden/ New York/Köln, p.329-362.

Ullmann M., 1972 - Die Natur- und Geheimewissenschften im Islam, Leiden.

UlmsChNeIDER H., 1992 - « 'Ain puoch von latein... daz hat Albertus maisterlich gesamnet'. $\mathrm{Zu}$ den Quellen von Konrads von Megenberg "Buch der Natur" anhand neuerer Handschrif tenfunde », Zeitschrift für deutsches Altertum und deutsche Literatur, 121, p. 36-63.

UlmSCHNEIDER H., 1994 - « 'Ain puoch von latein'. Nochmals zu den Quellen von Konrads von Megenberg "Buch der Natur" », Zeitschrift für deutsches Altertum und deutsche Literatur, 123, p. 309-333.

van den Abeele B., 1994 - « Bestiaires encyclopédiques moralisés. Quelques succédanés de Thomas de Cantimpré et de Barthélemy l'Anglais », Reinardus, 7, p. 209-228.

vAN DEN ABEELE B., 1997 - «Vincent de Beauvais naturaliste : les sources des livre des animaux du Speculum naturale », dans Paulmier-Foucart M., Lusignan S. (dir.), Lector et compilator. Vincent de Beauvais frère prêcheur. Un intellectuel et son milieu au XIII' siècle, Grâne, p. $127-151$. 
van Den Abeele B., 2002 - « Moralisierte Enzyklopädien in der Nachfolge von Bartholmäus Anglicus », dans MeIER C. (éd.), Die Enzyklopädie im Wandel vom Hochmittelalter bis zur frühen Neuzeit. Akten des Kolloquiums des Projekts D im Sonderforschungsbereich 231, 29.11.-01.12.1996, Munich (Münstersche Mittelalter-Schriften, 78), p. 279-304.

van DEN AbEele B., 2004 - « The Macrologus of Liège. An Encyclopedic Lexicon at the Dawn of Humanism », dans MacDonald A. A., Twomey M. W. (éd.), Schooling and Society. The Ordering and Reordering of Knowledge in the Western Middle Ages, Leuven/Paris / Dudley, MA., p. 43-60.

VAN DEN AbeELE B., 2007a - Fortune et mutations des encyclopédies latines durant le Moyen Âge tardif, Thèse d'agrégation, Université de Louvain, Louvain-la-Neuve.

van den Abeele B., 2007b - "Introduction générale », dans van den Abeele et al. (éd), Bartholomaeus Anglicus. De proprietatibus rerum. Volume I : Prohemium, Livre I-IV, Turnhout (De diversis artibus 78, N.S. 41), p. 135-199.

VAN DEN Abeele B., 2008 - « Diffusion et avatars d'une encyclopédie : le Liber de natura rerum de Thomas de Cantimpré », dans de Callatä̈ G., van den Abeele B. (éd.), Une lumière venue d'ailleurs, Héritages et ouvertures dans les encyclopédies d'Orient et d'Occident au Moyen Âge, Louvain-la-Neuve, p. 141-176.

van DER Lugt M., 2004 - Le ver, le démon, la vierge. Théories médiévales de la génération extraordinaire. Une étude sur le rapport entre théologie, philosophie naturelle et médecine, Paris.

van Moos P., 1975 - « Le silence d'Héloïse et les idéologies modernes », dans LouIs R., Jolivet J. et Châtillon J. (dir.), Pierre Abélard, Pierre le Vénérable: les courants philosophiques, littéraires et artistiques en Occident au milieu du XII ${ }^{e}$ siècle, Paris (Colloques internationaux du Centre national de la recherche scientifique, 546), p. 425-468.

VAnwijnsberghe D., 2000 - De fin or et d'azur. Les commanditaires de livres et le métier de l'enluminure à Tournai à la fin du Moyen Âge, Leuven.

VARdi A., 2004 - « Genre, Conventions, and Cultural Programme in Gellius’ Noctes Atticae », dans Holford-Strevens L., Vardi A. (éd.), The Worlds of Aulus Gellius, Oxford.

DE VAuX C., 1984 - Les Penseurs de l'islam, tome IV, Paris.

Vegetti M., 1981 - « Lo spettacolo della natura, Circo, teatro e potere in Plinio », Aut Aut, 184-185, p. 111-125.

Vegetti M., 1982 - « Zoologia e antropologia in Plinio », dans Alfonsi L. (éd.), Plinio il Vecchio sotto il profilo storico e letterario, Côme, p. 117-131.

Vegetti M., 1984 - « La scienza ellenistica: problemi di epistemologia storica », dans Giannantoni G., Vegetti M., (dir.), La scienza ellenistica, p. 427-470.

Vegetti M., 1992 - «Aristotele, il Liceo e l'enciclopedia del sapere », dans Cambiano G., CANFora L., Lanza D., (dir.), Lo spazio letterario della Grecia antica, vol. 1, Roma/Salerno, p. 587-610.

Ventura I., 1997 - « L'iconografia letteraria di Brunetto Latini », Studi Medievali, III, 38, p. $499-528$.

Ventura I., 2001 - « Der Liber Similitudinum Naturalium Konrads von Halberstadt und seine Quellen: ein Fallbeispiel aus der naturwissenschaftlichen Textüberlieferung im Spätmittelalter », dans Frümittelatlerliche Studien, 35, p. 349-406.

VentuRa I., 2003a - «Die moralisierten Enzyklopädien des späteren Mittelalters : ein Überblick unter Berücksichtigung der Fallbeispiele des Lumen Anime, des Liber de exemplis et similitudinibus rerum und des Liber Similitudinum Naturalium », Reti medievali, 4 (http://www. storia.unifi.it/_RM/rivista). 
Ventura I., 2003b - «L'erbario alfabetico del De Proprietatibus Rerum di Bartolomeo Anglico e le sue fonti : una panoramica sul ruolo della botanica nelle enciclopedie del XIII secolo », dans Stammen T., Weber W. E. J. (éd.), Wissensicherung, Wissensordnung und Wissensverarbeitung : Das europäische Modell der Enzyklopädien. Akten des Kolloquiums Augsburg, 26-28 September 2001, Berlin, p. 291-337.

Ventura I., 2004a - « Enciclopedie per una società civile: Il Tresor di Brunetto latini e l'encyclopedismo laico del duecento italiano », dans Mavrodin H. (dir.), Deteriorarea tensiunii ideale în cultura şi arta. Lo scadere della tensione ideale nella cultura e nell'arte, Atti del Simposio Bucarest, instituto di cultura italiano, 17-18 nov. 2003, Bucareste, p. 223-235.

Ventura I., 2004b - "Quaestiones and Encyclopedias. Some aspects of the Late Medieval Reception of pseudo-Aristotelian Problemata in Encyclopaedic and Scientific Culture », dans MacDonald A. A., M.Twomey W. (éd.), Schooling and Society. The Ordering and Reordering of Knowledge in the Western Middle Ages. International Conference Kowledge and Learning, 14-17 November 2001, Groningen, Leuven/Paris/Dudley (Groningen Studies in Cultural Change, 6), p. 23-42.

Ventura I., 2006 - « Aristoteles fuit causa efficiens huius libri. On the Reception of PseudoAristotle's Problemata in Late Medieval Encyclopedic Culture », dans Goyens M., DE LeEmans P. (éd.), Aristotle's Problemata in Different Times and Tongues (Interdisciplinary Workshop, Leuven, Katholieke Universiteit, 30-31), Leuven, 2006 (Mediaevalia Lovaniensia. Series 1, Studia, 39), p. 113-144.

Ventura I., 2007a - « Formen des Dominikanischen Enzyklopädismus im 14. Jahrhundert: Heinrich von Herford, Konrad von Halberstadt, Jakob von Soest », Sborník prací filozofické fakulty Brnĕnské Univerzity. Studia minora facultatis philosophicae Universitatis Brunensis, 12, p. 131-151.

Ventura I., 2007c - «Plant Symbolism in Thirteenth-Century Biblical Exegesis and in Bartholomaeus Anglicus' De proprietatibus rerum », Schola Salernitana Annali, 12, p. 121-134.

Ventura I., 2007d - «Per modum quaestionis compilatum... The Collections of Natural Questions and their Development from the Thirteenth to the Sixteenth Century », dans Michel P. (éd.), All you need to know : Encyclopaedias and the idea of general knowledge. Conference, Prangins, Switzerland, 18-20 Sept. 2003, publié sur le site web www. enzyklopaedie.C.

Ventura I., 2008 - «On Philosophical Encyclopaedism in the Fourteenth Century : the Catena aurea entium of Henry of Herford », dans DE CAllataÿ G. et van den Abeele B. (éd.), Une lumière venue d'ailleurs. Héritages et ouvertures dans les encyclopédies d'Orient et d'Occident au Moyen Âge. Actes du Colloque de Louvain-la-Neuve, 19-21 Mai 2005, Turnhout/Louvain-la-Neuve (Réminisciences, 9), p. 199-245.

Verger J., 1986 - «Enzyklopädie II.2: Spätmittelalter und Humanismus », Lexikon des Mittelalters, 3, col. 2033-2034.

VESEL Z., 1986 - Les encyclopédies persanes: essai de typologie et de classification des sciences, Paris.

VeSEL Z., 2008 - «Les encyclopédies persanes: culture scientifique en langue vulgaire », dans de Callataÿ G., van den Abeele B. (éds), Une lumière venue d'ailleurs. Héritages et ouvertures dans les encyclopédies d'Orient et d'Occident au Moyen Âge, Louvain-laNeuve, p. 49-89.

Viola C., 1982 - « Manières personnelles et impersonnelles d'aborder un problème: saint Augustin et le XII e siècle. Contribution à l'histoire de la quaestio ", dans Les Genres littéraires dans les sources théologiques et philosophiques médiévales: définition, critique et exploitation. Actes du colloque international de Louvain-La-Neuve, 25-27 mai 1981, Louvain-La-Neuve (Publication de l'Institut d'études médiévales, $2^{\mathrm{e}}$ série, 5), p. 11-30. 
VION R., 2005 - « Modalités, modalisations, interaction et dialogisme », dans BRES J., Haillet P. P., Mellet S., Nølke H., Rosier L. (dir.), Dialogisme et polyphonie. Approches linguistiques, Bruxelles, p. 143-156.

Virolleaud C., 1955 - « La littérature assyro-babylonienne », Histoire des littératures, tome 1, Paris (Encyclopédie de la Pléiade), p. 253-276.

Vollmann B. K., 2002 - «Enzyklopädie im Wandel: Thomas von Cantimpré, De natura rerum », dans MeIER C., Die Enzyklopädie im Wandel vom Hochmittelalter bis zur frühen Neuzeit, München (Münstersche Mittelalter-Schriften, 78), p. 169-188.

VON BürEN V., 2002 - « Écrites au $9^{\mathrm{e}}$, perdues au $20^{\mathrm{e}}$, retrouvées au $15^{\mathrm{e}}$ : à propos des gloses de Végèce "De re militari”" », dans Fera V., Ferraù G., Rizzo S. (éd.), Talking to the Text : Marginalia from Papyri to Print. Actes du Colloque tenu à Erice, 26 septembre - 3 octobre 1998 au Centro Interdisciplinare di studi Umanistici, Messina, p. 269-287.

von Büren V., 2003 - «Isidore, Végèce et Titanus au VIII e siècle », dans Defosse P. (éd.), Hommages à Carl Deroux, vol. 5, Bruxelles, p. 39-49.

von DEN Brincken A. D., 1978 - « Geschichtsbetrachtung bei Vincenz von Beauvais. Die Apologia Actoris zum Speculum Maius », Deutsches Archiv für Erforschung des Mittelalters, 34, p. 410-499.

von HeEs S., 2002 - Enzyklopädie als Spiegel des Weltbildes. Qazwīnīs Wunder der Schögfung - eine Naturkunde des 13. Jahrhunderts, Wiesbaden.

von HeEs S., 2006 - «Al-Qazwīn̄’’s 'ajā'ib al-makhlūqāt », dans EndREss G. (éd.), Organizing Knowledge. Encyclopaedic Activities in the Pre-Eighteenth Century Islamic World, Leiden, p. 171-186.

VoorbiJ J., 1986 - The "Speculum historiale" : Some Aspects of its Genesis and Manuscript Tradition », dans Aerts J. W., Smits E. R., Voorbi J. B. (éd.), Vincent of Beauvais and Alexander the Great. Studies on the Speculum Maius and its Translations into Medieval Vernaculars, Groningen, p. 11-55 (Mediaevalia Groningana, 7).

Voorbis J., 1991 - Het Speculum Historiale van Vincent van Beauvais. Een studie van zijn ontstaansgeschiedenis, Groningen.

VosковоYnikov O., 2006 - Arts, savoirs et visions de la nature à la cour de Frédéric II, ParisEHESS (thèse).

VRIN J., 1969 - Arts libéraux et philosophie au Moyen Âge. Actes du $4^{e}$ congrès international de Philosophie médievale, 27 août-2 sept. 1967, Montréal/Paris.

WAGNER C., 1986 - Materie im Mittelalter : Edition und Untersuchungen zur "Summa" (II,1) des Nikolaus von Strassburg O.P., Fribourg (Studia Friburgensis. Neue Folge, 67).

WANG Y., 1352 - Yuhai (La mer des jades), réimpr. 1977, Taibei, Dahua shuju.

WeIGand R., 1991 - Vinzenz von Beauvais. Scholastische Universalchronistik als Quelle volkssprachiger Geschichtsschreibung, Hildesheim (Germanistische Texte und Studien, 36).

Weijers O., 1989 - «Lexicography in the Middle Ages », Viator, 20, p. 139-153.

WeIJERs O., 1990 - « Les dictionnaires et autres répertoires », dans WeiJers O. (éd.), Méthodes et instruments du travail intellectuel au Moyen Âge. Études sur le vocabulaire, Turnhout, p. 197-208.

WeIJERs O., 1991 - Dictionnaires et répertoires au Moyen Âge. Une étude du vocabulaire, Turnhout.

WeiJers O., 1994 - «L'enseignement du trivium à la faculté des arts à Paris : la "quaestio" », dans HAMESSE J. (éd.), Manuels, programmes de cours et techniques d'enseignement dans les universités médiévales. Actes du Colloque International de Louvain-la-Neuve, 9-11 septembre 1993, Louvain-la-Neuve (Publications de l'Institut d'Études Médiévales. Textes, Études, Congrès, 16), p. 57-74. 
Weijers O., 1995 - La “disputatio" à la Faculté des arts de Paris (1200-1350 environ). Esquisse d'une typologie, Turnhout (Studia Artistarum, 2).

WeiJers O. (éd.), 1996 - Le Maniement du savoir. Pratiques intellectuelles à l'époque des premières universités (XIII'-XIV siècles), Turnhout.

WeIL E., 1946 - «L'anthropologie d'Aristote », Revue de Métaphysique et de Morale, 51, p. 7-36.

WeISEL B., 1993 - « Die Überlieferung des "Livre de Sidrac" in Handschriften und Drucken », dans Brunner H., Wolf N. R. (éd.), Wissensliteratur im Mittelalter und in der Frühen Neuzeit. Bedingungen, Typen, Publikum, Sprache, Wiesbaden, p. 53-66.

Wilkins J., 2000a - «Athenaeus and the Fishes of Archippus », dans BraUnd D., Wilkins J. (dir.), Athenaeus and his World, Exeter, p. 323-335.

Wilkins J., 2000b - « Dialogue and Comedy », dans Braund D., WiLkins J. (dir.), Athenaeus and his World, Exeter, p. 23-37.

WiLle G., 1967 - Musica Romana. Die Bedeutung der Musik im Leben der Römer, Amsterdam.

WiLliams S., 2003 - The Secret of Secrets. The scholarly career of a Pseudo-Aristotelian text in the Late Middle Ages, Ann Arbor.

Wins B., 1993 - « "Le Livre de Sidrac" - Stand der Forschung und neue Ergebnisse », dans BrunNer H., Wolf N. R. (dir.), Wissensliteratur im Mittelalter und in der Frühen Neuzeit. Bedingungen, Typen, Publikum, Sprache, Wiesbaden (Wissensliteratur im Mittelalter. Schriften des Sonderforschungsbereichs 226 Würzburg/Eichstätt, 13), p. 36-52.

Wissowa G., 1880 - De Macrobii Saturnaliorum fontibus capita tria, diss. Breslau.

Woesthuis M., 1997 - « Vincent of Beauvais and Helinand of Froidmont », dans Lusignan S. et Paulmier-Foucart M. (dir.) et Duchenne M.-C., Lector et compilator. Vincent de Beauvais, frère prêcheur, un intellectuel et son milieu au XIII siècle, Nancy-Montréal, p. 233-247.

Wooldridge T. R., Lancashire I. (dir.), 1995 - Les bases de dictionnaires anciens, Paris.

Wüstenfeld F. (éd.), 1849 - El-Cazwini's Kosmographie, Göttingen.

ZAHORA T., 2012 - «Amending Aquinas: Textual Bricolage of the Speculum dominarum as an Authorial Strategy in the Compilation Speculum morale », Cahiers de Recherches Médiévales et Humanistes, p. 505-524.

Zahora T., 2013 - «Virtue and the Politics of Salvation in the Age of the Apocalypse : the Case of the Speculum morale », (inédit).

Zahora T., Nikulin D., Mews C., SQuire D., 2012 - « Decompiling the Speculum morale. Uncovering Franciscan Voices in an Encyclopedia of Ethics with the Aid of Factotum Software », à paraître dans les actes du congrès de la FIDEM 2012.

ZAMBoni A., 1989 - L'etimologia, Bologna.

ZeCChini G., 1989 - La cultura storica di Ateneo, Milan.

Zecchini G., 2007 - «Athénée et les historiens », dans Lenfant D. (éd.), Athénée et les fragments d'historiens, Strasbourg, p. 19-27.

ZeLler E., 1897 - Aristotle and the earlier Peripatetics, Londres.

Zimmermann B., 1994 - « Osservazioni sulla "enciclopedia" nella letteratura latina », dans Picone M. (éd.), L'enciclopedismo medievales, Ravenna, Longo, p. 41-51

Zonta M., 1995 - « The Reception of al-Fârâbî’s and ibn Sînâ's Classifications of the Mathematical and Natural Sciences in the Hebrew Medieval Philosophical Literature », Medieval Encounters, 1.3, p. 358-382.

ZuCKer A., 2005 - Aristote et les classifications zoologiques, Louvain-la-Neuve.

ZuCKer A., 2012 - «Qu'est-ce qu'épitomiser? Étude des pratiques dans la Syllogé zoologique byzantine », Rursus, 7, mars 2012 [http ://rursus.revues.org/961] (38 p.). 

INDEX 



\title{
INDEX DES NOMS DE PERSONNES ET DES CEUVRES
}

\author{
par Guillaume Clamens
}

$\mathbf{A}$

Abel : 359-360

Abgar le Toparque d'Édesse : 127

Abolita: 291-292

Abraham: 131 (n. 27)

Abstrusa: 296

Abu-Faradj al-Isfahani : 36

Kitab al-aghani (Le livre des chants) : 35

Abū Hāmid al-Gharnātī: 202, 203

$\rightarrow$ Tuhfat al-albāb (Réjouissement des cœurs): 202

Abū 1-Sa'ādāt al-Mubārak ibn Muhammad al-Shaybānī Ibn al-Atīr al-Ğazarī : 208

Accius : 229

$\rightarrow$ Mélanippe : 229

Achille: 249

Adaios de Mitylène: 248 (n. 8)

Adalhard de Corbie : 259

Adam : 172, 176, 182-183, 191, 347, 359-360

Adélard de Bath: 104, 198, 383 (n. 11)

$\rightarrow$ Qucstiones naturales $(Q N): 198$

Adenulphe d'Anagni: 133 (n. 34)

Ælius Stilon: 281

Ælred de Rievaulx : 294 (n. 96)

Ailly (Pierre d') : 189

Aimeric de Gâtine: 288-289, 292

$\rightarrow$ Ars lectoria : 288, 292

Ajax: 249

Alain de Lille: 94-95, 167, 197

$\rightarrow$ Anticlaudianus: 197

$\rightarrow$ Cosmographia: 94

$\rightarrow$ De planctu natura: 95

Al-Battani: 113

$\rightarrow$ De scientia stellarum - De numeris stellarum et motibus: 113

Albert III, duc d'Autriche: 117

Albert le Grand: 16, 31, 55, 75, 87, 92, 104, 109-111 (n. 13), 113-114, 116, 118, 120, 121

$\rightarrow$ De animalibus: 118

$\rightarrow$ De mineralibus: 111 $\rightarrow$ De vegetalibus : 111

$\rightarrow$ Meteora: 118

Alberti (Leon Battista) : 42

Albinus : $314-315,317$

Al-Bitruji : 113

$\rightarrow$ De motibus celorum: 113

Albumasar (Abu Mash'ar): 196-197

$\rightarrow$ Introductorium majus : 197

Alcibiade : 255

Alcméon: 67

Alcuin: 16, 262, 271, 407

$\rightarrow$ Excerptiones super Priscianum majorem : 262

$\rightarrow$ Grammaire: 262,271

Aldhelm de Malmesbury: 267, 282 (n. 26), 407

Al-Dimashqī (Shams al-Dīn) : 202, 207, 211

$\rightarrow$ Nuhbat al-dahr fì 'a ăă'ib al-barr wa-l-bahr (Choix de ce que le monde nous offre en fait de merveilles de la terre et de la terre) : 207

Alembert (Jean Le Rond d') : 11, 33, 35, 41

(n. 15), 45-46, 50-51, 84, 239, 242, 334

$\rightarrow$ Discours préliminaire: 45,46

$\rightarrow$ (Dir. avec Diderot) L'Encyclopédie voir Diderot Alexandre le Grand: 126 (n. 5), 127, 203, 254, 404-405

Alexandre de Villedieu : 291 (n. 75), 293, 297

(n. 108)

$\rightarrow$ Doctrinale : 293

Alexis : 252-253

Al-Fârâbî: 93

Al-Farghani (Alfragan): 193

Alfred de Sareshel : 110

Al-Harrān̄̄ (Muhammad) : 209

$\rightarrow \breve{G} a ̄ m i$ 'al-funūn wa-salawat al-mahzūn (Recueil de matières diverses pour servir de consolation à l'homme affligé): 209

$\rightarrow$ Alia musica: 320

Alphonse X le Sage : 418 (n. 8)

Al-Qazwīnī: 142, 202, 204-209, 211, 212

$\rightarrow$ Les merveilles des choses créées et les faits miraculeux des choses existantes: 142, 204 
Alsted (Johann Heinrich) : 11 (n. 1), 238

$\rightarrow$ Scientiarum omnium Encyclopcedia: 238

Al-Umarī (Ibn Fadl Allāh) : 210

$\rightarrow$ Masālik al-absār fì mamālik al-amsār (Voies des regards sur les royaumes dotés de métropoles): 211

Al-Warrāq (Ğamāl al-Dīn al-Watwāt al-Kutubī): 207- 210, 212

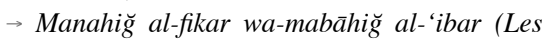
voies de la méditation et les réjouissances des exemplarités instructives): 207

$\rightarrow$ Nuzhat al-'uyūn fĩ arba'at funūn (L'agrément des yeux dans les quatre arts): 207

Alypius: 307, 314

$\rightarrow$ Isagoge: 307,314

Ambroise de Milan: 118, 131 (n. 26), 135, $167,180,259$

$\rightarrow$ Hexameron: 118, 167, 180, 259

Amérias : 246 (n. 4)

Ampélius (Lucius) : 18

$\rightarrow$ Liber memorialis : 18

Anaxandride : 254

Andronicos de Rhodes : 78

Anonymes de Bellermann: 312-313

Anselme de Cantorbéry: 171, 407

Anselme de Laon: 361 (n. 25)

Ansileube: 232, 292

Antoine (Marc): 127 (n. 9)

Apex physica: 94

Apion: 246 (n. 4)

Apollonios Dyscole: 249 (n. 16), 269

Apulée : $314-315$

Apulée le grammairien: 288-289, 293, 295-296

(n. 100)

$\rightarrow$ De nota aspirationis: 288, 293, 296

Archestrate de Géla: 246, 250, 255

$\rightarrow$ Gastrologie : 246, 250

Archiloque: 251

Archippe : 250

$\rightarrow$ Les poissons: 250

Archytas de Tarente: 304

Ariemaf: 422 (n. 16)

Aristide Quintilien: 312-313, 316-317, 320-321 (n. 34, 35)

$\rightarrow$ Musique: 312

Aristonyme: 246

Aristophane d'Athènes : 251

$\rightarrow$ Les Acharniens : 251

$\rightarrow$ Les Cavaliers: 251 $\rightarrow$ Les Guêpes: 251

$\rightarrow$ Les Lemniennes: 251

$\rightarrow$ Les Nuées: 251

Aristophane de Byzance: 77 (n. 61), 214

Aristote: 22, 30, 55-59, 61-76, 78-80, 87, 89, 92-93, 104, 109-110, 112-113, 117-118, 145-146, 148-154, 156-161, 163-164, 183, 188, 190-193, 196, 201 (n. 1), 251, 300, 303-304, 353-354, 365, 401, 403-405

$\rightarrow$ Seconds Analytiques (APo.) 71b9-11: 65 (n. 30)

$\rightarrow$ Seconds Analytiques (APo.) 77a26-28: 69

$\rightarrow$ Seconds Analytiques (APo.) 78b35-39: 68 (n. 41)

$\rightarrow$ Seconds Analytiques (APo.) 79a13-16: 68 (n. 42)

$\rightarrow$ De Calo (Cael.): 199

$\rightarrow$ Cal. 279a30: 61

$\rightarrow$ De Anima (DA): 71, 112

$\rightarrow$ DA: 402a1-2:64

$\rightarrow D A: 402 a 1-10: 71$

$\rightarrow$ DA: 402a7: 72

$\rightarrow$ Éthique à Nicomaque (EN): 68 (n. 38), 109, 188

$\rightarrow$ EN: 1096al-4: 61

$\rightarrow$ EN: 1139a7: 70

$\rightarrow$ Histoire des animaux (HA): 150, 157

$\rightarrow$ HA: 491a12: 150

$\rightarrow$ HA: 540 al9 sq.: 152

$\rightarrow$ Métaphysique (Meta.): 65, 67-70 (n. 37, 38), 75,78

$\rightarrow$ Meta. 980a20-27: 63

$\rightarrow$ Meta. 981b7: 72

$\rightarrow$ Meta. 982b2: 65

$\rightarrow$ Meta. 982b21: 65

$\rightarrow$ Meta. 983a25: 65

$\rightarrow$ Meta. 992b24-25, 33: 67 (n. 34)

$\rightarrow$ Meta. 993b1: 66 (n. 32)

$\rightarrow$ Meta. 1024b16: 67

$\rightarrow$ Meta. 1025b6: 68

$\rightarrow$ Meta. 1025b18: 70

$\rightarrow$ Meta. 1025b28: 73

$\rightarrow$ Meta. 1026a17: 70

$\rightarrow$ Meta. 1026b19-27: 71

$\rightarrow$ Météorologiques (Mete.): 73, 196

$\rightarrow$ Mete. 338a20-339a9: 55, 73-74

$\rightarrow$ Organon: 75,78

$\rightarrow$ Parties des Animaux (PA): 79, 156

$\rightarrow$ PA: 639a1-12: 79

$\rightarrow$ PA: 640b2: 70

$\rightarrow$ Parva naturalia: 354

$\rightarrow$ Physique (Ph.): 78, 110, 156

$\rightarrow$ Ph. 184a10: 72 
$\rightarrow$ Poétique (Poet.): 150

$\rightarrow$ Poet. 1454b18: 62

$\rightarrow$ Politique (Pol.): 72, 78, 188

$\rightarrow$ Pol. 1252a24sq. 72

$\rightarrow$ Problèmes: 67, 104, 116, 365

$\rightarrow$ Rhétorique: 78

$\rightarrow$ Seconds analytiques: 68

$\rightarrow$ Topiques: 145 a15: 69

Aristote (pseudo-) : 368

$\rightarrow$ Secretum secretorum (Sirr al-asrar) (Le Secré des secrés) : 368, 404, 405, 406, 424

Aristoxène de Tarente: 303-307, 309, 312-

313,322

$\rightarrow$ Éléments harmoniques (Harm.): 304, 313

$\rightarrow$ Éléments rythmiques : 304

Arjuna: 41

Arnold de Saxe : 20, 55, 83 (n. 11), 90-93, 96, $98,100,102,104,121,300$

$\rightarrow$ De celo et mundo: 91

$\rightarrow$ De floribus rerum naturalium: 55, 91, 93, 96, 100

Ars Lectoria: 293

Artémidore: 22-23 (n. 39)

Asclépiade de Myrléa: 248 (n. 15)

Assurbanipal: 24, 38

Athénée de Naucratis : 22, 215, 245-248, 250, 252, 254-257

$\rightarrow$ Les Deipnosophistes ou Banquet des Sophistes: 215, 245-246, 248-257

Audax : 261- 264, 269, 272

$\rightarrow$ Excerpta: 261,262

Auguste: 165, 231

Augustin d'Hippone: 14, 16-19, 22, 40, 83, 88, 97, 99, 110, 118, 121, 131, 133, 135, 137, 172, 216, 259, 261- 263, 274, 284 (n. 37), 301, 309-311, 314-315, 353, 363, 407, 427

$\rightarrow$ Confessions: 19 (n. 27)

$\rightarrow$ La Cité de Dieu: 131, 133, 259, 310, 427

$\rightarrow$ De doctrina christiana: 17- 19, 99

$\rightarrow$ De genesi ad litteram: 261-263

$\rightarrow$ De grammatica: 40

$\rightarrow$ De magistro: 17

$\rightarrow$ Ennarationes in Psalmos: 353

$\rightarrow$ Sur la musique: 40, 309, 314, 407

$\rightarrow$ De ordine: 19, 22, 311

$\rightarrow$ Retractationes: 310

Aulu-Gelle: 21-22 (n. 35), 139, 215, 221223, 226-227, 261, 354, 367, 369- 379

$\rightarrow$ Nuits Attiques (NA): 139, 221-222, 261, 354, 367, 369, 371-379 $\rightarrow$ NA Praf. $1: 373$

$\rightarrow$ NA Praf. $2: 373$

$\rightarrow$ NA Praf. $10: 376$

$\rightarrow$ NA Praf. $25: 377$

$\rightarrow N A 1.21: 223$

$\rightarrow$ NA $1.25: 222-223$

$\rightarrow$ NA 7.3: 221

$\rightarrow$ NA 17.21.1:379

$\rightarrow$ NA 18.8: 222

Averroès : 110, 113, 353

Avicenne: 37 (n. 7), 113

Aviénus : 371

Axionicos : 253

\section{B}

Bacon (Francis) : 22, 44- 46, 354

Bacon (Roger): 293, 297 (n. 110)

$\rightarrow$ Grammatica Graca: 293

Badius Ascensius (Josse Bade, dit) : 239

Balbi (Giovanni) ou Jean de Gênes : 227, 235 , 260, 274-275(n. 55), 277-278, 280 (n. 17, 20), 284, 286-290 (n. 47, 64, 68, 70), 294, 297, 358, 361, 382 (n. 6)

$\rightarrow$ Catholicon: 235, 239, 260, 275, 285, 287, 294, 358

Barthélémy de Parme: 103 (n. 74)

Barthélemy 1'Anglais: 14, 18, 20, 31, 55, 75, 81, 83 (n. 11, 12), 89-93, 95-101, 110, 119-121, 125, 131, 142, 187, 190, 192-193, 195-196, 199, 302, 351-352, 354, 358, 403

$\rightarrow$ Liber de proprietatibus rerum: 18, 20, 81, 89, 91-92, 95, 99-101, 104, 120, 125, 131, 187-188, 192, 194, 196, 200, 302, 351, 354355,357

Basile le Grand : 18-19, 141, 167, 192

$\rightarrow$ Hexameron: 167, 192

Bate de Malines (Henri): 31, 108, 110, 111116, 121-122

$\rightarrow$ Speculum divinorum et quorandum naturalium: 108, 111-114

Bayle (Pierre) : 47, 239-240 (n. 34)

$\rightarrow$ Dictionnaire historique et critique: 47

Bébius Macer: 149 (n. 20)

Bède le Vénérable: 88, 96, 118, 130, 132, 134135, 141, 169-170, 180, 191, 198, 200, 407

$\rightarrow$ De natura rerum: 130, 132, 141, 169-170, 180

$\rightarrow$ Expositio actuum apostolorum: 132

$\rightarrow$ Musica theorica: 191 
Bède (pseudo-): 199

$\rightarrow$ De mundi celestis terrestrisque constitutione: 199

Beethoven (Ludwig von) : 322

Beitang shuchao voir Yu Shinan

Belcazer (Vivaldo) : 101

Beleth (Jean): 289 (n. 64)

Bellermann (Heinrich): 320

Bencao Gangmu : 34

Bene de Florence: 290 (n. 68)

Bernard de Chartres : 86

Bernard de Clairvaux : 135, 137, 294 (n. 96)

Bernard d'Utrecht: 422 (n. 15)

Bernard Silvestre: 95, 130, 167

$\rightarrow$ Cosmographia: 95, 130

Bersuire (Pierre) : 101, 104, 190, 302, 349359, 361-362

$\rightarrow$ Cosmographia sive mappa mundi: 350

$\rightarrow$ De poetarum fabulis ou Ovidius moralizatus: 349,357

$\rightarrow$ Reductorium morale super totam Bibliam: 101, 104, 190, 302, 349-357, 359-361, 363

$\rightarrow$ Repertorium morale: $350,358-359,361-363$

Bible: 39-40, 84, 86, 108, 119-120, 131, 133, 136, 141, 174, 176-177, 179-180, 182-183, 184, 236, 302, 337, 350, 358-359, 361, 419

$\rightarrow$ Actes des Apôtres: 134

$\rightarrow$ Ancien Testament: 417, 423

$\rightarrow$ Cantique des Cantiques: 167

$\rightarrow$ Ecclésiaste: 89, 177, 191

$\rightarrow$ Ecclésiastique: 40,405

$\rightarrow$ Évangiles: 202

$\rightarrow$ Genèse (Gn): 40, 91, 97, 117, 119, 122, 131, 141-142, 167-172, 175-182, 184, 191-192, 361,419

$\rightarrow$ Gn 1.16: 183

$\rightarrow$ Gn $4: 361$

$\rightarrow$ Livre de la Sagesse (ou Sagesse de Salomon): 40

$\rightarrow$ Luc (Évangile de): 360-361

$\rightarrow$ Matthieu (Évangile de): 291

$\rightarrow$ Jean (Évangile de): 178

$\rightarrow$ Psaumes (Ps.): 167,184

$\rightarrow$ Ps. 135.6: 184

Boctus (roi): 337, 339-340, 343, 346, 368, 382-383, 403-404, 408, 416- 423, 425

Boèce: 19, 41, 110, 192, 262 (n. 14), 270271, 273-274, 301, 306-307, 309, 311, 315$318,320-322,407$ $\rightarrow$ Institution arithmétique: 311

$\rightarrow$ Institution musicale : 306, 309, 315-316, 318, 320

$\rightarrow$ Peri Hermeneias (Periherm.): 271

Boniface: 282 (n. 26)

Braulio, évêque de Saragosse: 20 (n. 30)

Budé (Guillaume) : 13

Buffon (Georges Louis Leclerc de) : 146, 152

$\rightarrow$ De la manière d'étudier et de traiter l'Histoire naturelle: 146

Burgos (Vicente de) : 101

\section{C}

Cæcilius (Sextus): 229, 379

$\rightarrow$ Hypobolimaus Charestratus: 229

Caïn : 131, 360

Callimaque de Cyrène : 248, 255

$\rightarrow$ Causes: 248

$\rightarrow$ Tables des personnalités dans chaque branche et liste de leurs écrits : 255

Callixène de Rhodes: 248 (n. 9)

Cao Cao: 324

Cao Pei : $323-324$

Cao Yin: 35

$\rightarrow$ Qan tang shi: 35

Caper: 287

$\rightarrow$ De orthographia: 288

Cassiodore: 14, 19, 42, 88, 226 (n. 19), 278

(n. 7), 280, 301, 309, 311, 314-315, 322

$\rightarrow$ Institutions des lettres divines et humaines (Inst.): 19, 42, 309, 311, 314

Caton: 14 (n. 14), 22, 58 (n. 10), 87, 221, 230

Cefu yuangui (Leçons tirées du palais des livres): 329

Celse : 87, 145, 147, 154-156, 235

$\rightarrow$ Artes: 154

$\rightarrow$ Médecine: 154, 156, 235

Censorinus: 308-309, 311, 314

$\rightarrow$ De die natali $: 308,314$

$\rightarrow$ Epitoma disciplinarum: 309, 314

César (Jules) : 126-128, 134, 138

Chambers (Ephraïm): 11 (n. 1), 34, 47, 56, 59-61, 80, 240-241

$\rightarrow$ Cyclopadia or Universal Dictionary of the Arts and Sciences: 43, 47, 56, 60-61, 240

Changzhou yujing (le Miroir de jade de l'île longue): 325

Charisius : 224-225

Charlemagne: 262 
Charles V, roi de France: 101, 120, 188

Charles d'Anjou : 338 (n. 9)

Chen Yuanlong: 332

$\rightarrow$ Gezhi jingyuan (Examen approfondi de la nature des choses) : 332-333

Cheng Tsu (Chengzu) voir Yung-le

Christine de Pisan : 189

$\rightarrow$ Livre du chemin de long estude: 189

Chuxue ji (Notes pour l'entrée dans les études) : 329

Cicéron: 23, 39, 58 (n. 10), 68 (n. 38), 72 (n. 51), 148, 187, 222, 308-309 (n. 12), 371,407

$\rightarrow$ Partitiones oratorice: 407

$\rightarrow$ République (Rép.): 308

$\rightarrow$ Rép. 6.18: 308

$\rightarrow$ Songe de Scipion: 187,308

Ci nous dit: 353

Claude, empereur romain : 154

Claudius Quadrigarius : 223

Cledonius: 291 (n. 75)

Clément d'Alexandrie: 17, 39

$\rightarrow$ Stromates: 17

Cléonide : 307

Clitarque d'Égine: 246 (n. 4)

Compendium philosophice: 31, 93, 96, 108111, 116-117, 121

Compilatio de libris naturalibus: 96

Compilation Impériale des Temps Anciens et Modernes 35

Comte (Auguste) : 46

Condillac (Étienne Bonnot de) : 46

Conrad de Mure : 20, 102

$\rightarrow$ Fabularius: 102

Conrad d'Hirsau: 422 (n. 15)

Conrad (Konrad de Megenberg) : 95, 108-109 (n. 10)

$\rightarrow$ Buch der Natur ou Buch von den natürlichen Dingen: 95,108

Consentius : 291 (n. 75)

Constantin VII, empereur byzantin: 15

$\rightarrow$ Collectanea: 15

Constantin l'Africain : 177

Coran : 203

Corbechon (Jean): 101, 120, 192-193, 196, 351 (n. 9)

$\rightarrow$ Livre des propriétés des choses: 188, 192194, 196-197

Coronelli (Vincenzo): 11 (n. 1)
Cratès d'Athènes : 246 (n. 4)

Cratès de Mallos: 257

Cuba (Jean de) : 102

$\rightarrow$ Gart der Gesundheit 102

Curtius (Marcus) : 355-356

Cynulque: 254, 257

Cyrano de Bergerac (Savinien de): 402 (n. 87)

Cyrus le Grand: 418

\section{D}

Daniel : 418, 425

Daniel de Morley : 89

Dante : 189

David, roi d'Israël: 131

Démétrios de Phalère: 56 (n. 2)

Démocrite: 57, 67, 256

Démosthène : 254, 372

$\rightarrow$ Sur les forfaitures de l'ambassade: 254

Denys, fils de Tryphon: 246 (n. 4)

Denys d'Halicarnasse : 282 (n. 27)

Denys l'Aréopagite (Pseudo-): 91, 110

Denys l'Aréopagite: 129 (n. 17)

Denys l'Iambe: 246 (n. 4)

Derivationes : 277

Descartes (René) : 46

Deschamps (Eustache) : 410 (n. 9)

Diderot (Denis) : 11, 21 (n. 34), 33-35, 37-38, 41 (n. 15), 43-48, 50-51, 55, 59-60, 84, 141, 239, 242, 300, 334

$\rightarrow$ Discours préliminaire: $59,241-243$

$\rightarrow$ (Dir. avec d'Alembert) L'Encyclopédie ou Dictionnaire raisonné des arts, des lettres et des métiers (DDA): 11-12, 22, 33, 35, 38, 41, 43-48, 50-51, 56, 59-62, 77-78, 80, 84, 141, 220, 241-244, 334

$\rightarrow$ Prospectus : 44, 47-48, 300

Didyme: 246 (n. 4)

Differenta: 260

Digeste: 135 (n. 45)

Dioclès le comique : 246

Diodore de Sicile : 22, 149

$\rightarrow$ Bibliothèque historique: 149

Diodore le Dialecticien: 58 (n. 9)

Diogène Laërce: 38, 58 (n. 9), 62

Diomède, roi d'Athènes : 249

Diomède le grammairien: 225, 261, 263, 266-267, 269, 272, 291 (n. 75)

$\rightarrow$ Ars grammatica: 261, 263, 266-267 
Dioscoride : 247 (n. 5)

Disaire: 371

Diwang jiyao (l'Essentiel des collections des empereurs et des princes) : 325

Domitius : 221-222, 224, 226-227

Donat: 96, 214, 260, 262, 278

$\rightarrow$ Ars grammatica: 260

$\rightarrow$ Glose sur Térence, Adelphes: 96, 214

Dorion: 246

$$
\rightarrow \text { Sur les poissons: } 246
$$

Dorothée d'Ascalon: 246 (n. 4)

Du Cange (Charles du Fresne) : 239

Du You: 329 (n. 10)

Durand (Guillaume): 289 (n. 64)

\section{$\mathbf{E}$}

Eckart (Maître): 108

Égimios : 255

Élias: 72 (n. 51)

Élien: 245 (n. 2)

$\rightarrow$ Empédocle: 126 (n.5)

Enciclopedia universal illustrada europeaamericana, dite Espasa: 48

Encyclopedia Britannica: 48, 52, 220

Engelhus (Dietrich ou Thierry): 98

$\rightarrow$ Chronica: 98

$\rightarrow$ Promptus: 98

Ennius : 370

Enoch: 133 (n. 35)

Enseignement d'un père à son fils: 407

Entsiklopetitcheskeii Slovar: 48

Épicrate: 254

Érasme: 14 (n. 12), 42-43

$\rightarrow$ Éloge de la folie: 43

Érotien : 214, 247 (n. 5)

Ersch (Johann Samuel) / Gruber (Johann Gottfried): 48

$\rightarrow$ Allgemeine Encyclopädie der Wissenschaft und Künste: 48

Eschine: 254

Eschyle: 249

Estienne (Robert) : 239

Étienne de Bourbon: 292 (n. 81), 294-295 (n. 97), 353, 361

$\rightarrow$ Tractatus de diversis materiis pradicabilibus : 294-295, 353

Eucher de Lyon: 260, 295 (n. 100), 407

Euclide: 307,314 $\rightarrow$ Section du canon: 307

Eucrate l'Alouette : 253

Eugène de Tolède : 267

Eumée: 248 (n. 13)

Eusèbe de Césarée : 247, 365

$\rightarrow$ Onomasticon: 247

Eustathe, fils de Macrobe: 372

Eutrope : 260

$\rightarrow$ Abrégé de l'Histoire romaine: 260

Évandre: 284

Ève: 120 (n. 52)

Évrard de Béthune: 280 (n. 17), 290-291 (n. 75), 297

$\rightarrow$ Gracismus: 290, 297

Évrart de Conti: 350

\section{F}

Favonius Eulogius: 308-309, 311

Favorinus d'Arles: 221-222, 226-227, 378-379

Ferrières (Henri de) : 407

$\rightarrow$ Livre du roi Modius et de la royne Ratio: 407

Festus, le grammairien : 214, 224-225, $227-$ 230, 286 (n. 40)

Flaviens: 165

Flavius-Josèphe : 132

Folsham (Pseudo-John) : 94 (n. 42)

Fournival (Richard de) : 197

Frédéric II de Hohenstaufen, empereur germanique: 103, 407, 423

Frères de la Pureté (Ikhwân al-Safâ): 35-37, 50, 201

$\rightarrow$ Épîtres des Frères de la Pureté (Rasâ'il al-Ikhwân al-Safâ): 35-37, 142, 201

$\rightarrow$ Épître compréhensive (Al risala al-djami'a) : 37

Fronton : 371

Fulgence de Ruspe: 227, 260

Furetière (Antoine) : 239-241 (n. 34)

$\rightarrow$ Dictionnaire universel: 239-240

\section{G}

Gabriel, archange : 37

Ğāhiz: 211

Ğāhiz (pseudo-): 202

$\rightarrow$ Livre de l'avertissement: 202

Galien: 56, 214

Gaudence : 307, 314-315

Gellius (Cnaius) : 372 
Gérard de Crémone : 90 (n. 29)

Gerson (Jean) : 407, 410 (n. 9), 427

$\rightarrow$ La Mendicité spirituelle: 407

Gervais de Tilbury: 91, 354

$\rightarrow$ Otia imperalia: 91,354

Gesner (Conrad) : 213

Gil de Zamora (Juan) : 90, 98

$\rightarrow$ Historia naturalis: 90,98

Glossarium Salomonis : 260

Glosulce: 271

Godefroi de Bouillon : 126 (n. 5)

Gossuin de Metz: 95, 187-189, 191, 195196, 198-200, 302, 335, 338, 341, 345-346, 382-383 (n. 11), 393, 395, 397, 412, 424

$\rightarrow$ Image du monde (I.du M.): 95, 189, 191, 196, 198, 302, 335-336, 338-339, 341, 344-348, $367,382,393-394,399-400,424$

Gratien : 135

$\rightarrow$ Décret: 135

Grégoire le Grand: 131 (n. 26), 170, 180, 192, 260

$\rightarrow$ Dialogi: 260

$\rightarrow$ Moralia: 260

Grégoire IX, pape: 133 (n. 34)

Grégoire de Montesacro: 91-92

$\rightarrow$ De hominum deificatione: $91-92$

Grégoire de Nazianze: 170

Gruber (Johann Gottfried) voir Ersch

Guibert de Nogent : 168

Guillaume de Conches: 92, 115, 142, 167, 171, 175-177, 182-183, 187, 382-383 (n. 6, 11), 394 (n. 55)

$\rightarrow$ Dragmaticon philosophia: 115, 175-176, 182-183

$\rightarrow$ Philosophia mundi: 92, 167, 175-176, 187

Guillaume de Malmesbury: 134 (n. 38)

Guillaume le Breton: 277-278, 292 (n. 81), 295-296 (n. 98, 101)

$\rightarrow$ Expositiones vocabulorum Biblie: 277

Gujin tushu jicheng (Compilation des images et des écrits anciens et récents): 332

\section{H}

Halberstadt (Konrad von): 99 (n. 59), 104

$\rightarrow$ Liber similitudinem naturalium: 104

Han, empereurs de Chine : 323-324

Harpocration: 257

Hautfuney (Jean de) : 358
Hegel (Georg Friedrich Wilhelm): 21, 33

Hégésippe: 255

Hélinand de Froidmont: 125 (n. 2), 137

$\rightarrow$ Chronicon: 137

Helpéric : 200

Henricus de Schüttenhoffen: 101

$\rightarrow$ Liber de naturis animalium cum moralitatibus: 101

Henri de Gand: 354

Henri de Herford : 31, 108, 110-111, 114-118, 121-122

$\rightarrow$ Catena aurea entium: 108, 111, 114-116, 118

Henri de Langenstein: 31, 108, 117-120, 122

$\rightarrow$ Lecturce super Genesim: 108, 117-120

Henri d'Oyta: 117

Héracléon: 246 (n. 4)

Héraclide de Mopse : 256

Héraclide du Pont: 256

Héraclite: 58 (n. 7)

Hermann de Carinthie: 197

Hermeneumata Einsidlensia : 292

Hermippe le comique : 256

Hérodique de Babylone: 257

Hérodote : 149

Herrade de Landsberg : 101

$\rightarrow$ Hortus deliciarum: 101

Hésiode : 57 (n. 5)

Hésychius : 248

Hilaire de Poitiers : 260

Hildegarde de Bingen : 94, 102

$\rightarrow$ Physica: 94, 102

Hipparque: 191

Hippias: 58 (n. 7)

Hippocrate: 56, 60 (n. 13)

$\rightarrow$ Du régime: 163

Historia Brittonum: 134

Homère : 57, 248, 250-251, 254

$\rightarrow$ Iliade: 11.636-637: 249

$\rightarrow$ Iliade: $21.353: 250$

Honorius Augustodunensis: 91-92, 95, 128, 130, 142, 167, 171-174, 198, 291 (n. 78), 383 (n. 11), 385 (n. 18), 407, 420

$\rightarrow$ Hexcemeron ou Neocosmos: 172, 174

$\rightarrow$ Imago mundi: 91, 92, 95, 128, 130, 167, 171174, 198

$\rightarrow$ Élucidaire: 172, 420, 424

Hualin pianlïe (Abrégé de l'ensemble [des livres de la bibliothèque] de la Forêt des fleurs): 325 
Huanglan (Miroir de l'empereur): 323-326

Hucbald de Saint-Amand: 318- 320

$\rightarrow$ Traité de musique: 318

Hugues d'Amiens : 169

Hugues de Fleury: 132, 134

$\rightarrow$ Histoire ecclésiastique: 134

Hugues de Fouilloy voir Hugues de SaintVictor (pseudo-)

Hugues de Saint-Cher: 84

Hugues de Saint-Victor: 17, 22, 41, 87-88, 92-93, 97, 129 (n. 17), 132, 134-135, 137 $138,167,169,341$ (n. 19)

$\rightarrow$ Chronicon: 132

$\rightarrow$ De sacramentis christiance fide: 137, 167, 169

$\rightarrow$ Descriptio mappe mundi: 132

$\rightarrow$ De tribus maximis circumstantiis gestorum: 137

$\rightarrow$ Didascalicon: $17,22,87-89,93,135,138$

$\rightarrow$ Dragmaticon: 92

Hugues de Saint-Victor (pseudo-) [Hugues de Fouilloy] : 286

$\rightarrow$ De bestiis et aliis rebus: 286

Hugutio de Pise: 135, 216, 227, 267, 274275, 277-278, 280-281 (n. 17), 283-291 (n. 75), 293-297

$\rightarrow$ De dubio accentu: $289-290$

$\rightarrow$ Liber derivationum ou Derivationes: 135, 267, 275, 285-290, 293-295

Hygin : 378

\section{I}

Ibn Abd Rabbih: 36

$\rightarrow$ Collier: 36

Ibn al-'Arabī: 202

Ibn al-Wardī : 209

Ibn Baytār: 211

Ibn Shabīb al-Harrānī: 208

Isidore de Séville: 14, 18-20, 24, 26-27, 39, $55,82,87-89,91,93,96,110,116,118,130-$ 132, 134-136, 141, 169, 180, 189, 192, 194, 196, 198, 213, 215-216, 224, 226-227, 234, 236, 259, 261-263, 265, 272, 276-280 (n. 2, 3, 13), 283-284 (n. 38), 286-292, (n. 60, 63), 294-295, 299-301, 309, 314-315, 322

$\rightarrow$ De natura rerum: 82, 91, 141, 196, 259

$\rightarrow$ Differentia: : 259, 295-296

$\rightarrow$ Étymologies ou Origines: 20, 27, 82, 87, 93-95, 116, 118, 130-131, 134-136, 189, 194,
$213,215,224,234,236,259,261,263,265-$ 266, 274, 277-278, 283, 290, 300, 309, 315

$\rightarrow$ Liber officiorum: 259

$\rightarrow$ Libri de ortu et orbitum patrum : 259

Isocrate : 14

Iunilius Africanus : 407

\section{$\mathbf{J}$}

Jacob : 189

Jacques de Lausanne: 104

$\rightarrow$ Compendium moralitatum: 104

Jacques de Vitry: 94, 167

Jacques de Voragine : 41

$\rightarrow$ Légende dorée: 41

Jamblique: 311

$\rightarrow$ In Nicomachi Arithmeticam introductionem: 311

Japhet: 422

Jean (Prêtre) : 126 (n. 5)

Jean de Capoue : 418 (n. 8)

Jean de Garlande : 231-232, 280 (n. 17), 288, 293, 296

$\rightarrow$ Ars lectoria Ecclesie: 288, 293

$\rightarrow$ Compendium Gramatice: 296

Jean de Gênes voir Balbi (Giovanni)

Jean de la Rochelle: 87

Jean de Meung : 41

$\rightarrow$ Roman de la Rose: 41

Jean de Saint-Laurent de Liège: 99 (n. 59)

Jean de Saint-Victor: 31-32, 87 (n. 21), 98, 125-126, 128-138

$\rightarrow$ Memoriale historiarum 32, 98, 125-138

$\rightarrow$ Tractatus de origine et divisione regnorum: 127-128, 135

Jean de Salisbury: 86 (n. 20), 188, 277 (n. 5)

Jean de San Giminiano: 99 (n. 59), 101

$\rightarrow$ Liber de exemplis et similitudinibus rerum: 101

Jean de Séville: 197

Jérôme: 118, 121, 131, 134, 259, 295 (n. 100), 360 (n. 23)

$\rightarrow$ Contra Jovinianum: 131

$\rightarrow$ Liber de situ et nominibus locorum hebraicorum: 131, 134

$\rightarrow$ Quastiones Hebraica in genesim: 131, 134, 260

Jésus Christ: 203, 356, 360, 362, 423, 425, 427

Jésus Sirach: 405, 418

Jia Sixie : 333 
Qimin yaoshu (Techniques essentielles pour la population) : 333

Jin, empereurs chinois : 324

Johannes Hispalensis : 404

Jujia biyong shilei quanji (Les affaires indispensables à la maison en version intégrale): 333

Jupiter: 284 (n. 37), 316

Justin (pseudo-) : 365

Juvénal : 131

\section{$\mathbf{K}$}

Kalila et Dimna : 418-419

Kant (Emmanuel): 46

Kelu (Catalogue des spécialités): 325

K'ien Long, empereur: 35

Kilwardby (Robert) : 22

$\rightarrow$ De ortu scientiarum (DOS): 22

Krishna: 41

$\mathbf{L}$

Laban: 131 (n. 24)

Lactance: 282 (n. 27)

Lactantius Placidus: 291 (n. 79)

Laîs : 372

Lambert de Saint-Omer: 100

$\rightarrow$ Liber floridus: 100

Langton (Étienne) : 133, 181

Lardner (Dionysius) : 48

$\rightarrow$ Encyclopédie (Cabinet cyclopaedia) $: 48$

Latini (Brunetto): 20, 93, 100, 102, 121-122 (n. 55), 131, 188, 190, 194-196, 198-200, $302,335,337,339,341-342,382-383$ (n. 11), 393-397, 403, 411, 416 (n. 3, 4), 421 (n. 13)

$\rightarrow$ Livre du Trésor (Li livre dou Tresor) (L. du T.) : 20, 93, 100, 102, 131, 188, 194, 199200, 302, 335, 337-339, 341-342, 344, 346, $348,367,382,393-394,396,399-400,411$

Laure: 361

Leibniz (Gottfried Wilhelm) : 45

Leiyuan (le Jardin des catégories) : 325

Li Jie : 333

$\rightarrow$ Yingzao fashi: 333

Liber glossarum (LG): 216, 232, 259-274, 277, 291, 296

Li Fang: 35 $\rightarrow$ Encyclopédie de l'ère T'ai P'ing (T'ai P'ing Yu Lan): 35

Liu Shao: 324

Livius Larensis : 245

Livre de Sydrac le philosophe ou La Fontaine de toutes sciences (Syd.): 115, 193, 195196, 200, 302, 335, 337-338, 340, 343$344,346,348,367-368,382-385,388,400$, 403-413, 415-427

Louis IX (Saint Louis) : 42, 405

Lu Ban jing (Livre de Lu Ban): 333

Lucilius : 226

$\rightarrow$ Saturarum (Sat.): 226

Lucrèce: 161

$\rightarrow$ De natura rerum: 161

Lupercus : 282-285

Lulle (Raymond) : 407

Lumen anime : 104

Lycæus, épithète de Zeus : 284 (n. 37)

Lyncée de Samos : 253-254

Lysias : 378

\section{M}

Ma Duanlin: 331 (n. 16)

Machaut (Guillaume de) : 353

Macrobe: 17 (n. 21), 187, 227, 308-309, 311, 366-367, 369-375, 378-379

$\rightarrow$ Miscellanea $: 366$

$\rightarrow$ Saturnales (Sat.): 367, 369-373, 375-376, 378

$\rightarrow$ Sat. Praf. 3: 374

$\rightarrow$ Sat. 5.1.7: 371

$\rightarrow$ Sat. 6.9.9: 370

Macrologus : 104

Maerlant (Jacob van) : 95-96

$\rightarrow$ Naturen Blumen: 96

Maffei (Raffaello): 237

Mahabharata: 41

Mahomet: 36

Major (frères, éditeurs) : 334

Mamun: 37

Marc d'Orvieto: 99 (n. 59), 101, 351 (n. 10)

$\rightarrow$ Proprietates rerum moralisate: 101

$\rightarrow$ Tractatus septiformis de moralitatibus rerum: 101

Mardouk : 38

Marie (la Vierge): 179

Marius Victorinus : 286 (n. 40) 
Martianus Capella: 14, 40-41, 88, 130, 192, 235, 243, 301, 309-310, 313, 316-322, 354

$\rightarrow$ Noces de Philologie et de Mercure: 40, 130, 235, 309, 311, 313, 354

Martini (Simone): 362

Martyrius : 225

Masha'allah ibn Athari al-Basri (Misalath): 196

Matrān Fāris (Yasū ?) : 202

Medicina Plinii : 156

Mélanthios d'Athènes : 246

Ménandre: 253

Merlin : 418, 425

Métagène: 252 (n. 17)

Méthode d'Olympe : 132

Métrobe : 255

Meydenbach (Jacob von) : 102

$\rightarrow$ Hortus sanitatis: 90, 98, 102

Mézières (Philippe de): 189

Michel d'Éphèse : 79 (n. 64)

Mnaséas de Patres : 246

Moïse : 127, 129 (n. 18), 173

Montaigne (Michel de) : 379

$\rightarrow$ Essais: 379

Moralisacium avium et quadrupedum : 101

Moschion : 253

Muhammad ibn Qalawūn: 210

Multifarium: 101

Muses: 62 (n. 22)

Musici scriptores graeci: 307

Mutianus : 315

\section{$\mathbf{N}$}

Nabû: 38

Nabuchodonosor: 418

Neckam (Alexandre): 22 (n. 36), 89, 91-92, 95-96, 110, 141-142, 168, 171, 177, 179180, 182-184, 188, 191, 193, 198

$\rightarrow$ De naturis rerum: 89, 92, 141-142, 167, 171, 177-180, 183, 188, 191

Néoptolème de Parium: 248

Nestor: 248-249

New International Encyclopadia (The): 48

Nicandre de Colophon: 246 (n. 4)

Nicandre de Thyateires: 246 (n. 4)

Nicolas de Cues: 111 (n. 23)

Nicolas de Damas: 70 (n. 47)

Nicolas de Lyre: 118 $\rightarrow$ Postilla: 118

Nicolas de Strasbourg: 116

$\rightarrow$ Summa: 116

Nicomaque de Gérasa: 307, 311

$\rightarrow$ Manuel d'harmonique: 307

Noé : 415-416, 419, 422

Nonnius Marcellus : 227

Numa Pompilius : 230

Nuwayrī (Al-): 210, 212

$\rightarrow$ Nihāyat al-arab fì funūn al-adab (Les éléments les plus précieux dans diverses branches du savoir): 210

\section{$\mathbf{O}$}

Opicinus de Canistris : 350,363

Oresme (Nicole): 120, 189

Origène: $17,39,365$

$\rightarrow$ Lettres à Grégoire: 17

Orose: 131, 170, 260, 356

$\rightarrow$ De Ormesta mundi: 131

$\rightarrow$ Histoires contre les païens: 260

Osbern de Gloucester: 227, 274-275, 277278, 281 (n. 23), 284-287, 289 (n. 64), 294, 296-297

$\rightarrow$ Panormia ou Derivationes: 275, 285-286, 296

Otton IV de Brunswick: 91

Ovide: 131, 290, 302, 349 (n. 4), 350, 358, 361

$\rightarrow$ Métamorphoses: 349

Ovide (pseudo-) : 197

$\rightarrow$ De vetula: 197

\section{$\mathbf{P}$}

Pamphile d'Alexandrie: 246 (n. 4)

Pan, dieu gréco-latin: 282-284

Panckoucke (Charles-Joseph) : 242-243, 334

$\rightarrow$ Encyclopédie méthodique ou par ordre de matières: 242

Papias: 215-216, 220, 224, 227, 232-235, 260, 272-275, 277-278, 281-288, 290-293, 295-297 (n. 98)

$\rightarrow$ Ars grammatica: 293

$\rightarrow$ Elementarium doctrince rudimentum ou Vocabularium: 215-216, 233, 260, 272-275, 277, 282, 285-286, 290-291

Parrot (Georg Friedrich) : 402 (n. 86, 88, 89)

Paul: 174 
Paul, personnage du Liber glossarium: 262

Perotti (Niccolò) : 237

Pétrarque : $350,361,363$

$\rightarrow$ Canzoniere: 361

Phaïstos : 255

Philémon d'Athènes: 246 (n. 4)

Philippus Tripolitanus : 404

Philitas de Cos: 246 (n. 4)

Philolaos : 304

Philon : 14,17

$\rightarrow$ De congressu: 17

Philopon (Jean): 72 (n. 51)

Philoxène Pique-Jambon : 253

Phocas: 266, 282 (n. 26)

Photios : 41, 215

$\rightarrow$ La Bibliothèque: 41

$\rightarrow$ Lexicon: 215

Pic de la Mirandole (Jean): 42-43, 59 (n. 11)

Pierre le Chantre (Petrus Cantor): 181, 294 (n. 96)

Pierre le Mangeur: 121, 132, 181, 353

$\rightarrow$ Histoire ecclésiastique: 353

$\rightarrow$ Historia scolastica: 132

Pierre Hélie: 279, 280-281 (n. 21, 23), 289

$\rightarrow$ Summa super Priscianum: 279

Pierre Lombard: 132, 167

$\rightarrow$ Livre des Sentences: 132, 167

Pierre de Lyon (Jehan) : 423

Pindare: 379

Placide: 260, 282

$\rightarrow$ Glossaire: 260, 282-283

Placides: $337,339,340,384-386,389-393$

(n. 50), 395-396 (n. 60), 400 (n. 78)

Placides et Timéo ou Li secrés as philosophes: 102, 188, 192, 302, 335, 337-341, 343-344, $348,367,382,384-392,395-399,407$

Platon: 14, 56, 58 (n. 7), 62-63 (n. 22, 23), 66-68, 72-73 (n. 52, 53), 113, 160-161, $177,182,198,320$ (n. 34), 378

$\rightarrow$ Timée : 182, 192, 304, 311

Platon le comique : 255

Pline l'Ancien: 15, 23 (n. 39), 26-27, 39, 56, $59,87,94,116,118,131,139-141,145-$ $166,235,307,375,377$

$\rightarrow$ Continuation d'Aufidius Bassus : 149

$\rightarrow$ Guerres de Germanie: 149

$\rightarrow$ Histoire naturelle $(H N): 39,59,87,94,116$, 118, 139-141, 145-147, 149-152, 154-155, 157-158, 160-161, 165-166, 235, 307 $\rightarrow H N$, praf. $1: 148$

$\rightarrow$ HN, praf. 13: 148

$\rightarrow$ HN, praf. $14: 147-148$

$\rightarrow$ HN, praf. 17: 149

$\rightarrow H N$, praf. $25: 149$

$\rightarrow H N 2.166: 164$

$\rightarrow H N 3.39: 165$

$\rightarrow H N$ 7.6: 163-164

$\rightarrow H N$ 8.13: 152

$\rightarrow H N$ 9.16: 152

$\rightarrow H N$ 9.17: 152-153

$\rightarrow H N 9.18: 153$

$\rightarrow H N 9.19: 153$

$\rightarrow H N$ 9.166: 152

$\rightarrow$ HN 11.6: 159

$\rightarrow H N$ 11.8: 145, 159

$\rightarrow H N$ 18.67: 164

$\rightarrow$ HN 20.1 : 162

$\rightarrow H N$ 22.106: 162

$\rightarrow H N$ 22.117: 162

$\rightarrow H N$ 24.1: 155, 164

$\rightarrow$ HN $27.2: 163$

$\rightarrow$ HN 29, index: $17: 164$

$\rightarrow$ HN 33.3: 159

$\rightarrow H N 37.60: 164$

$\rightarrow H N$ 37.186: 157-158

$\rightarrow H N 37.201: 165$

Pline le Jeune: 149 (n. 20), 371

Plutarque: 56 (n. 1), 256, 282 (n. 27), 366

$\rightarrow$ Propos de table: 366

Polemius Silvius : 267

Polémon le périégète: 256

Politien (Ange): 13

Pollux : 214, 246, 248, 252

$\rightarrow$ Onomasticon: 214

Pomponius Mela: 131

$\rightarrow$ De situ orbis terrarum: 131

Pôros, roi indien: 126 (n. 5)

Porphyre: 310

$\rightarrow$ De regressu anima : 310

Posidonios: 22, 38, 58 (n. 10), 77 (n. 60), 147, 187

Priscien de Césarée : 216, 260, 262, 268-273, 278-280 (n. 16, 17), 282 (n. 26), 288-289, 291-293 (n. 75)

$\rightarrow$ Institutiones grammatica $: 260,262,268-271$, 273, 292

Probe: 292

$\rightarrow$ Catholica: 292 
Prophécies Merlin: 407, 418

Ptolémée II Philadelphe: 249

Ptolémée (Claude) : 87, 191, 193-194, 198, 306-307, 314

$\rightarrow$ Almageste: 194, 198-199

$\rightarrow$ Harmoniques: $306-307$

Pythagore: 67, 304, 322

\section{Q}

Qianlong, empereur de Chine: 333

Quastiones salernitana: 115

Quintilien: 14, 17, 83, 148, 224-225, 237-238

(n. 28, 29), 287, 307, 413

$\rightarrow$ Institution oratoire $17,287,307,413-414$

Quod: 261-264, 266

\section{$\mathbf{R}$}

Raban Maur: 16, 19, 20, 55, 75, 89, 91, 95-96, 141, 180, 190, 282 (n. 26), 286, 290-291 (n. 73, 78), 360 (n. 23), 407

$\rightarrow$ De naturis rerum: $95,141,190$

$\rightarrow$ De universo: 89, 91, 286

Rabelais (François): 13, 43, 247

$\rightarrow$ Quart-Livre: 247

Rainaud de Saint-Éloi: 142, 169-172, 174, 180-181, 184

Remi d'Auxerre: 284 (n. 38), 291 (n. 81), 421-422 (n. 15)

Rémus : 282 (n. 27)

Ricci (Matteo) : 331

$\rightarrow$ Yudi shandai quantu (Carte complète des monts et des mers de la Terre) : 331

Richard de Saint-Victor: 87, 97, 132, 136

$\rightarrow$ Liber exceptionum: 87, 132, 136

Richelet (Pierre) : 239

$\rightarrow$ Dictionnaire françois, contenant generalement tous les mots et plusieurs remarques sur la langue françoise [...] : 239

Ripelin de Strasbourg (Hugo) : 109

Rohault (Jacques): 402 (n. 86, 87)

Roman d'Eneas: 187

Roman de Thèbes: 187

Romulus : 282 (n. 27)

Rousseau (Jean-Jacques) : 140

Rufius Albinus : 370

Rupert de Deutz: 169

\section{S}

Sacrobosco (Jean de): 116, 199

$\rightarrow$ De Sphara: 116, 199

Sade (marquis de) : 41

Salluste : 371

Salomon : 40

Scalich (Paul): 11 (n. 1), 238

$\rightarrow$ Encyclopadia seu orbis disciplinarum: 238

Scipion l'Africain: 187

Scipion Émilien : 308

Scot (Michel) : 103

$\rightarrow$ Liber introductorius: 103

Scribonius Largus : 154-156

$\rightarrow$ Compositiones: 154

Sedulius Scottus : 291 (n. 81)

Seguin : 292, 295-296 (n. 100)

$\rightarrow$ Ars lectoria : 293, 297

Séleucos d'Alexandrie: 246 (n. 4)

Sénèque: 14, 131, 148, 196, 376

$\rightarrow$ Lettre à Lucilius: 376

$\rightarrow$ Qucestiones naturales: 196

Sergius : 264

Servius : 226, 282-284 (n. 27), 290-292 (n. 82), 370

$\rightarrow$ Commentaire sur l'Énéide: 226, 283-284, 290

Shadrach: 418

Shanhai jing (Livre des monts et des mers): 332

Shengshou tang yulan (Ce qu'a examiné l'empereur dans la salle de la Longévité sainte): 325

Shouguang shuyan (le Jardin des livres $d u$ palais de l'éternelle splendeur) : 325

Shutu quanhai (Les sources et la mer des écrits et des images): 325

Siderocrates (Samuel) : 103

$\rightarrow$ Cyclopadia Paracelsica Christiana: 103

Sidrach: 418

Sigebert de Gembloux : 134

Simariste : 248

$\rightarrow$ Synonymes: 248

Simias de Rhodes: 246 (n. 4)

Simon de Hinton: 119

Simplicius: 62 (n. 19), 72 (n. 51)

Sindonius (sic): 267

Sisebut: 20 (n. 30)

Socrate: 72, 255, 320 (n. 34), 378

Solin : 131 
$\rightarrow$ Mirabilia mundi: 131

Song Yingxing : 333

$\rightarrow$ Tiangong kaiwu (L'exploitation des cuvres de (a nature): 333

Sosibios: $249-250$

Souda (Le Rempart) : 41, 215, 248

Speusippe: 38,58

Sseu K'ou K'iuan chou (Collection complète des quatre dépôts $): 35$

Strabon: 17, 26, 56 (n. 2), 68, 72 (n. 51)

$\rightarrow$ Géographie: 17, 69

Suétone : 22, 149, 224-225, 231, 261, 267-268

$\rightarrow$ De Grammaticis (Gramm.): 224, 231

$\rightarrow$ Prata: 261, 267

Sulpicius Rufus (Servius): 229

Summarium Heinrici: 260

Sunesen (Andreas) : 181, 185

$\rightarrow$ Hexcemeron: 181

Sydonius (sic): 267

Sydrac: 193, 195, 337, 340, 343, 346, 368, 386 (n. 21), 403-404, 408-409, 416-419, 421-422, 424-427

Symmaque : 371

Synonyma Ciceronis : 260

\section{$\mathbf{T}$}

Tabarī (Muhammad b. Ayyūb) : 203 (n. 4)

Taiping yulan (Ce qu'a examiné l'empereur à l'ère de la grande paix): 329-330

Taizong (Tai Tsong): 35, 325 (n. 5), 329-330

Tertullien: 295 (n. 100)

Thalès: 57 (n. 6)

Théodore d'Antioche: 423

Théophraste : 38, 56, 66, 77, 146, 148-152 (n. 16), 156-157

$\rightarrow$ Recherches sur les plantes $(H P): 156$

$\rightarrow H P: 1.1: 156$

Théopompe le comique: 256

Thierry de Chartres: 142, 171, 175-177, 183

$\rightarrow$ Traité sur l'œuvre des six jours (De sex dierum operibus): 176

Thomas d'Aquin: 42, 75, 87, 93 (n. 38, 39), 110-111, 113-114, 116, 120, 189, 199, 361, 403

$\rightarrow$ Somme: 42

Thomas de Cantimpré: 14, 20, 31, 55, 75, 81, 83 (n. 11, 12), 89-90, 95-98, 104, 108 (n. 9), 110, 141, 188, 354 (n. 16) $\rightarrow$ Liber de natura rerum: 20, 55, 81, 89, 95, 98, 104, 141

$\rightarrow$ Thomas III: 89

Thomas Gallus (Thomas de Saint-Victor): 133

Tian Xi : 325 (n. 5)

Tibère: 154

Timachidas: 246 (n. 4)

Timée : 247 (n. 5)

Timéo: 337, 340, 384, 386-393 (n. 37, 50), 395-396, 398, 400 (n. 78)

Timocle : 252

Timocrate: 252

Tite-Live: 149, 282 (n. 27), 349

$\rightarrow$ Décades: 349

Titus: 39, 148, 165

Trevisa (John) : 101

Tryphon d'Alexandrie: 246 (n. 4), 249 (n. 16), 251

Tristan: 42

Tuhfat al-ğă'ib wa-turfat al-garā'ib (Le don des merveilles et le cadeau des étrangetés): 208-209, 211

Tūsī Salmānī (Muhammad b. Mahmūd b. Ahmad) : 203-204

$\rightarrow$ Les merveilles des choses créées et les faits miraculeux des choses existantes ('A $\breve{g} a$ ' $i b$ al-mahlūqāt wa-garā'ib al-mawğūdāt) : 203

\section{$\mathbf{U}$}

Ulpien : 256, 257

Ulysse: 248 (n. 13)

\section{V}

Valère Maxime: 131

$\rightarrow$ Facta et dicta mirabilia antiquorum: 131

Valla (Lorenzo) : 237

Varron: 14 (n. 14), 22, 38, 58 (n. 10), 87, 96, 147, 149, 214, 222, 224-226, 235, 243, 280 (n. 19), 284 (n. 37), 287, 307, 311, 313, 378

$\rightarrow$ Antiquitates rerum humanarum et divinarum: 39, 149

$\rightarrow$ De lingua latina $(L L): 214,224$

$\rightarrow$ Disciplina: 39

$\rightarrow$ Disciplinarum libri: 235, 307

Veda: 34

Végèce: 131

Velius Longus : 287 (n. 54) 
Verrius Flaccus : 215, 222, 227-231

Villon (François) : 353

Vincent de Beauvais: 14-15, 20, 24, 31-32, 42, 60, 75-77 (n. 62), 81, 84-85, 88, 90-93, $95-98,100,110,117,119-122,125,128-$ 131, 137-138, 167-168 (n. 6), 187-188, 195, 300, 309, 358, 361, 403, 405

$\rightarrow$ De scientiis et artibus homini datis ob miserice remedium: 188

$\rightarrow$ Libellus apologeticus $(V B, L A): 15,20,60,84$

$\rightarrow V B, L A$, c. $1: 85$

$\rightarrow V B, L A$, c. $3: 90,91,96$

$\rightarrow V B, L A c .4: 100$

$\rightarrow V B, L A, c .6: 85$

$\rightarrow V B, L A, c .7: 86-88$

$\rightarrow V B, L A, c .8: 87$

$\rightarrow V B, L A, c .11: 85,88,90$

$\rightarrow V B, L A, c .16: 90$

$\rightarrow V B, L A$, c. 17: 90, 97

$\rightarrow$ Speculum doctrinale: 93,97

$\rightarrow$ Speculum historiale: 97-98, 128, 130-131, 358

$\rightarrow$ Speculum majus: $32,42,81,84,88,91,98$, 117, 125, 128-131, 137, 187, 405

$\rightarrow$ Speculum morale: 98

$\rightarrow$ Speculum naturale: 91-92, 97, 119, 122, 128, 188

Vinci (Léonard de) : 42-43

Virgile: 170, 223, 260, 262, 282 (n. 26), 370371, 378-379

Virgilius Maro grammaticus: 227 (n. 21)

Vitruve: 16, 22-23 (n. 39), 26, 39, 60 (n. 12), 68, 148, 160-161, 235, 303-304, 307-308, 311

$\rightarrow$ De architectura: 16, 39, 60 (n. 12), 68, 235, 303

Voltaire : 242

Vulgate : 418

\section{W}

Walafrid Strabon: 118, 361 (n. 25)

$\rightarrow$ Glosa ordinaria : 118, 361

Wang Huisi : 331

Wang Qi : 331

$\rightarrow$ Sancai tuhui (Les dessins des trois puissances de l'univers): 331-332

Wang Xiang: 324

Wang Yinglin: 331 $\rightarrow$ Yuhai (La Mer des jades): 331

Wensi boyao (L'essentiel des lettres et des idées): 330

Wenyuan yinghua (Florilège du jardin des lettres) : 329

Wowern (Johann van): 238

$\rightarrow$ De polymathia tractatio: 238

\section{$\mathbf{X}$}

Xanthippe: 255

Xiuwen dian yulan (Ce que l'empereur a examiné au palais de la Culture des lettres) : 325-326, 330

Xun Xu: 324

\section{$\mathbf{Y}$}

Yao Kuang-hsiao: 35

Yaolu (Listes essentielles) : 325

Yiwen leiju (Collection par catégories d'ouvres littéraires) : 329-330

Yu Shinan: 326

$\rightarrow$ Beitang shuchao (Extraits des livres de la salle du Nord) : 301, 325-329, 332

Yun chi ch'i ch'ien (Casier de livres aux nuages et sept bandes de bambous) : 35

Yung Cheng (Yongzheng) : 35, 333

Yung-le (Yongle), nom de règne de Cheng Tsu (Chengzu) : 35, 332

$\rightarrow$ Yongle dadian (Grands documents de l'ère de la Joie éternelle ou Grand dictionnaire de Yung-le): 35

Yunji qiqian (Bibliothèque des nuages aux sept étiquettes) : 330

\section{Z}

Zerclaere (Thomasin von): 188

$\rightarrow$ Welsche Gast : 188

Zhang Huang: 331

$\rightarrow$ Tushu bian (Compilation des images et des écrits): 331

Zhang Junfang: 330

Zhenzhong: 329

Zhu Mu: 331

$\rightarrow$ Gujin shiwen leiju (Collection par catégories de faits et de textes anciens et récents): 331

Zola (Émile) : 49 


\title{
INDEX RERUM
}

\author{
par GUILlAUME CLAMENS
}

\section{A}

Agriculture: 136, 332-333

Allégorie: 97, 216, 280, 313, 420

Aristotélisme: 55, 66, 77, 92

Artes lectoria: : 287, 292-293

Artes liberales: 14, 142

Astrologie : 103, 112-113, 120, 189-190, 194198, 404, 409-411 (n. 9), 413, 422 (n. 16)

Astronomie: 14, 38-39, 41, 55, 58 (n. 9), 68-69 (n. 41, 44), 101 (n. 70), 103, 112113,116 (n. 37), 142, 167, 187-192, 195196, 198-200, 211, 309, 311, 347-348, 422

Auctoritates : 28, 32, 86-87, 89, 111-114, 117$118,120-121,129-130,133,152,171-172$, 192, 221-223, 229, 244, 287, 303, 312, 314,318

\section{B}

Banquet: 215, 245-246, 250, 252, 254-256, 369-371

Bible: 24 (n. 42), 32, 34, 36, 39-40, 84, 86, 88-89, 108, 119-120, 131, 133, 141, 174, 176-177, 179-180, 182-184, 236, 302, 337, 349-350 (n. 4), 352, 358-359, 361, 419

Bibliothèque: 24, 26, 34-35, 37-38, 42, 45 (n. 22), 48-50, 56 (n. 2), 63 (n. 23), 86, 88, 101 (n. 63), 104, 106, 109, 113, 126, 131-133, $149,260,262,274,310,314,323-326,329$, 349-351 (n. 5, 6, 9), 358 (n. 20), 373, 411

Botanique: 83, 102, 149, 151, 156-157 (n. 2), 201

\section{C}

Carte: 44, 132, 172, 324, 331, 363

Catalogue: 27, 103 (n. 74), 215, 246-248, 250, 252, 254-256, 323-325, 329, 333, 343, $348,370,383,406,425$ (n. 20)
Catégories: 11, 26, 31, 35, 57-59 (n. 7), 70, 89, 94, 100-101, 104, 107, 133, 139, 146, $148,150,156,166,192-194,196,206$, 209, 218, 227, 235, 241, 270, 274, 289, 301, 323-326, 328-334, 345, 354, 382, 396, 404, 406-407

Cercle (des savoirs) : 14, 36, 40, 44, 50, 148, 213, 238, 423

Commentaire (biblique): $32,89,108,117-$ 119, 121-122, 131, 134, 137, 141-142, 167175, 177-181, 184, 190-192, 199, 226 (n. 19), 349-350 (n. 4), 352, 360

Compilation: 20, 24, 26, 35, 67, 84-86, 89, 90, 102, 104-105, 109-111, 116-117, $122-$ $123,126,129-130,135,139,141,170$, 197, 202, 209, 211-212, 214-215, 218, 221222, 225-227, 232, 243, 246, 257, 261 (n. 12), 299, 301-304, 312-315, 317, 322, 329 , 331-332, 338, 340 (n. 18), 369, 373, 375, 386 (n. 23), 403, 404

Composition: 21, 67 (n. 35), 74, 93 (n. 38), 132 (n. 32), 139, 162, 205, 226 (n. 18), 245 (n. 2), 279, 323, 327-328, 339-340, 369, 373- 376, 379

Conversation: 246, 255, 366-367, 369-371, $379,381,388,393$ (n. 52), 398, 403, 407 409, 413-414, 420

Cosmologie: 113, 157 (n. 52), 161, 164, 166, 171, 187, 190-191

Création (du monde): 32, 42, 91-92, 97, 101, 117-119, 127, 128, 135, 138, 141, 167-169, 174-176, 178, 182, 190, 193, 203, 207, $210,339,347,361,411,422$

\section{D}

Derivatio: 135, 228, 232, 274, 277-282 (n. 10, 26), 285-286, 289, 297

Dialogue: 58, 102, 115, 245-246, 254-255 (n. 19), 302, 304, 335, 337-338, 340, 343, 
346, 359, 365-368, 370, 381-385, 387 (n. 26), 389-394 (n. 45, 50, 51), 396-397 (n. 62), 399-402, 404, 406-408, 412, 415-416, 418-420 (n. 7, 8), 424-427

Dictionnaire: 11 (n. 2), 27, 35, 41, 43-44, 46-49, 60-61, 102, 104, 135, 215, 217-221, 224 (n. 11), 226-228, 230-235, 237, 239-244, 247, 277, 292 (n. 81), 302, 358-359, 361

Diffusion: 15, 19, 31, 58, 72, 86, 97-100, 105, 112 (n. 24), 155, 202, 206, 222, 260, 262, 274 (n. 56), 299, 301, 322, 329, 334, 368

Disciplina: 12, 14-16 (n. 20), 22, 26-27 (n. 46), 30, 36, 39-40, 44, 64-65, 68-69 (n. 44), 71, 77 (n. 60), 83-84, 91-93, 97, $102,105,120,122,128,140,146,160$, $163,201,218,221,222,236,238,310$

\section{$\mathbf{E}$}

Éléments : 18 (n. 23), 72, 74, 91, 93-95, 102, 113-115, 143, 156, 169, 170-173, 175-177, 179-180, 182-183, 204-205, 208, 210, 302, $347,355,363,414$

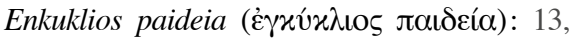
21, 39, 83, 87, 140, 145, 147-148, 238 (n. 29)

Enquête: 13, 23, 63-65, 67, 71-74, 76-77 (n. 61), 79, 139-140, 145-146, 148-151, $156-159,162,164-165,359$

Énumération: 202-203, 205, 209, 211, 239, 247, 252, 254, 313, 425

Épistémologie: 11, 21-22, 30-31, 57-60, 62-65 (n. 25), 69, 71, 73, 75, 78-80, 84, 88, 157, 201, 305-306, 358

Érudition: 21, 23-24, 43, 58 (n. 7), 60, 77, $105,108,215,245,252,254,258,327$, $361,370-372$

Esprit pragmatique: 34, 114, 119, 121, 301, $353,358,368,397,413,427$

Éthique: 39, 45, 56, 69, 75, 98, 102, 109, 114, 187-188, 222, 338, 348, 404

Étymologie: 13, 19, 27, 89, 135-136, 149, 169, 190, 198, 200, 213-214, 216, 221, 223, 228, 229, 235, 275-283, 285-289, 291-294 (n. 81), 296-297

Exégèse: 18-20, 30, 32, 55, 57 (n. 5), 89, 108, 117-120, 128, 131-132, 134, 137, 141-142, 168-171, 173-174, 177-181 (n. 58), 184185, 202, 214, 248, 277, 281, 297 (n. 110), $302,319,365$
Expansion du savoir : 289, 368, 411

Expositio: 16, 27, 62, 65, 73, 78, 118, 129, 136, 140, 148, 158, 201, 216, 219-220, 236, 241-242, 271 (n. 54), 279-281, 285, 297, 301, 413, 420

\section{G}

Genèse : 40, 91, 97, 108, 117-120, 122, 131, 133 (n. 37), 136, 141-142, 167-172, 175182, 184, 191-192

Genre (littéraire) : 12, 22-23 (n. 40), 26, 31, 48, 55-56, 60, 81-82, 84-85, 87, 101, 103 $105,107,110,111,115-116,120,123,125$, $128,130,140,143,146-147,149-150$, 167-168, 170-171, 177, 180-181, 184, 188 (n. 5), 193, 202-203, 206, 213, 215-216, 220-221, 226-227, 232, 235-236, 239, 244245, 252, 259, 275, 278, 293, 297, 299, $301,308,324-325,328,335,368,370$, 403-404, 406-409, 416, 426

Géographie: 26, 36, 68, 74, 95, 102 (n. 71), 131, 132, 134-136, 157 (n. 52), 170-171, 174, 201, 205, 207-208, 210-211, 346-347

Glossographie (glossaires): 215, 221, 222, 224227, 229-230, 232-234, 243, 250, 259, 260, 277, 278 (n. 8), 282, 285, 292-293, 296, 316

Grammaire: 14, 39-41, 93, 215-216, 221, 225-228, 230, 234-235, 244, 252, 260-264, 268, 276-279 (n. 14), 280-281, 285, 289, 292-293, 310

\section{H}

Hexæmeron: 9, 92, 118, 141-142, 167-172, 174-175, 177, 180-181, 184-185, 190-193, $259,354,411$

Histoire: 9, 12, 16, 19 (n. 26), 23, 26, 30-31, 33, 35-36, 39, 40, 45 (n. 26), 50, 59, 65, 90, 97, 101-102, 114, 125, 128, 132, 134, 137-138, 140, 149, 163, 167, 171-172, 174, 210-211, 231, 237, 239, 325, 327, 342, 378

Histoire naturelle : 9, 90, 108, 126, 141, 145$148,150-151,156,188,239$

\section{I}

Illustration : 332

Imprimerie : 333, 349 (n. 1), 426 
Innovation: 9, 232, 244, 262 (n. 14), 269, 278, 307, 313, 322-323, 408 (n. 6), 417

Intertextualité : 25, 368, 382 (n. 9), 417

Islam: 33, 35-37, 53, 56, 202, 206, 212

\section{$\mathbf{L}$}

Lapidaire: 90, 111, 204, 209, 424

Lexicographie: 27, 61, 80, 105, 206 (n. 7), 213-216, 220-222, 227, 240, 245-248, 250, 252, 254-255, 257, 274-279 (n. 9), 282, 284-285, 287, 289-290, 293-294, 297

Linguistique: 56, 64 (n. 25), 78, 215, 246, 276-277, 279, 281, 287, 296, 301, 317, 322

Lecture: 16-17 (n. 21), 19-20, 24, 28, 42, 47 , 57, 67, 88-89, 92, 102 (n. 71), 118, 129, 131, 133, 137-138, 146, 152, 154, 174, 178, 181-182, 198-200, 210, 218, 231, 250, 271, 296, 299, 301, 304, 310 (n. 15), 314, $319,327-328,336,340-343,346-348,354$, $357,361,369-370,372-377,412,419,426$

\section{M}

Manuscrit: 24 (n. 42), 93-94 (n. 38, 41), 101, 103-104 (n. 74), 109, 111, 114, 116-117 (n. 37), 126-127, 130 (n. 23), 181 (n. 63), 196, 206, 208-209, 232, 246, 260 (n. 6), 262, 274, 302, 309, 316 (n. 27), 318-319, 325, 332, 335-336 (n. 5), 338-340 (n. 15), 343-349 (n. 1), 351, 393, 404, 406, 420 (n. 12), 426

Manuel : 14, 20, 31, 34, 40, 79, 85, 107, 117, $132-133,135,301-302,307,333,405,408$, 412-413 (n. 13), 420

Médecine: 14, 39, 68-69 (n. 42), 74, 93, 103, 114, 136, 154-157 (n. 52), 162-163, 201, 354, 404

Merveilles: 40, 105, 149, 164 (n. 77), 166, 198, 202-205, 209, 341, 347, 352-355 (n. 16), 357,370

Métaphysique: 34, 37, 41, 45-46, 52, 60, 75, 103 (n. 74), 113, 201

Méthode: 13, 17, 31-32, 49, 55, 60, 65, 67-68, 72, 74, 78, 80, 84, 85, 102 (n. 71), 104, 120-121, 125, 138, 149-151 (n. 16), 156-158, 168, 170, 179, 206, 212, 216, $221,227,237,241-242,246,254,260$, 274, 276-281 (n. 3, 12), 285, 300, 305 (n. 5), 357-358, 373-375, 386-387 (n. 24)
Miroir des princes : 188, 368, 404, 406, 418

Morale: 14 (n. 13), 42, 62 (n. 22), 65, 77-78, 88-89, 91, 93, 97, 99, 128, 131, 135, 141142, 145, 156-157, 160-162, 170, 177-179, 187, 189, 191, 207, 221, 301-302, 326, 328-329, 336-337, 340, 342, 345, 352-353, 355, 357, 361-362, 366, 388 (n. 29), 413

Musique: 14, 39, 41, 77, 191, 219, 300-301, $303-318,320,322,328,330,332,378$

\section{$\mathbf{N}$}

Néoplatonisme: 40, 92, 113, 115-116, 201, $307,310,312,322,369,374,379$

\section{$\mathbf{O}$}

Ordre alphabétique: 11 (n. 1), 15 (n. 15), 26, 31, 42, 44, 61, 84, 90-91, 96, 102 (n. 71), 104, 111, 133, 205-206, 211, 214-220, 230-237, 240-243, 246-248, 250, 261, 274, 276-277, 350, 355, 358, 362, 412

Organisation: 9, 16, 21, 23-25, 31-32, 39, 51, $55,59-60,66,68,73,78,80,84,88,90$, $92,105,107-108,113,115,121-123,126$, $134,139,141,146,149,150,154,155$, $160,166,168,209,232,243,247,255$, $300-302,310,325,330,336,341,343-$ $344,346,348,354-355,359,368,374$, 398, 411, 413

Organicité : 21, 58, 60, 71, 80, 369, 374, 379

Orthographia: 287-288 (n. 56), 292, 297 (n. 109)

\section{$\mathbf{P}$}

Paradigme encyclopédique : 81,84

Paratexte : 302, 346

Pédagogie: 9, 13 (n. 9), 14-17, 20, 26-27, 55, 60, 62, 66 (n. 31), 72-73, 75, 78-79, 89, 196, 200, 237, 299-302, 312, 341, 346-347, 365-366, 391, 401

Péritexte: 302,343

Philologie: 26, 30, 38, 102 (n. 71), 152, 154, 213-214, 237, 250, 279 (n. 14), 281 (n. 22)

Physique: 20 (n. 32), 26, 45, 57, 67-70, 73-75, 77-78, 93, 103, 109, 143, 146, 176177, 182-183, 190, 198, 201 (n. 1), 204, 207, 211, 239, 309, 409 
Poétique: 45 (n. 26), 66, 69, 73, 75, 93, 150, 167, 207, 248, 254, 327, 367, 369-370, 374, 378-379

Politique: 20, 23-24, 30, 33-34, 37-38, 42, $51-52,57,69,75,78,93,102,128,135$, $142,149,165-166,187-189,230,301-302$, 324, 326, 328-329, 336, 338, 342, 378

Problemata: 67, 75, 78, 83, 104, 113, 115116, 122, 245, 365, 393 (n. 52), 409

Programme: 14 (n. 14), 18-19, 21, 23-24, 26, 29, 33, 57, 64, 67, 73-75, 78-80, 83, 99, $133,139,147,161,176,206,242,299-$ 300, 302, 367, 369, 371

Prologue (préface): 15, 17 (n. 21), 18, 20, 28 (n. 48), 43, 72, 79, 87, 93 (n. 39), 98-100 (n. 55), 103 (n. 74), 105, 109 (n. 14), 117, 119 (n. 49), 126-127, 129, 138, 147-150, 155, 157 (n. 52), 171, 177, 205-206, 238-240, 243 (n. 37), 281 (n. 23), 302, 326, 335-344, 346, 348, $355,362,367-368,371-377,386$ (n. 23), 408, 412, 415-417, 419, 421-425, 427

Qucestiones: 115, 365, 381, 409

Rhétorique: 14, 16, 28, 39-41, 58, 67, 75, 77-78, 93, 102, 148, 216, 280, 300, 310, $335,342,352-353,359,366,396,413$

\section{S}

Savoir narratif: 368, 417, 419-421, 426

Savoir gréco-arabe: 92,411

Science: 18-19, 21-22, 26, 33, 42, 44, 48, 55, 63, 65-67, 69-71, 73, 77, 79-80, 84, 88, 97, 108, 142, 146-147, 155, 157, 182-183, 187-188, 191, 199, 216, 218, 237, 240, 277 (n. 5), 309-310 (n. 12), 322, 368, 410 (n. 9)

Sophistique : 57, 65-66 (n. 30), 245-246

Système: 21, 23, 36, 41, 43, 45-48, 51, 57-58, $60,71,74-76,78,82,86,92,100,103,105$, 110 (n. 16), 122, 127, 129-130, 132-133, 138, 160-161, 199-200, 204, 215, 236, 240-241, 260, 276-277, 300, 303-305, 313, 316-317, 320-321, 329-330, 358, 385 (n. 19), 409, 411, 425

\section{$\mathbf{T}$}

Techniques: $37,39,59,69,76,141,145,160$, 162-163, 237, 246, 276, 302, 324, 330-331, $334,343,361,402$
Terminologie: 65 (n. 28), 221-222, 312, 317, 319-320, 322

Théologie: 14, 17-20 (n. 32), 22, 40, 46, 55, 69-70, 75-76, 86, 92-93, 108-109, 111, 114, 116-117, 120, 125, 276 (n. 3)

Totalisation: $27,30,33-34,45,48-49$

Totalité : 23, 34, 37-41, 43, 45-50, 65, 76-77, $85,138,146,149,161,165-166,312,404$, 416, 419

Traduction: 20, 61 (n. 18), 64 (n. 25), 83-84, 86, 90-92 (n. 29, 35), 95, 100-101, 103, 109, 122 (n. 24), 152, 188, 194 (n. 8), 198199, 201, 221, 252, 276, 304, 312-313, 315-317, 322, 329 (n. 12), 339 (n. 15), 349, 351 (n. 9), 404, 419-420 (n. 8), 423-424

Transmission: 9, 19, 25, 28, 30, 50, 60, 62, 72, 81-82 (n. 3), 107-108, 147, 237, 240, 299-304, 318, 322, 339, 343, 367, 369, 377, 403-405, 409, 416-417, 419-420 (n. 12), 423,426

Typologie: 20, 31, 69-70 (n. 46), 98, 104-105, $155,192,199,359,382-383$ (n. 6), 385

\section{$\mathbf{U}$}

Unité: 18, 21, 37, 42-46, 59-61 (n. 16), 71, 73 (n. 54), 76-77, 240, 322, 366, 368, 371, $375,415-417,420$

Universel: 9, 13, 17, 21 (n. 35), 30, 33-39, 41-45, 47, 50, 52-53, 58-59, 63-66 (n. 33), 75-77, 79, 85, 93, 95, 97 (n. 52), 100, 102, $106,108,111,125-127,135,138-139,158$, $166,213,240-242,358,368,415$

Utilité : 17, 63, 79, 96, 98, 100, 102, 105-106, 160-161, 242

\section{V}

Varietas: 366, 410, 413

Vulgarisation scientifique: 13, 20, 24, 30, $62,111,142,171,174,177,199,300,335$, $343,346,382$

\section{$\mathbf{Z}$}

Zoologie: 56, 68, 149, 151, 157-158, 201, 206, 210 


\section{TABLE DES MATIÈRES}

Arnaud Zucker, Avant-propos ......................................... 9

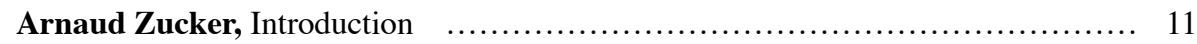

Première partie: DES CONNAISSANCES AU SAVOIR ENCYCLOPÉDIQUE $\ldots \ldots \ldots \ldots \ldots \ldots . . . . .29$

Christian Godin, Des encyclopédies chinoises à Wikipédia :

le rêve d'empire ..................................................... 33

Arnaud Zucker, Y a-t-il un modèle aristotélicien d'encyclopédisme ?............. 55

Isabelle Draelants, Le « siècle de l'encyclopédisme » :

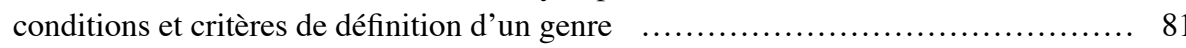

Iolanda Ventura, Encyclopédie et culture philosophique au Moyen Âge :

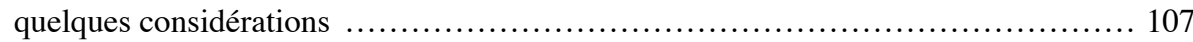

Isabelle Guyot-Bachy, Ambition encyclopédique ou influence

du genre encyclopédique au début du XIV ${ }^{\mathrm{e}}$ siècle?

le Memoriale historiarum de Jean de Saint-Victor ................................ 125

Deuxième partie: LE TRAITEMENT UNIVERSEL DE LA NATURE $\ldots \ldots \ldots \ldots \ldots \ldots \ldots \ldots \ldots$

Valérie Naas, Indicare, non indagare:

encyclopédisme contre histoire naturelle chez Pline l'Ancien ?................... 145

Emmanuel Bain, Hexaemeron et encyclopédisme au XII siècle .................... 167

Bernard Ribémont, Encyclopédies médiévales et nature supralunaire:

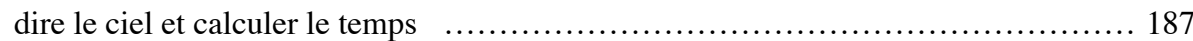

Jean-Charles Ducène, Les encyclopédies et les sciences naturelles dans le monde

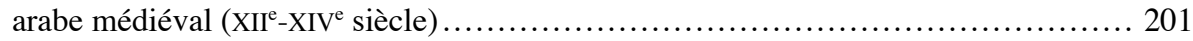

Troisième partie: LE TRAITEMENT LEXICAL DU RÉEL ........................... 213

Carmen Codoñer, Encyclopédie et dictionnaire : affinités et différences ............ 217

Benoît Louyest, La mémoire ordonnée. Le maniement de la forme lexicographique et ses effets sur la représentation de la langue grecque,

dans la fiction d'Athénée 
Anne Grondeux, L'entrée uox du Liber glossarum.

Les sources et leur mise en œuvre

Laura Biondi, Parcours étymologiques et parcours lexicographiques

de la Latinité médiévale : l'apport de l'étymologie à la constitution

du savoir encyclopédique

Quatrième partie: L'ENJEU PATRIMONIAL ET DIDACTIQUE

Jean-Baptiste Guillaumin, La musique grecque dans la latinité tardive:

compilation et transmission d'un millénaire de théorie musicale

Jean-Pierre Drège, De l'innovation des encyclopédies chinoises?

Chantal Connochie-Bourgne, Ordonner les éléments du savoir:

l'exemple des premiers « livres de clergie » en langue française (XIII ${ }^{\mathrm{e}}$ siècle)

Denis Hüe, Tradition et moralisation chez Pierre Bersuire

Cinquième partie: FORMULES DIALOGIQUES ET FORMES OUVERTES

Benjamin Goldlust, Le projet d'Aulu-Gelle et sa lecture par Macrobe :

de la disparilitas affectée à la recherche d'un ordre caché ?

Christine Silvi, La voix de l'autre dans la construction du savoir

(Placides et Timeo, Sydrach, L'Image du Monde, Li Livres dou Tresor):

quelles stratégies discursives pour quels enjeux?

Doris Ruhe, Stratégies de la transmission de savoir:

l'exemple du Livre de Sydrac

Ernst Peter Ruhe, La légitimation du savoir :

le dialogue encyclopédique Le Livre de Sydrac

Bibliographie

Index des noms de personnes et des œuvres 483

Index rerum 